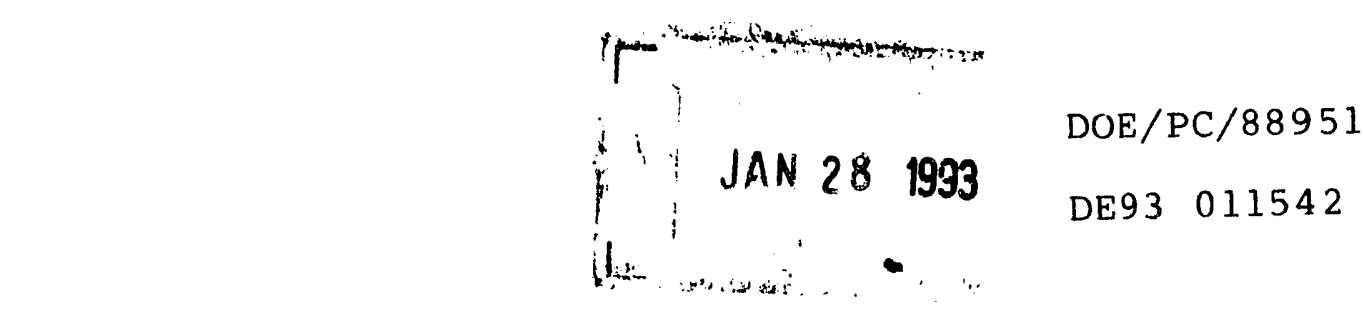

\title{
DETERMINATION OF FLOW-REGIME BOUNDDARIES FOR COHESIVE PARTICLES
}

Project 61093 Final Report

For the Period September 20, 1988 Through March 31, 1992

by

T. M. Knowlton

J. G. Findlay

Subcontractor: Illinois Institute of Technology

H. Arastoopour

D. Gidaspow

INSTITUTE OF GAS TECHNOLOGY

3424 SOUTH STATE STREET

CHICAGO, ILLINOIS 60616-3896

for

UNITED STATES DEPARTMENT OF ENERGY PITTSBURGH ENERGY TECHNOLOGY CENTER P. O. BOX 10940

PITTSBURGH, PENNSYLVANIA 15236

DOE Contract No.: DE-AC22-88PC88951

October 1992

\section{MASTER}

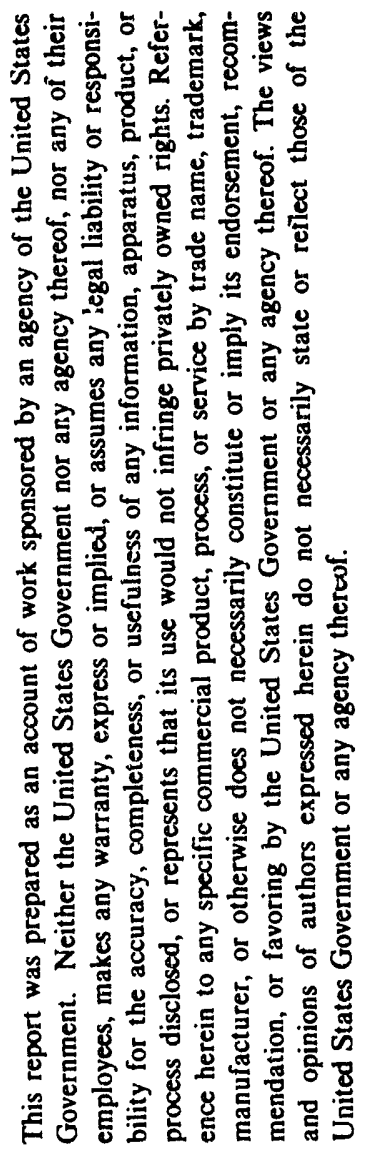


Cohesive particles (Geldart Group $C$ powders) are fine particles generally less than 30 microns in size. Interparticle forces are large relative to inertial forces in these particles, and cause clumping, sticking, and channeling when attempts are made to fluidize them. These solids do not flow easily through pipes, and bridge extremely easily.

The objectives of the work in this program were 1) to develop a hydrodynamic model which can be applied to cohesive solids, and 2) to obtain data in a large-scale $(30-\mathrm{cm}$-diametex) riser to test the model. The work was divided into six tasks:

Task 1. Preparation of a Project Work Plan

Task 2. Hydrodynamic Model Development

Task 3. Determination of Rheological Properties for Incorporation into the Model

Task 4. Small-Scale Flow Tests

Task 5. Large-Scale Flow Tests

Task 6. Comparison of Model With Data

The work was conducted by the Institute of Gas Technology (IGT) in collaboration with the Illinois Institute of Technology (IIT). This work combined the expertise of IIT in model development, with the large-scale experimental capabilities of IGT. IIT researchers developed the hydrodynamic model in the program, while the large-scale data were generated by IGT.

Following the preparation of the Project Work Plan in Task 1, work was started on the development of a two-dimensional hydrodynamic model to enable the behavior of cohesive solids in a dilute-phase riser to be simulated. In Task 2, two hydrodynamic models were developed based on the kinetic theory model of granular flow. The models were used to predict data presented in the literature, as well as data generated in Task 5 of this study.

In Task 3, rheological data on cohesive ofl shale with an average particle size of approximately 12 microns was obtained using a unique device called a cohetester. This instrument measured the tensile strength $\left(r_{c}\right)$ of 
various materials as a function of the solids volume fraction $\left(\epsilon_{s}\right)$ of the material. The more cohesive the solid, the greater its tensile strength. For cohesive oil shale, the following relationship between $\tau_{c}$ and $\epsilon_{s}$ was obtained:

$$
\tau_{c}=10^{2.75} \epsilon_{s}+2.36
$$

This relationship was then incorporated into the models.

Fluidization tests with the cohesive oil shale were conducted in Task 3. The material channelled at low gas velocities, and then formed relatively large (1000 micron) soft agglomerates, which could be easily broken up by hand. Because of the agglomerates, the velocity required to fluidize the material was quite high - surprisingly so for 12-micron material.

The cohesive oil shale tended to bridge across pipe openings and would not flow. Therefore, a procedure was developed in which gas was pulsed into the shale for approximately 0.2 seconds every 10 seconds. The pulsing prevented bridges from forming, and allowed the shale to flow. This procedure was used successfully to discharge solids from a hopper into a feed screw, and to cause the solids to flow down a standpipe, through a slide valve, and into a riser in the large-scale testing.

Experiments with a Laser Doppler Velocimeter (LDV) were used to gain information about the flow of dilute suspensions of cohesive solids. The LDV was evaluated as a potential tool to measure the density of cohesive solids in a dilute suspension. During the investigation, a technique was developed which enabled the determination of the solids volume fraction and the particle size distribution of the solids simultaneously.

In Task 4, tests to determine the variation of solids mass flux, particle velocity, and solids volume fraction with radial position in a riser were conducted in a small (7.6- $\mathrm{cm}$-diameter) test unit using FCC catalyst material. The test unit was used to provide information on the general nature of the flow, and to evaluate using an $x$-ray densitometer as a device to measure the radial distribution of solids density on a larger-scale unit. All of the radial profiles were found to be parabolic, and a core-annulus type of distribution of the solids was found to exist.

A large test unit with a $30-\mathrm{cm}$-diameter riser, was then modified to measure the pressure-drop-per-unit-length in the riser as a function of gas 
velocity and solids mass flur. These data were then used to determine the choking velocity (the flow-regime boundary between dilute and dense-phase conveying) for the cohesive oil shise. Radial distributions of riser density and particle velocity were also obtained in the unit. These distributions were then used to calculate the solids mass flux as a function of radial position in the riser. The cohesive solids were also found to flow in a coreannular distribution, although it was not as sharply defined as the FCC catalyst core-annulus flow. The contacting-bond energy hydrodynamic model was then used to model the data obtained on the large-scale test unit. It was found that the model predicted the data trends extremely well, and could predict choking velocities and pressure drops in the riser to within approximately 308 . 
vi

I N S T I T U T E

O F

G A S

T E C H N O L O G 
OBJECTIVES

INTRODUCTION

TECHNICAL PROGRESS REPORT

Task 1. Preparation of Project Work Plan

4

Task 2. Hydrodynamic Model Development

4

Contacting Bond Energy Model

Particle Agglomeration

Non-Thermal Agglomeration

Boundary Conditions

Task 3. Determination of Solid Rheological Properties for Incorporation Into the Hydrodynamic Mode1

Subtask 3.1

Parameter Determination

Subtask 3.2. Fluidization and Flow Testing

Task 4. Small-Scale Flow Tests

Riser Test Unit

$\mathrm{X}$-Ray Densitometer

Extraction Probe

Laser-Doppler Velocimeter Experimental Unit

Measurement of Particle Size With an LDV

Noise Rejection 78

Particle-Size Calibration Curve 79

Solid Concentration Measurement Using the LDV 80

Experimental Equipment

Experimental Results $\quad 84$

Verification of Maxwellian Velocity Distribution Assumption 
TABLE OF CONTENTS (Continued)

Page

Task 5. Large-Scale Flow Tests 106

Large-Scale Flow Tests 106

$\begin{array}{ll}\text { Experimental Results } & 108\end{array}$

Task 6. Comparison of Model With Data and Preparation
of Final Report

$\begin{array}{ll}\text { NOMENCLATURE } & 120\end{array}$

$\begin{array}{ll}\text { LITERATURE CITED } & 123\end{array}$

viii

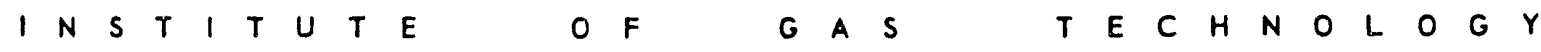


ix 


\section{LIST OF FIGURES}

Figure No,

Page

1

6

7

8

9

Geometry and Inlet and Outlet Conditions Assumed for Model

9

10

Time-Averaged Radial Profiles of Solids Volume Fraction at Heights of 4 Meters and 9.1 Meters

Time-Averaged Gas and Solid Velocities at a Height of

4 Meters

Time-Averaged Gas and Solid Velocities at a Height of 9.1 Meters

Correctional Coefficient as a Function of the Ratio of the Contacting Bond Energy and the Fluctuation Energy of the particles

Split Cell Type Tensile Strength Tester

Cohetester Test Cell Construction

Test Cell and Compaction Weight Stabilizer

Typical Tensile Strength Vs. Displacement Relationship for a Group $C$ Powder

Comparison of Measured Solids Volume Fraction for theat Flour With Data From the Hosokawa Corporation 5-Micron Oil Shale

Comparison of Cohesive Forces of Bag Filter Fines and Beneficiated Shale

A Comparison of the Cohesive Force of Whcat Flour and Bag Filter Fines

Fluidization Curve for Cohesive 0il Shale Fines

Schematic Drawing of Test Hopper and Distributor

Schematic Drawing of Small-Scile Test Unit

Schematic Drawing of X-Ray Densitometer 
LIST OF FIGURES, Cont.

Figure No,

Page

20

$X$-Ray Densitometer Calibration Curve for FCC

Catalyst

21

X-Ray Densitometer Calibration Curve for Air

54

22

Schematic Drawing of Mass Flux Extraction Probe

Schematic Drawing of Mass Flux Collection

Equipment

Radial Mass Flux Profile as a Function of

Superficial Gas Velocity

Radial Solids Volume Fraction Profile as a Function of Superficial Gas Velocity

Radial Solids Velocity Profile as a Function of Superficial Gas Velocity

Radial Solids Mass Flux Profile as a Function of Solids Mass Flux

Radial Solids Volume Fraction as a Function of Solids Mass Flux

Radial Solids Particle Velocity as a Function of

Solids Mass Flux

Radial Solids Mass Flux Profiles as a Function of Riser Height

Radial Solids Volume Fraction Profiles as a Function of Riser Height

Radial Solids Particle Velocity Profiles as a

Function of Riser Height

Schematic Drawing of Laser-Doppler Velocimeter

Schematic Drawing of Laser-Doppler Velocimeter

Operating Principle

Light Intensity Variation in the LDV

Schematic Drawing of Solids Recirculation LDV Test Loop 
LIST OF FIGURES, Cont.

Figure No.

Page

39 Particle Size Distribution at Tube Centerline

(Gas Flow Rate: 0.4 SCFM)

87

40 Particle Size Distribution at Dimensionless Radial

Position of 0.4 (Gas Flow Rate: 0.4 SCFM)

88

41 Particle Size Distribution at Dimensionless Radial

Position of 0.8 (Gas Flow Rate: 0.4 SCFM)

89

42

Particle Size Distribution at Dimensionless Radial

Position of 0.99 (Gas Flow Rate: 0.4 SCFM)

90

43 Particle Size Distribution at Tube Centerline

(Gas Flow Rate: 12 SCFM)

91

Particle Size Distribution at Dimensionless Radial

44

Position of 0.4 (Gas Flow Rate: 12 SCFM)

92

Particle Size Distribution at Dimensionless Radial

45

Position of 0.8 (Gas Flow Rate: 12 SCFM)

93

Particle Size Distribution at Dimensionless Radial

46

Position of 0.99 (Gas Flow Rate: 12 SCFM)

94

Average Particle Size Versus Dimensionless Radial

47

Position (Gas Flow Rate: 0.4 SCFM)

95

Average Particle Size Versus Dimensionless Radial

Position (Gas Flow Rate: 12 SCFM)

96

Variation in Average Particle Size With Gas Flow Rate (75 $\mathrm{g}$ and $750 \mathrm{~g}$ Inventory)

Radial Profiles of Mean Particle Velocity as a

Function of Particle Size (Gas Flow Rate: 0.4 SCFM)

51 Radial Profiles of Mean Particle Velocity as a
Function of Particle Size (Gas Flow Rate: 12 SCFM)

100

52

Radial Profiles of Fluctuating Particle Velocity as a

Function of Particle Size (Gas Flow Rate: 0.4 SCFM)

101

53 Radial Profiles of Fluctuating Particle Velocity as a

Function of Particle Size (Gas Flow Rate: 12 SCFM)

54 Radial Void Fraction Profiles as a Function of Gas

Flow Rate (750 g Inventory)

55 Comparison of Maxwell Distribution with Experimental Probability Density 
LIST OF FIGURES, Cont.

Eigure No.

56

57

58

59

60

61

62
Schematic Drawing of Cold-Flow Model

107

Schematic Drawing of Large-Scale, Cold-Flow Model

109

The Phase Diagram for Cohesive Oil Shale

110

Riser Density Variation With Superficial Gas Velocity

for FCC Catalyst and Cohesive Oil Shale

112

Radial Riser Suspension Density Profiles for Cohesive oil Shale

Comparison of Radial Riser Suspension Density Profiles for Cohesive 0il Shale and FCC Catalyst

115

Comparison of Experimental Data and Model Predictions 


\section{LIST OF TABLES}

Table No.

Page

1. Governing Equations for Gas-Solid Flow

2. Cohetester Measurement

3. Oil Shale Particle-Size Analysis 25

4. Particle-Size Distribution of Cohesive Oil-Shale Particles

5.

Particle-Size Distribution of FCC Catalyst Material 


\section{OBJECTIVES}

The overall objective of this program is the development of a hydrodynamic model to predict the choking/non-choking flow regime boundary of fine, cohesive (i. e., Geldart Group C) powders. Specific objectives are to:

1. Develop a two-dimensional hydrodynamic model that can be applied to cohesive solids.

2. Obtain data in a large-scale $(30-\mathrm{cm}-$ diameter $)$ riser to test the model. 


\section{INTRODUCTION}

The objectives of this program were to -

1. Develop a two-dimensional, hydrodynamic model that could be applied to cohesive solids.

2. Generate large-scale solids-flow data to verify the model.

The research was divided into six tasks:

Task 1. Preparation of a Project Work Plan

Task 2. Hydrodynamic Model Development

Task 3. Determination of Solid Rheological Properties for Incorporation Into the Hydrodynamic Model

Task 4. Small-Scale Flow Tests

Task 5. Large-Scale Flow Tests

Task 6. Comparison of Model With Data and Preparation of Final Report.

In Task 1, a detailed Project Work Plan describing the tests to be conducted was prepared and sent to the Department of Energy (DOE) for review and approval.

An existing, two-dimensional mathematical model was extended to include interparticle forces such as exist in cohesive solids in Task 2. The resulting model was called the K-Fix Cohesive model. A new contacting-bond energy model was also developed to apply to cohesive solids.

In Task 3, the rheological properties of a cohesive oil shale test material were determined and incorporated into the $\mathrm{K}-\mathrm{Fix}$ Cohesive model to improve its capability for predicting gas and solid velocity profiles for gas and cohesive solids in two-phase flow. In addition, the fluidization and flow charactexistics of cohesive ofl-shale powders were determined.

A small-scale (3-inch-diameter), solids-flow test facility was modified in Task 4. The facility was operated with FCC catalyst to provide solids concentration and gas velocity data.

In Task 5, cohesive flow tests were conducted in a large-scale (12-inchdiameter) solids flow unit to obtain data for comparison with model 
predictions. The large-diameter line minimized wall effects that can be substantial in smaller units.

In Task 6 , the contacting-bond energy hydrodynamic model was compared with the results from large-scale test unit. The model was used to predict the flow-regime boundary (choking velocity) between dense and diiute-phase conveying for cohesive oil shale. The final report for the project was also prepared in this task. 


\section{Task 1. Preparation of Profect Work Plan}

A Project Work Plan (PWP) was prepared and submitted to the Technical Project Manager. The PWP was reviewed and approved by the Department of Energy.

Task 2. Hydrodynamic Model Development

The objective of the work in this task was to develop two-dimensional hydrodynamic models which can be used to predict dilute-phase flow conditions for cohesive solids. Therefore, the kinetic theory model for granular flow (which was used by Ding and Gidaspow (1989) for non-cohesive Geldart Group B solids in bubbling beds) was modified to apply to the vertical transport of fine, cohesive solids. The advantage of using the kinetic theory model approach for granular flow is that it eliminates the need for guessing or empirically determining the solids viscosity.

The equations of continuity, momentum, and fluctuating energy of the particle phase were derived from the well-known boltzman equation. The resulting governing equations for gas-solids, two-phase flow are listed in Table 1. The coefficient of restitution was assumed to be 0.9 during all of this work.

The cohesive force of fine particles depends on the physical condition of the powder (e.g., moisture content, particle geometry, particle size, etc.) and particle volume fraction. For a given powder with a uniform particle size, it was assumed that

$$
r_{c}=\tau_{c}\left(\epsilon_{s}\right)
$$

where $r_{c}$ is the cohesive stress in the solids phase. The measurement of cohesive force for oil shale $\left(d_{p}-5 \mu \mathrm{m}, \rho_{p}-2.1 \mathrm{~g} / \mathrm{cm}^{3}\right)$ using a cohetester was determined to be calculable from the equation

$$
T_{C}=10^{2.75 \epsilon}+2.36
$$


Table 1, Part 1. GOVERNING EQUATIONS FOR GAS-SOLID FLOW In the following equations, a tensor is represented as [ ].

1. CONTINUITY EQUATION FOR PHASE $k \quad k=g$ for gas phase

$$
\frac{\partial}{\partial t}\left(\epsilon_{k} \rho_{k}\right)+\nabla \cdot\left(\epsilon_{k} \rho_{k} v_{k}\right)=0
$$

\section{MOMENTUM EQUATION FOR PHASE $k$}

$\frac{\partial}{\partial t}\left(\epsilon_{\mathrm{k}} \rho_{\mathrm{k}} \mathrm{v}_{\mathrm{k}}\right)+\nabla \cdot\left(\epsilon_{\mathrm{k}} \rho_{\mathrm{k}} \mathrm{v}_{\mathrm{k}} \mathrm{v}_{\mathrm{k}}\right)=-\epsilon_{\mathrm{k}} \nabla \rho_{\mathrm{g}}+\epsilon_{\mathrm{k}} \rho_{\mathrm{k}} \mathrm{g}+\nabla \cdot\left[\tau_{\mathrm{k}}\right]+\beta\left(\mathrm{v}_{1}-\mathrm{v}_{\mathrm{k}}\right)$

\section{GAS PHASE STRESS}

$$
\left[r_{g}\right]-2 \epsilon_{g} \mu_{g e}\left[S_{g}\right]
$$

where

$$
\mu_{g e}=\mu_{t}+\mu_{g}-\rho_{g}\left(c_{t} \Delta\right)^{2}\left(2\left[S_{g}\right] \cdot\left[S_{g}\right]\right)^{1 / 2}+\mu_{g}
$$

$c_{t}=0.1$, and

$$
\left[S_{g}\right]=\frac{1}{2}\left[\nabla v_{g}+\left(\nabla v_{g}\right)^{T}\right]-\frac{1}{3} \nabla \cdot v_{g}
$$

\section{SOLID PHASE STRESS}

$$
\left[\tau_{s}\right]-\tau_{c}[I]+\left[-\rho_{s}+\epsilon_{s} \xi_{s} \nabla \cdot v_{s}\right][I]+2 \epsilon_{s} \mu_{s}\left[S_{s}\right]
$$

where the cohesive stress is defined as

$$
\tau_{c}=10^{2.75 e_{s}+2.36 \quad \text { dynes } / \mathrm{cm}^{2}}
$$


Table 1, Part 2. GOVERNING EQUATIONS FOR GAS-SOLID FLOW

the deformation rate is defined as

$$
\left[S_{s}\right]-\frac{1}{2}\left[\nabla v_{s}+\left(\nabla v_{s}\right)^{T}\right]-\frac{1}{3} \nabla \cdot v_{s}[I]
$$

the solid phase pressure is defined as

$$
P_{s}=\epsilon_{s} \rho_{p}\left[1+2(1+e) \epsilon_{s} g_{o}\right] T
$$

the solid phase bulk viscosity is defined as

$$
\xi_{S}=\frac{4}{3} \epsilon_{S} \rho_{p} d_{p} g_{0}(1+e)\left(\frac{T}{\pi}\right)^{1 / 2}
$$

the solid phase shear viscosity is defined as

$$
\mu_{s}=\frac{4}{5} \epsilon_{s} \rho_{p} d_{p} g_{o}(1+e)\left(\frac{T}{\pi}\right)^{1 / 2}
$$

the radial distribution function is

$$
g_{0}-\frac{3}{5}\left[1-\left(\frac{\epsilon_{s}}{\epsilon_{s} \max }\right)^{1 / 3}\right]^{-1}
$$

the fluctuating energy $\frac{3}{2} T\left(-\frac{1}{2}\left\langle C^{2}\right\rangle\right)$ equation is

$\frac{3}{2}\left[\frac{\partial}{\partial t}\left(\epsilon_{s} \rho_{p} T\right)+\nabla \cdot\left(\epsilon_{s} \rho_{p} v_{s} T\right)\right]-\left[\tau_{s}\right]: \nabla v_{s}-\nabla \cdot q-\gamma-3 \beta T$

the collisional energy dissipation, $\gamma$, is

$$
\gamma=3\left(1-\epsilon^{2}\right) \epsilon_{s}^{2} \rho_{p} B_{o} T\left(\frac{4}{d_{p}}\left(\frac{T}{\pi}\right)^{1 / 2}-\nabla \cdot v_{s}\right)
$$


Table 1, Part 3. GOVERNING EQUATIONS FOR GAS-SOLID FLOW

the flux of fluctuating energy, $q$, is, and

$$
\mathrm{q}=-\kappa \nabla \mathrm{T}
$$

and the conductivity of the fluctuating energy is

$$
\kappa-2 \rho_{p} \epsilon_{s}^{2} d_{p}(1+e) g_{0}{\frac{T}{\pi^{2}}}^{1 / 2}
$$

5. GAS -SOLID DRAG COEFFICIENTS

for $\epsilon<0.8$, (based on the Ergun equation)

$$
\beta=150 \frac{\epsilon_{s}^{2} \mu}{\epsilon d_{p}^{2}}+1.75 \frac{{ }^{\rho}{ }_{g}^{\epsilon} s\left|v_{g}-v_{s}\right|}{d_{p}}
$$

for $\epsilon>0.8$, (based on an empirical correlation)

$$
\beta=\frac{3}{4} C_{d} \frac{\epsilon \epsilon_{s}{ }^{\rho} g}{\left|v_{g}-v_{s}\right|} \epsilon^{-2.65}
$$

where,

$$
\begin{aligned}
& C_{d}=\frac{24}{R_{e p}}\left[1+0.15\left(R_{e p}\right)^{0.687}\right], \quad \text { for } R_{e p}<1000 \\
& C_{d}=0.44, \quad \text { for } R_{e p} \geq 1000, \\
& R_{e p}=\frac{\epsilon \rho_{g}\left|v_{g}-v_{s}\right| d}{\mu_{g}}
\end{aligned}
$$

7

$\begin{array}{lllllllllll} & N & S & T & \text { I } & T & \text { U T } & \text { O } & \text { F }\end{array}$

GA S

TE C H NO LO 
Equation (2) was added to the computer code to enable the computation of the flow of oil shale in a large-scale (30-cm-diameter, 12-meter-high) vertical pipe used by Bader et al. (1988).

The equations listed in Table 1 were solved by using the ICE (Implicit Continuous Eulerian) method. The previous computer code, Gidaspow (1986), (which was developed from the K-Fix code) was modified by adding the kinetic theory model and by introducing a variable grid size. Therefore, this model was named the K-Fix Cohesive model.

The Reynolds number for the gas flow based on the pipe diameter is generally high. For the experimental conditions of Bader et al. (1988), the Reynolds number is about 75,000. Thus, the flow would be expected to be turbulent. The effect of particles on the turbulent eddies in the flowing stream is not known. Therefore, only the gas-phase turbulence was considered. A simple subgrid scale (SGS) model for gas turbulence used by Deardorff (1971) was used. The eddy viscosity equation for this model is given in Table 1.

For boundary conditions, it was assumed that the gas velocity at the wall was zero. The solids velocity was assumed to be under a partial-slip condition such that

$$
v_{s} l_{w}=-\left.\lambda_{p} \frac{\partial v_{s}}{\partial x_{1}}\right|_{w}
$$

where

$$
\lambda_{p}=\frac{1}{\epsilon_{s}^{1 / 3}} d_{p}
$$

The granular temperature flux at the solid wall was also assumed to be zero.

The inlet conditions for the vertical riser used in the computation are shown in Figure 1. At the outlet, the pressure was assumed to be ambient, and the mass flow assumed to be continuous. The initial gas velocity inside the pipe was taken to be zero.

A two-dimensional pipe was used to model the cylindrical pipe as shown in Figure 1. In Figure 2, the non-uniform finite difference grid used in the computation is presented. The time step, $\Delta t$, was selected to be $4 \times 10^{-5}$ seconds. The computation was carried out for 10 seconds of real time. 


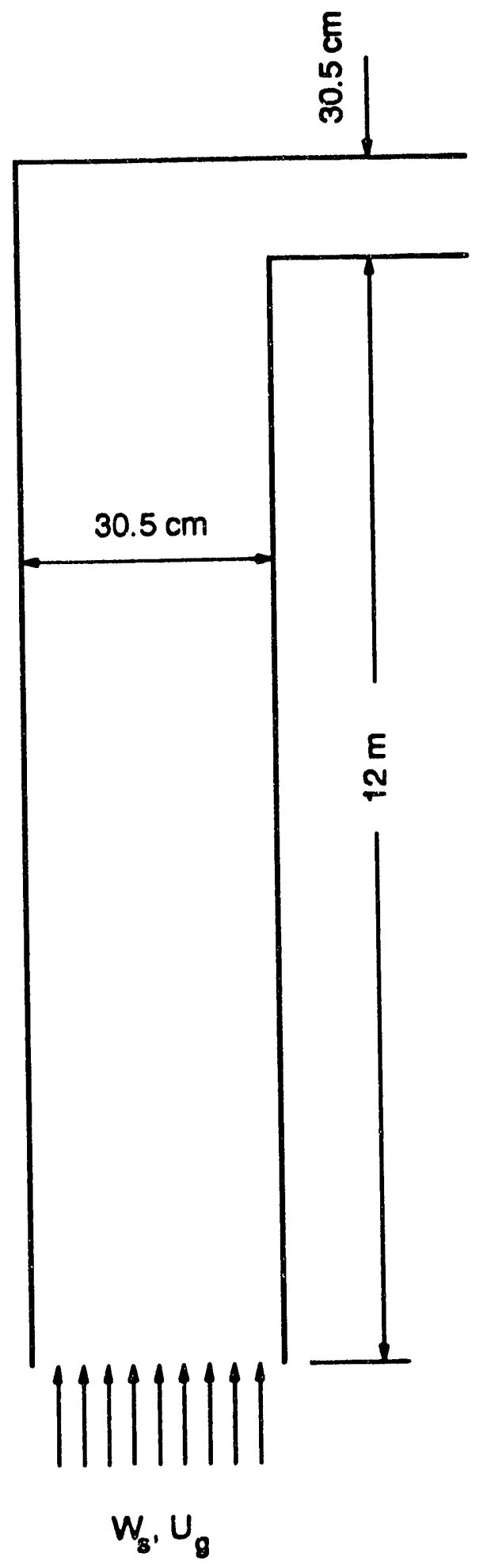

Particle Diameter: 5 microns

Particle Density: $2.1 \mathrm{~g} / \mathrm{cc}$

Inlet Conditions:

Superficial gas velocity: $3.7 \mathrm{~m} / \mathrm{s}$

$$
\varepsilon=0.25
$$

$W_{\mathrm{s}}=98 \mathrm{~kg} / \mathrm{s}-\mathrm{m}^{2}$

$P=123.3 \mathrm{kPa}$

\section{Outlet Conditions:}

$$
\begin{aligned}
& \frac{d f}{d x}=0, f=\left(\varepsilon, U_{g}, U_{8}\right) \\
& p=1 \mathrm{~atm}
\end{aligned}
$$

Fooo10s

Figure 1. GEOMETRY AND INLET AND OUTLET CONDITIONS ASSUMED FOR MODEL 


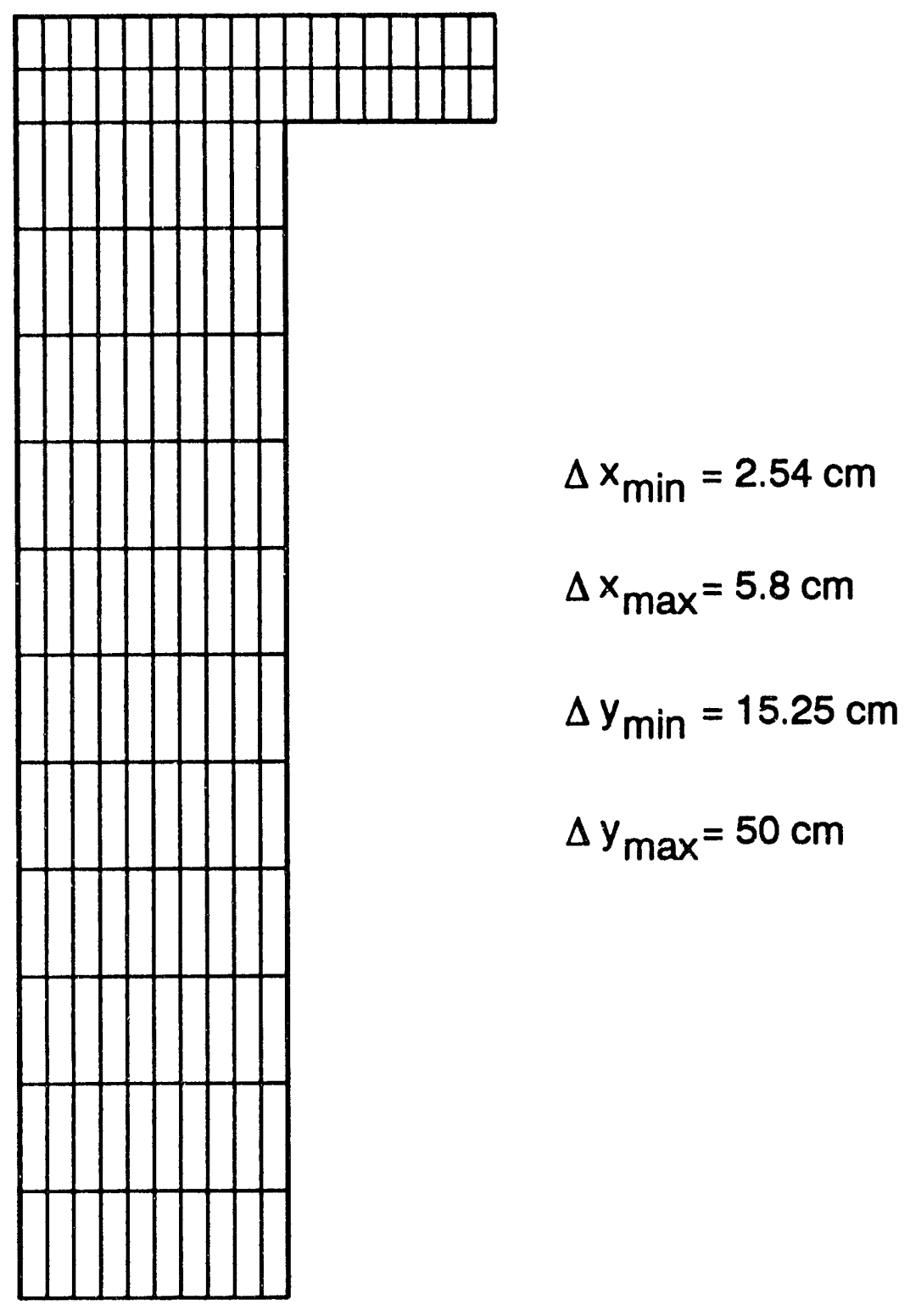

F900106

Figure 2. FINITE DIFFERENCE GRID USED IN THE CALCULATIONS 
Particle distributions in the pipe over the period of time from 1 to 10 seconds were calculated by the model. The model showed that the solids phase was denser near the pipe wall than at the pipe center.

In Figure 3, the time-averaged solids volume fraction is shown as a function of pipe radius. The calculations were averaged over the time period of 7 to 10 seconds to obtain this curve. The asymmetric radisi solids volume fraction profile is due to the nonsymmetrical outlet geometry.

The time-averaged axial gas and solld velocities at a height of 4 meters above the pipe inlet are shown in Figure 4. Downflow of both gas and solids at the wall is indicated. The maximum gas and solids velocity occurs about $2 \mathrm{~cm}$ to the right of the center of the pipe. At a height of 9.1 meters from the pipe inlet (Figure 5), both profiles were more symmetric. In both Figure 4 and in Figure 5, the gas and solids velocities were essentially equal to each other because the small particles are carried along at virtually the same velocity as the gas.

\section{Contacting Bond Energy Model}

A second hydrodynamic model was also developed for cohesive solids. This model was based on theoretically-derived equations which can predict when cohesive particles will agglomerate. The general theory behind the derivation of the equations is presented below along with the equations.

\section{Particle Agglomeration}

Many fluidized-bed systems used in the coal conversion and pharmaceutical industries are operated under agglomerating conditions. This agglomeration is due to the cohesiveness of the particles. In general, there are two types of agglomeration:

Thermal Agglomeration, which occurs under high-temperature conditions where materials partially melt and become sticky. Under these conditions, particles agglomerate upon collision with each other.

Non-Thermal Agglomeration, which occurs for particles which have strong interparticle forces. These agglomerates may be de-agglomerated as a result of the fluid interaction with them. 


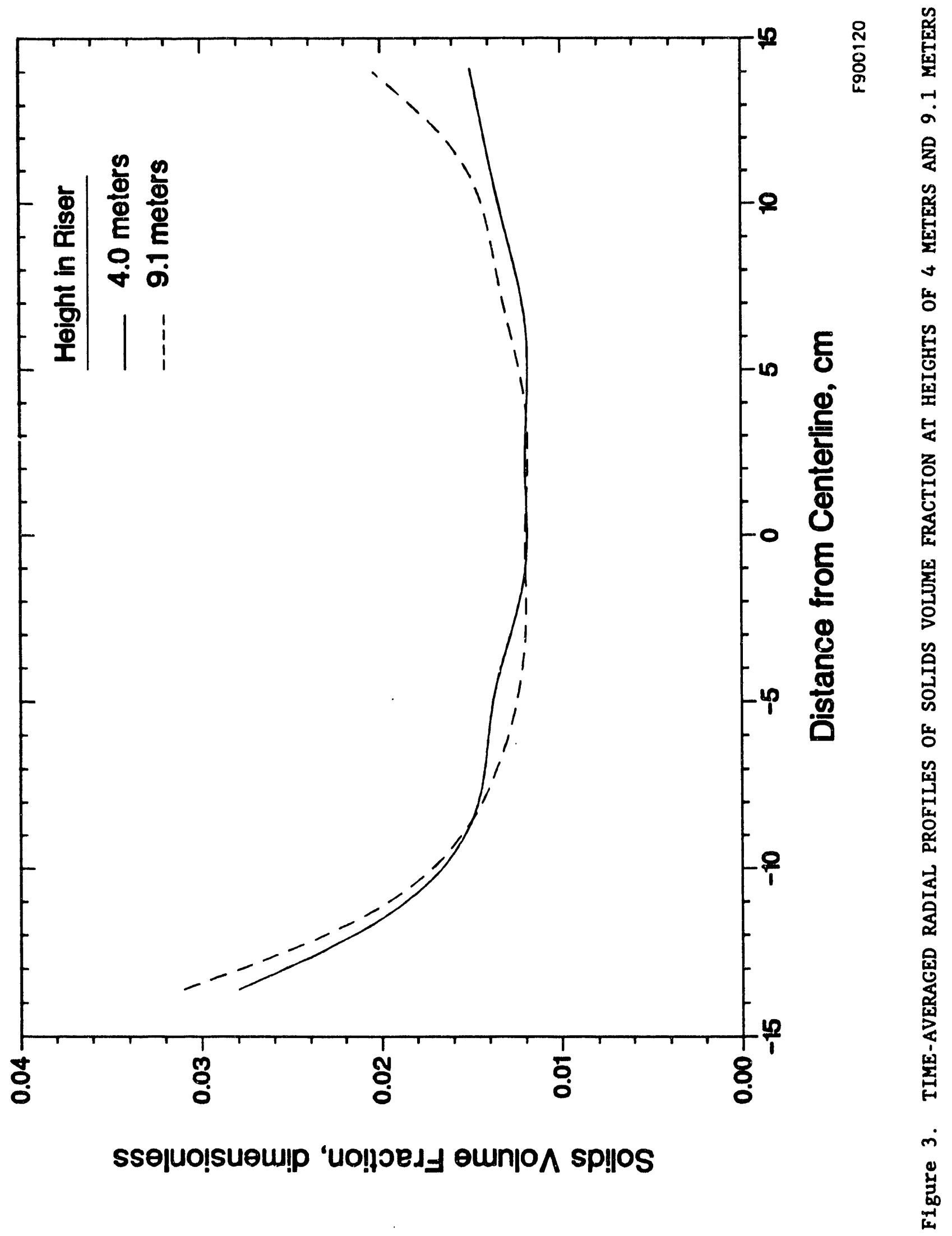

I N S T I T U T E O F G A S T E C H N O L O G Y 


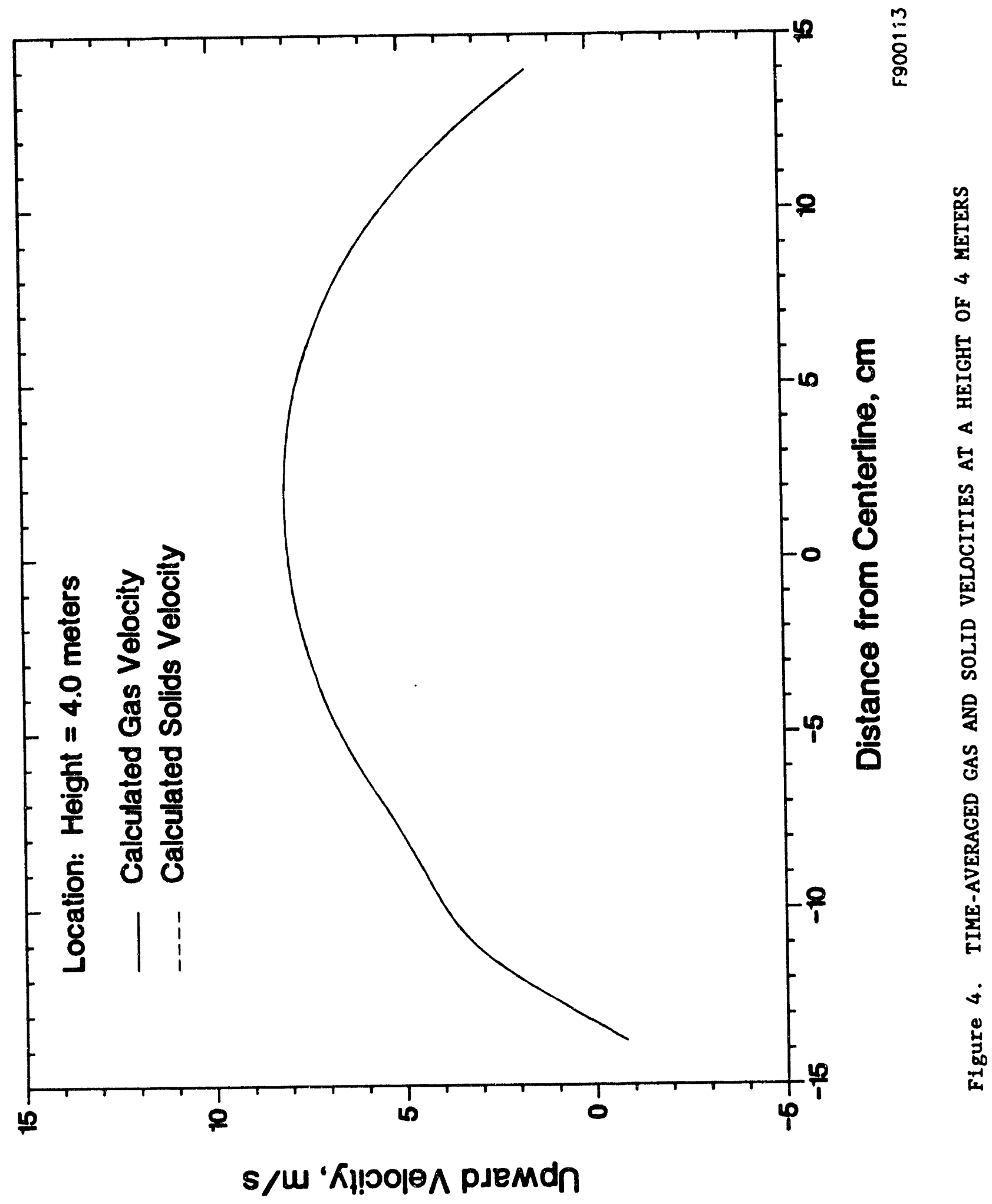




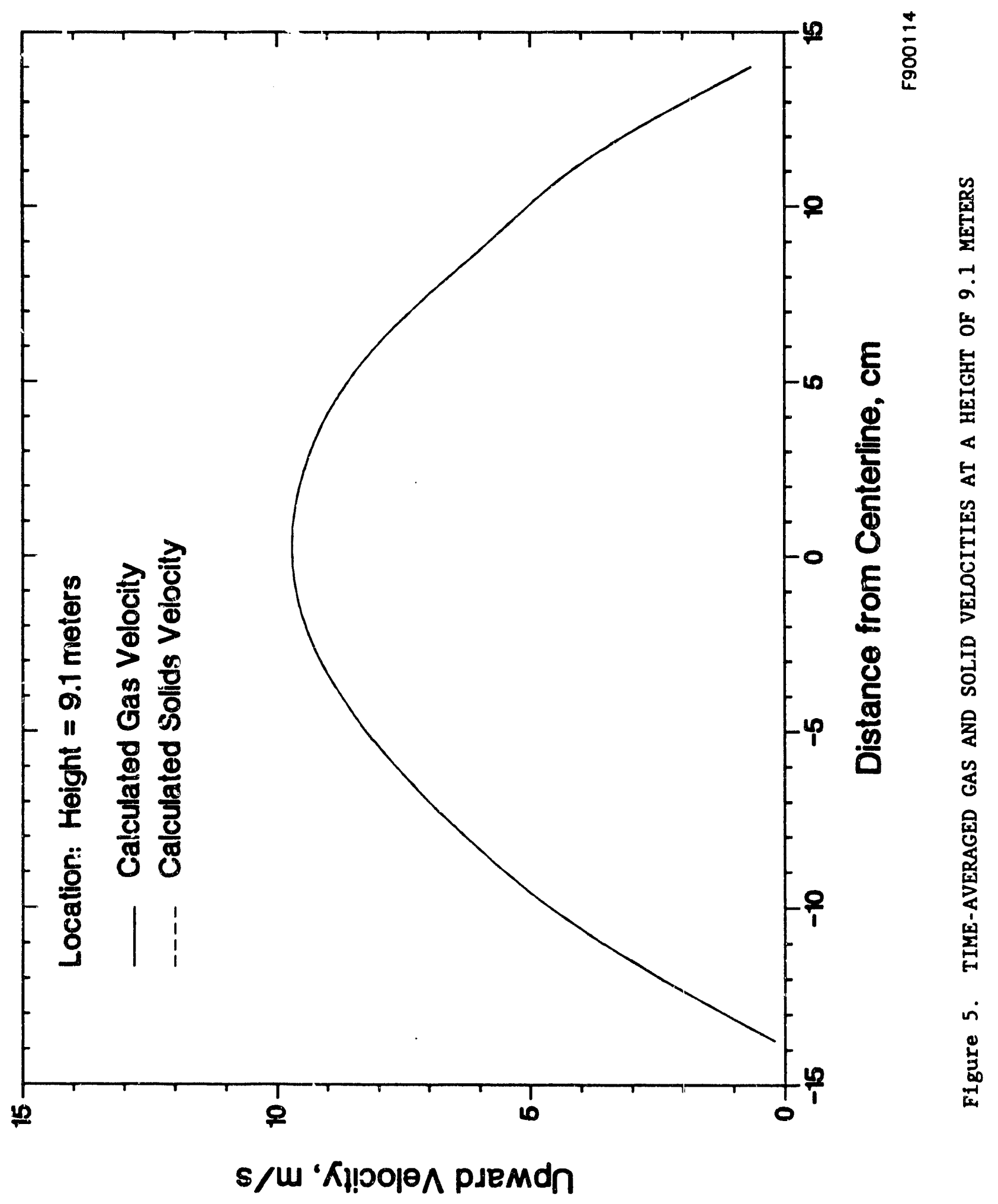

I NSTITUTE T O F G A S TE CH NOL O G Y 
Non-Thermal Agglomeration

Unlike non-cohesive particles, cohesive particles may not separate after colliding with each other. The inherent cohesiveness of particles arises from the complicated forces between two contacting surfaces. The contacting forces may be Van der Waals, static electricity, or surface tension caused by liquid bridges.

Particles in general tend to agglomerate due to an interparticle force. This attractive force is very strong in the case of very fine particles. In order to separate the particles, some mechanical work is required to overcome the contacting energy. This contacting energy is transferred into thermal energy irreversibly, and is defined as the Contacting Bond Energy, $E_{c}$.

$E_{c}$ is assumed to be only a function of the surface properties of the particle. By analogy with the concept of chemical bond energy, $E_{c}$ is considered to quantitatively represent the strength of the contacting bond. The higher the value of $E_{c}$, the more cohesive the particles. In the case vhere $E_{c}=0$, the particles are not cohesive.

With the contacting bond energy concept, it is possible to determine the collision mechanics of two cohesive particles. Upon collision of two particles, the total energy loss is equal to the energy loss due to incomplete restitution plus the energy consumed during the breakage of the contacting bonds. The criterion for agglomeration for two colliding particles is given below.

If the kinetic energy of two colliding particles remaining after collision, $(\mathrm{KE})_{Y}$, is greater than the contacting bond energy, then the two particles will separate after a collision. If the kinetic energy remaining is less than the contacting bond energy, the particles will agglomerate. Mathematically, if $z_{c}$ is the ratio of $E_{c}$ and $(K E)_{r}$, then

if $Z_{c}=E_{c} /(K E)_{r}>1$ then agglomeration occurs

if $Z_{c}-E_{c} /(K E)_{r}<1$ then separation occurs.

For non-cohesive particles, $\mathrm{E}_{\mathrm{c}}-0$, and no agglomeration occurs.

Non-thermal agglomerates of cohesive particles may be broken either by collision or by interaction with the fluld phase. The breakage mechanism is very complicated. The fluid motion produces the shearing, twisting, 
elongating and turbulent conditions that may break the agglomerates. However, sometimes the fluid-phase interaction may enhance the contact bonds.

At equilibrium, the total mechanical energy of an agglomerate consisting of several small particles is $E_{\text {abs }}$. Mathematically, $E_{\text {abs }}$ equals the sum of the kinetic energy of the large aggomerate, KE $E_{D}$ plus the potential energy of the system, $E_{\text {pot }}, 1$. e.,

$$
E_{\text {aBg }}=K E_{D}+E_{p o t}
$$

When the large aggomerate (D) breaks into two smaller agglomerates $\left(D_{1}\right.$ and $D_{2}$ ), then the total mechanical energy is:

$$
E_{\text {broken }}=K E_{D 1}+K E_{D 2}+E_{\text {pot }}
$$

where $E_{\text {pot }}$ is the same in both cases.

By the Minimum Energy Principle, the lower the mechanical energy, the more stable is the system. Therefore, if

$$
E_{\text {ags }}>E_{\text {broken }}+n_{c} E_{c}
$$

(where $\mathrm{n}_{\mathrm{c}}$ is the number of contacting points between two agglomerates) then the unbroken agglomerate status will be unstable. Therefore, it can overcome the energy barrier $\left(n_{c} E_{c}\right)$ due to the cohesive contacting bond, and will break into two agglomerates.

If

$$
E_{\text {ags }} \text { is }<E_{\text {broken }}+n_{c} E_{c}
$$

then the agglomerate remains stable. 
The energy dissipation between the two cases can be defined as:

$$
\Delta E-E_{a s s}-E_{b r o k o n}
$$

If $\Delta E>0$, then an agglomerate of Mass $M$, will split into two smaller agglomerates of masses $m_{1}$ and $m_{2}$, respectively. $\Delta E$ can be shown to be mathematically equivalent to:

$$
\frac{-m_{1} m_{2}}{M} D \vec{U} 1 \cdot \nabla \vec{U}(Z)
$$

where $D$ - diameter of largest agglomerate

$$
\nabla U \text { - velocity gradient }
$$

$\mathrm{Z}$ - unit vector in $\mathrm{z}$ direction

1 - unit vector for the orientation of the agglomerate

The velocity gradient has a significant role in the breakage of agglomerates by shear. For example, if the velocity gradient vanishes, then there will be no breakage of agglomerates.

If $\omega$ is the angle between the unit vector and $\nabla U$, then from the definition of $\Delta E$,

$$
\cos (\pi-\omega)>\frac{n_{c} E_{c} M}{m_{1} m_{2} D U \nabla U}-Y_{c}
$$

If $Y_{c}>1$ then

$$
U \nabla U<\frac{n_{c} E c M}{m_{1} m_{2} D}
$$

and no breakage occurs.

If $0<Y_{c} \leq 1$, then 


$$
U \nabla U>\frac{n_{c} E_{c} M}{m_{1} m_{2} D}
$$

and breakage will occur under the following conditions:

$$
\pi+\cos ^{-1} Y_{c}>\omega>\pi-\cos ^{-1} Y_{c}
$$

otherwise the agglomerate is stable. If it is assumed that the orientation of the agglomerate is random (i.e., $\omega$ varies between 0 and $2 \pi$ ), then the probability of the agglomerate breaking into two smaller agglomerates is

$$
\text { Probability of breakage }-(1 / \pi) \cos ^{-1} Y_{c}
$$

If $Y_{c}=0,\left(E_{c}=0\right)$ or ( $\nabla U$ goes to $\left.\infty\right)$, then the particles are not cohesive or they are under extremely high shear. In this instance the probability of breakage reaches a maximum value of 0.5 . This means that under the most unstable case, the agglomerate still has a 0.5 probability of remaining stable because some orientations of the agglomerate are always stable orlentations (i.e., $\pi / 2>\omega>-\pi / 2$ ).

The value of $Y_{c}$ can also be expressed as

$$
Y_{c}=\frac{12\left(1-\epsilon_{a}\right) N_{c} E_{c}}{\pi \rho_{s} D_{p}^{2} U \nabla U D_{1} D_{2}}
$$

Lower values of $Y_{c}$ result in higher probabilities that an agglomerate will break. From the latter equation, it can be seen that the smaller the difference between $D_{1}$ and $D_{2}$, the greater the probability of breakage. Therefore, the most likely probability anong all of the breakage possibilities is that the agglomerate will split into two equal pieces (i.e., $D_{1}-D_{2}=$ $0.5 \mathrm{D})$. Therefore, the probability that the agglomerate will split into two equal pieces is:

$$
\text { Prob two oqual pioces }-(1 / \pi) \cos ^{-1} \frac{48 \epsilon_{\mathrm{a}} N_{c} E_{c}}{\pi \rho_{8} D_{p}^{2} U \nabla U D_{1} D_{2}}
$$


The probability that an aggomerate will break into two unequal pieces is :

$$
\text { Probunequal pieces }-(1 / \pi) \cos ^{-1} \frac{12 \epsilon_{\mathrm{a}} N_{c} E_{c}}{\pi \rho_{\mathrm{s}} D_{\mathrm{p}}^{3} U \nabla U\left(D-D_{p}\right)}
$$

Thus, the following factors will result in a higher probability that agglomerates will break up:

1. increasing agglomerate size, D

2. increasing the size of the particles comprising the agglomerates, $D_{p}$

3. higher particle densities, $\rho_{\mathrm{B}}$

4. higher gas velocity gradients (i. e. more shear), $\nabla 0$

5. loose packing of the individual particles in the agglomerates, higher $\epsilon_{a}$

6. greater turbulence in the flowing fluid

Fluid-phase turbulence interacts with particle fluctuation in a very complicated manner. When solid particles flow in the presence of fluid turbulence, the simultaneous particle velocity will be a summation of the mean velocity and the randomly distributed fluctuating velocity, i.e.:

$$
U=U_{\text {mean }}+u
$$

and

$$
U^{2}=U_{\text {mean }} U_{\text {mean }}+u u+2 U_{\text {mean }} u
$$

Using statistical averaging it can be shown that: 


$$
\begin{aligned}
& U^{2}=U_{\text {mean }}^{2}+u^{2} \\
& U \nabla U=U_{\text {mean }} \nabla U_{\text {mean }}+u \nabla u
\end{aligned}
$$

It can be readily seen from the equations above that the presence of turbulence will provide more instability and increase the probability of agglomeration.

The kinetic theory of gases was originally developed by Chapman and Cowling (1970). Researchers have tried to extend the kinetic theory and apply it to interparticle collisions in gas-solid, two-phase flow systems. In this work, the kinetic theory has been applied for the first time to cohesive particles.

With this second hydrodynamic model, the equations of continuity, momentum, and fluctuating energy were derived from the Boltzman equation. When applying these equations, the coefficient of restitution was taken to be 0.8 . Using the kinetic theory approach, the granular temperature, $\mathrm{T}_{\text {gran, }}$ represents the fluctuation enery of the particles, i.e.,

$$
\begin{gathered}
T_{B \operatorname{ran}}=(1 / 3)\left(\mathrm{C}^{2}\right\} \\
\mathrm{C}=\mathrm{C}-\mathrm{U}_{\mathrm{B}}
\end{gathered}
$$

where $C$ is the fluctuating velocity.

The equations for this hydrodynamic model (based on kinetic theory and the Contact Bond Energy concept for cohesive particles) are given below.

Mass Balance

fluid phase

$$
\frac{\partial}{\partial t}\left(\epsilon_{f} \rho_{f}\right)+\nabla \cdot\left(\epsilon_{f} \rho_{f} \vec{U}_{f}\right)=0
$$

solid phase
I N S T I T U T E
O F
G A S
T E C H N O L O G Y 


$$
\frac{\partial}{\partial t}\left(\epsilon_{s} \rho_{s}\right)+\nabla \cdot\left(\epsilon_{s} \rho_{s} \vec{U}_{s}\right)-0
$$

\section{Momentum Balance}

fluid phase

$$
\begin{aligned}
\frac{\partial}{\partial t}\left(\epsilon_{f} \rho_{f} \overrightarrow{\mathrm{U}}_{f}\right)+\nabla \cdot\left(\epsilon_{f} \rho_{f} \overrightarrow{\mathrm{U}}_{f} \overrightarrow{\mathrm{U}}_{f}\right) & -\nabla \cdot\left(\mathrm{T}_{\mathrm{k}}+\mathrm{T}_{\mathrm{c}}\right) \\
& +\epsilon_{f} \rho_{f} \overrightarrow{\mathrm{g}}+\epsilon_{f} \rho_{f}\left(f_{\mathrm{drag}}\right)
\end{aligned}
$$

solid phase

$$
\begin{aligned}
\frac{\partial}{\partial t}\left(\epsilon_{s} \rho_{s} \vec{U}_{s}\right)+\nabla \cdot\left(\epsilon_{s} \rho_{s} \vec{U}_{s} \vec{U}_{s}\right) & =-\nabla \cdot\left(T_{k}+T_{c}\right) \\
& +\epsilon_{s} \rho_{s} \vec{g}+\epsilon_{s} \rho_{s}\left(f_{\text {drag }}\right)
\end{aligned}
$$

where for the solids phase, the kinetic stress of the solid phase is

$T_{k}=\epsilon_{s} \rho T_{g r a n} I$

the collisional stress of the solid phase is

$\mathrm{T}_{\mathrm{c}} \quad-\mathrm{P}_{\mathrm{s}} \mathrm{I}-2 \epsilon_{\mathrm{s}} \mu_{s}\left[\mathrm{~S}+\frac{5}{6}\left(\nabla \cdot \overrightarrow{\mathrm{U}}_{\mathrm{S}}\right) I\right]$

where $S$ is the non-divergence shear tensor:

s $\quad-\frac{1}{2}\left[\left(\nabla \vec{U}_{S}\right)+\left(\nabla \vec{U}_{S}\right)^{T}\right]-\frac{1}{3}\left(\nabla \cdot \vec{U}_{S}\right) I$

the solid phase collisional pressure, $P_{S}$, is

$\mathrm{P}_{s}=\mathrm{P}_{s} \circ\left[1+\xi_{\rho}\left(\mathrm{R}_{\mathrm{c}}\right)\right]$

the solid phase collisional viscosity, $\mu_{s}$, is

$\mu_{s} \quad-\mu_{s} 0\left[1+\xi_{v}\left(R_{c}\right)\right]$

$R_{c}$ is the dimensionless constant representing the ratio of the contacting bond energy and the fluctuating energy of the particles:

$R_{C} \quad-\sqrt{\frac{E_{C}}{e^{2} m T_{B r a n}}}$ 
and $p_{80}$ and $\mu_{30}$ are the solid phase collisional pressure and viscosity for non-cohesive particles, respectively:

Pso $-2(1+e) \rho_{S} \epsilon^{2} g_{0} T_{B r a n}$

$\mu_{\mathrm{s} 0}-\frac{4}{5} \epsilon_{\mathrm{S}} \rho_{\mathrm{SBO}}(1+e) \sigma \sqrt{\frac{\mathrm{T}_{\mathrm{Bran}}}{\pi}}$

and where $\xi_{\mathrm{P}}$ and $\xi_{\mathrm{V}}$ (the cohesive correction coefficients due to cohesivevess for the pressure and viscosity term, respectively) are:

$$
\begin{aligned}
\xi_{P} & =\frac{e}{1+e}\left(e^{-R_{c}^{2}}-1\right) \\
\xi_{v} & =\frac{e}{1+e}\left[e^{R_{c}^{2}}-1+\frac{1}{8} R_{c}^{4} E_{I}\left(-R_{c}^{2}\right)\right. \\
& \left.-R_{c}^{4} \sum_{n=1}^{\infty} \frac{(2 n+1) ! !}{(2 n+4) ! !} R_{c}^{2 n} \Gamma\left(-n, R_{c}^{2}\right)\right]
\end{aligned}
$$

( $\left.f_{\mathrm{drag}}\right)$ is the average fluid drag force acting on the unit mass of the particles.

The fluctuating energy balance of the solid phase is:

$$
\begin{array}{r}
\frac{\partial}{\partial t}\left[\epsilon_{s} \rho_{S}\left(\frac{3 \mathrm{~T}_{\mathrm{gran}}}{2}\right)\right]+\nabla \cdot\left[\epsilon_{\mathrm{s}} \rho_{\mathrm{s}} \overrightarrow{\mathrm{U}}_{\mathrm{s}}\left(\frac{3 \mathrm{~T}_{\mathrm{gran}}}{2}\right)\right]--\nabla \cdot \overrightarrow{\mathrm{q}}-\left(\mathrm{T}_{\mathrm{k}}+\mathrm{T}_{\mathrm{c}}\right): \nabla \overrightarrow{\mathrm{U}}_{\mathrm{s}} \\
+\epsilon_{\mathrm{s}} \rho_{\mathrm{S}}\left(f_{\mathrm{drag}} \cdot \overrightarrow{\mathrm{C}}+\mathrm{N}_{\mathrm{C}}\left(\frac{1}{2} \mathrm{mC}^{2}\right)\right.
\end{array}
$$

where the collision flux of the fluctuation energy, $q_{c}$, is given by

$$
\vec{q}_{c}=\vec{p}_{c}\left(1 / 2 m C^{2}\right)
$$

\section{Boundary Conditions}

The boundary conditions to be applied to the equations shown above are listed below. For all of the equations, axisymmetry is assumed around the riser center line. At the riser wall, the radial velocity of the gas and solid are assumed to be zero, 1 . e.,

$$
\mathrm{U}_{\mathrm{Br}}=0, \quad \mathrm{U}_{\mathrm{Br}}=0
$$


A force balance over the boundary thickness, $\delta$, gives:

$$
\delta\left[\beta\left(U_{s z}-U_{B z}\right)-\frac{\partial P}{\partial t}-\epsilon_{s} \rho_{B g}\right]-\mu_{z} \frac{\partial U_{B z}}{\partial r}-\frac{2 \mu_{B} U_{B z} T_{B r a n}}{U_{t} \delta}=0
$$

Considering the momentum transfer due to the inelastic collision of a particle with a rough wall,

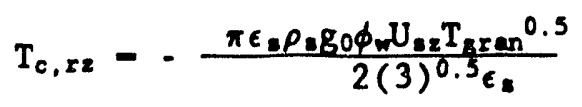

where $\phi_{w}$ is the specularity coefficient which depends on the roughness of the wall. For the granular temperature, an energy balance over the wall boundary gives

$$
q_{c}=-\gamma_{w}+U_{s z} T_{c, r z}
$$

where $\gamma_{m}=N_{c, m}\left(0.5 m c^{2}\right)$

$$
\begin{gathered}
\gamma_{w}=\gamma_{w 1}+\gamma_{w 2} \\
\gamma_{W 1}=-12 \epsilon_{s}^{2} \rho_{s} g 0 T_{B r a n}\left(1-e_{w}^{2}\right)\left[\left(T_{B r a n} / \pi\right)\right]^{0.5}\left\{1+\xi_{71}\left(R_{c}\right)\right\} \\
\gamma_{w 2}=3 \epsilon_{s}^{2} \rho_{s} g_{0} T_{B r a n}\left(1-e_{w}^{2}\right)\left(\nabla \cdot U_{s}\right)\left[1+\xi_{72}\left(R_{c}\right)\right] \\
\xi_{71}\left(R_{c}\right)=\left[e^{2} /\left(1-e^{2}\right)\right]\left[1-\exp \left(-R_{c}^{2}\right)\right] \\
\xi_{72}\left(R_{c}\right)=\left[e^{2} /\left(1-e^{2}\right)\right]\left[1-\left(1-1.5 R_{c}^{2}\right) \operatorname{erfc}\left(R_{c}\right)-\left\{2 R_{c} /\left(\pi^{0.5}\right)\right\} \exp \left(R_{c}{ }^{2}\right)\right]
\end{gathered}
$$

The particle velocity at the wall, $U_{s z}$, can be determined from the following derivation: 
Assume the boundary area, $a_{c}$, per particle is

$$
a_{c}-\left(s+d_{p}\right)^{2}
$$

where, $s$, the average distance between particles is

$$
s=d_{p} \epsilon_{m} /\left(g_{0} \epsilon_{m}\right)
$$

The average number of particles per unit area of wall boundary is

$$
\Psi_{1}-1 / a_{c}
$$

The average collision frequency of each particle with the wall is

$$
\Psi_{2}=\left[\left(3 T_{g r a n g 0}\right)^{0.5} / d_{p}\right]\left(\epsilon_{\mathrm{g}} / \epsilon_{\mathrm{m}}\right)^{1 / 3}
$$

The average momentum transfer per collision is

$$
\Psi_{3}=\left(\left(\pi d_{p}^{2}\right) / 6\right) \phi_{w} \rho_{s} U_{s z}
$$

Then, the wall shear stress is

$$
T_{w}=-\Psi_{1}+\Psi_{2}+\Psi_{3}
$$

In general, cohesive and non-cohesive particle systems have similar types of collisional stresses. The primary difference between the two is the solid viscosity. Compared to non-cohesive particles, cohesive particles may not separate after collision. This means that cohesive particles will lose more kinetic energy during the collision.

However, because cohesive particles can form agglomerates, the momentum changes due to collision are less than that for non-cohesive particles. As a result, for the same granular temperature (1.e., for the same particle

$$
\begin{array}{lllllllllllllllllllllll}
\text { I N S T I T U T E } & \text { O F F } & \text { G A S } & \text { S } & \text { T E } & \text { C H N } & \text { O } & L & O & G & Y
\end{array}
$$




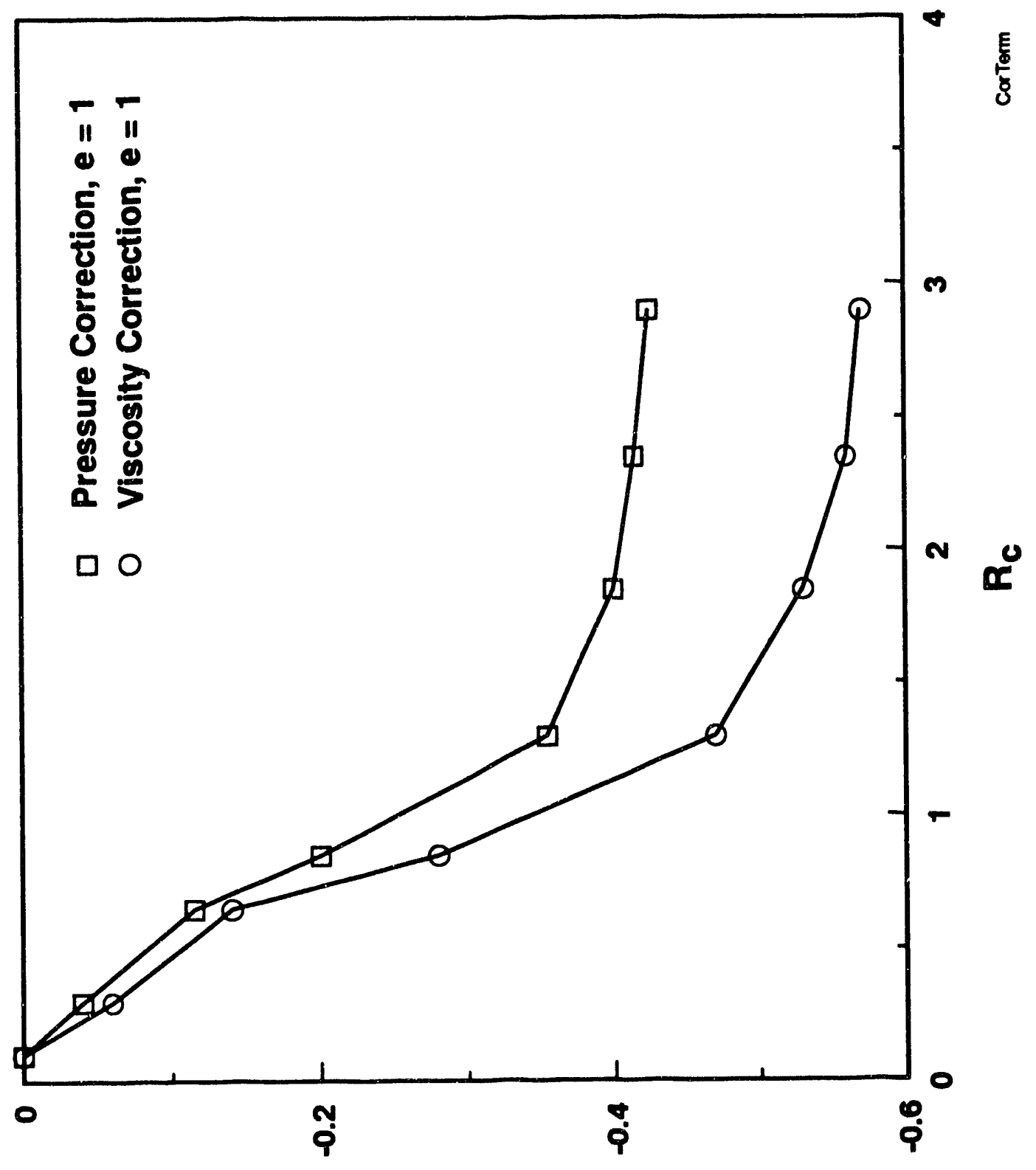

ह

号

总

器果

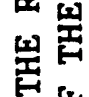

击

皆

읍

㫐福

它

4

\&

它星

sin

법 띤

㟧是

엉령

청

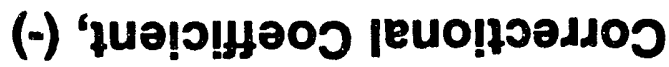

它

G A S

TECH NOL 


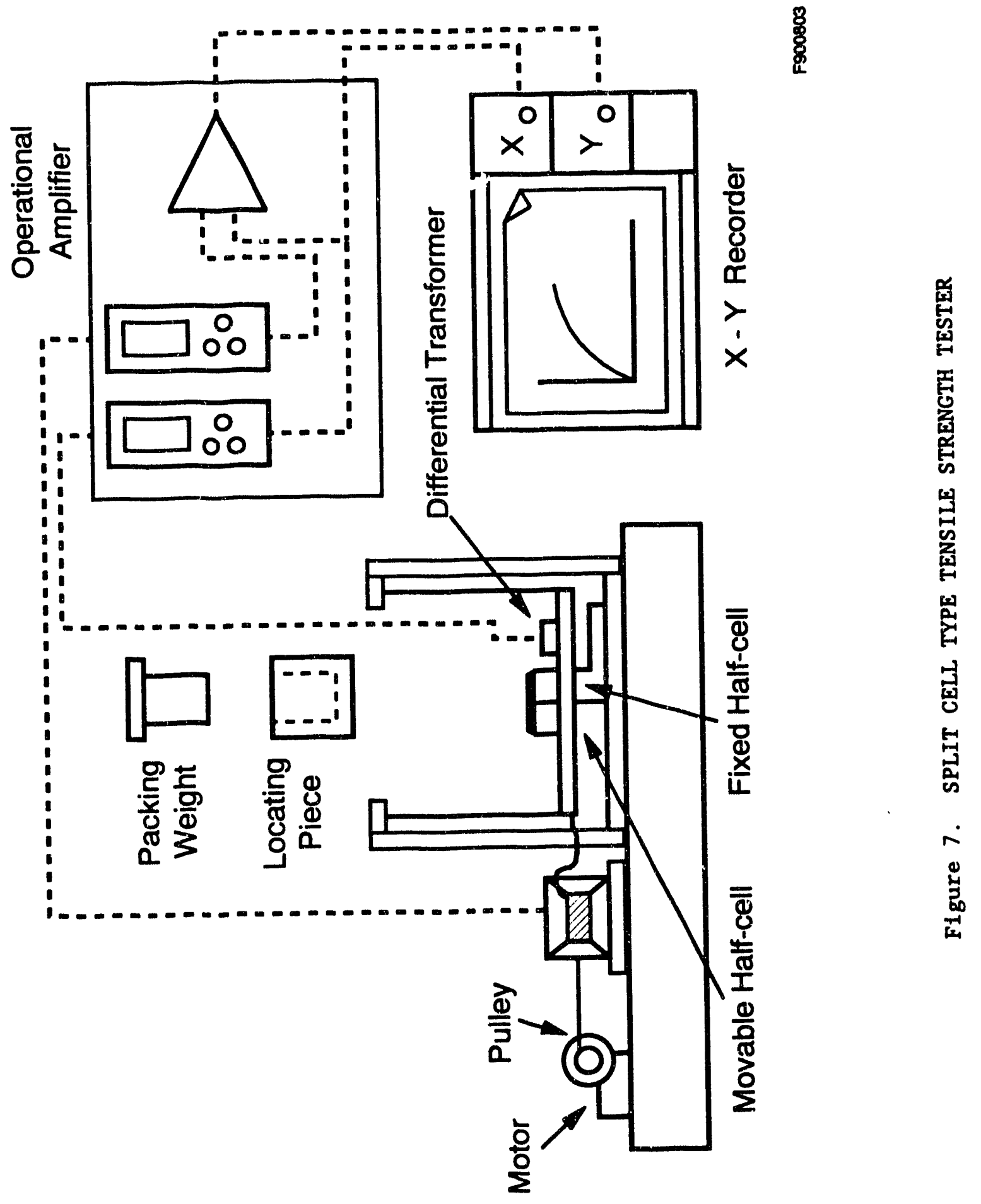
I N S T I T U T E
O F
G A S
TE C H N O L O G Y 
The operational amplifier consists of a strain amplifier, a displacement. meter, and a signal processor. The function of the signal processor is to Indicate the actual load to the powder layer. The signal processor calculates the actual force by subtracting the force required to pull apart the empty cell from the total force required to pull apart the solids and the cell. The ou:put of the operational amplifier is connected to an $x-y$ recorder. The $x$-axis of the recorder is the displacement, the y-axis is the tensile strength on the recorder.

In operation, the motor is turned on and begins pulling the movable half cell away from the fixed half cell at a constant linear (displacement) rate. As the linear disiance increases, the force on the powder increases. At some point, the force on the powder exceeds the cohesive force holding the powder together. The powder separates when this force is achieved. The magnitude of this force is recorded from the output of the strain gauge by the $x-y$ recorder. The procedure used to operate the cohetester is described below.

\section{Test Procedure}

1. Blank Test:

This test is conducted to determine the stress required to pull apart the empty cell. The blank test is conducted by turning on the motor and pulling the cell sections apart with no load. Once the blank test is made, an adjustment is then made to zero the instrument.

\section{Test With Sample Powder:}

a. The first step in making a test with a sample powder is to clean the cell. The test cell is divided into two hal:res, (Figure 8), one half remains fixed while the other half is free to move. The contact surface between these two parts is thoroughly clearad.

b. The movable half of the cell is then fixed by turning t.1e securing knob. The cell extension tube is then placed on the fell.

c. A known weight of the sample is placed in the cell. Normally this is approximately 20 to $30 \mathrm{gm}$ of powder.

d. The powder is then compacted using a compaction weight stabilizer (Figure 9). The powder layer is then allowed to stabilize for 10 minutes, to ensure the formation of a stable layer.

e. The vold frartion of the powder layer is calculated from the equation : 


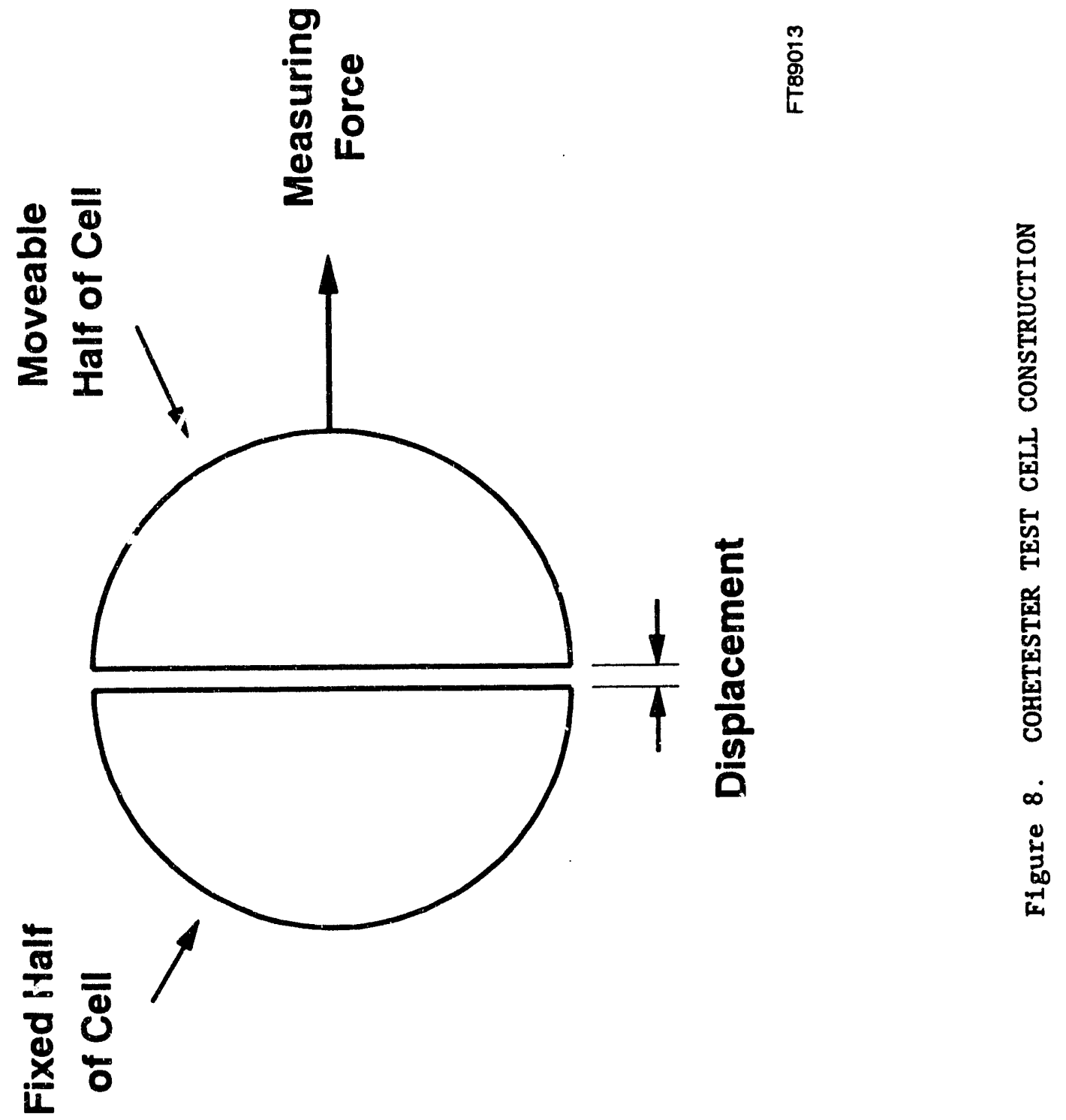




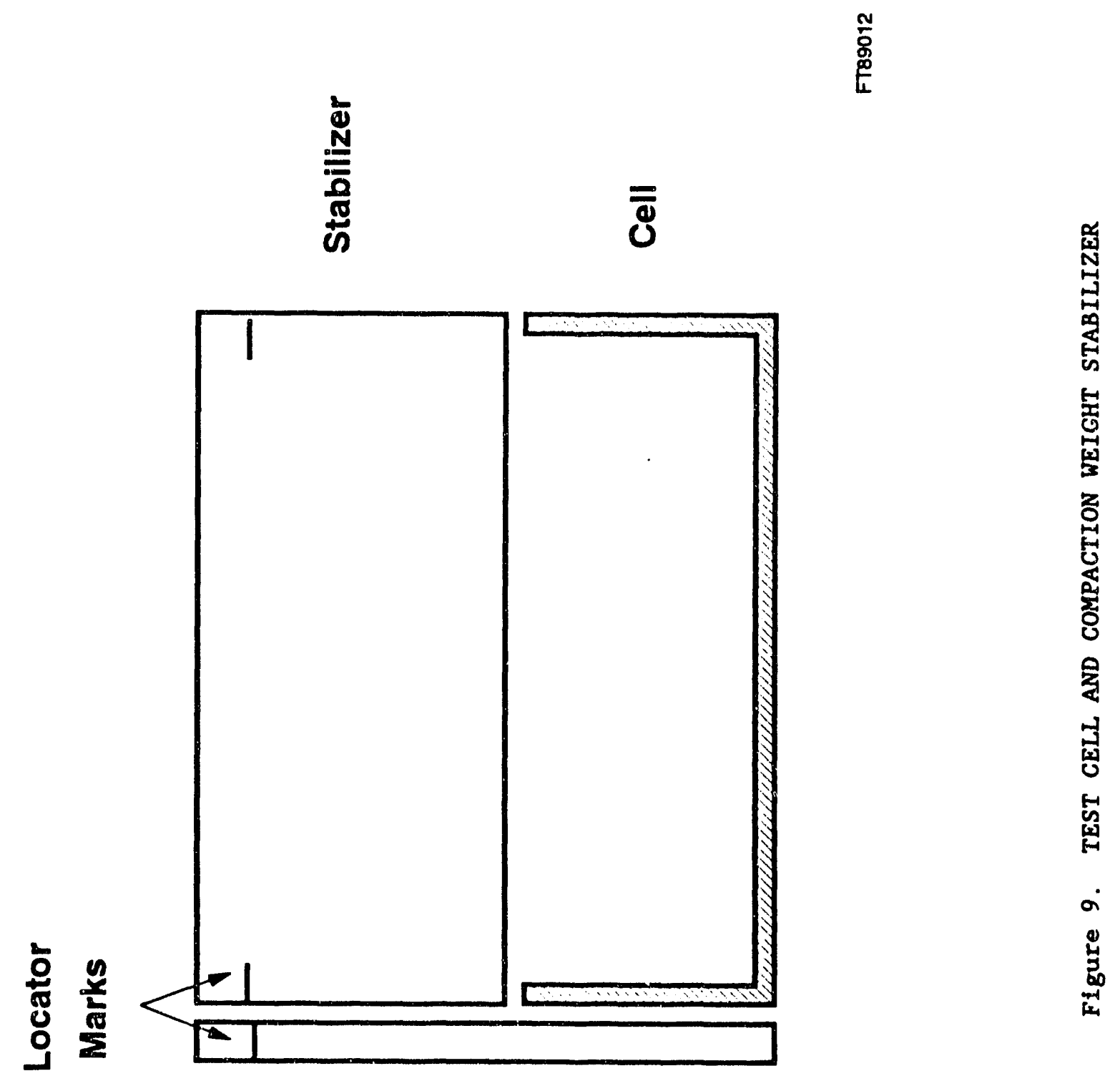

G A S TE C H N O L O G Y 


$$
\epsilon_{s}-\frac{W_{p}}{\rho_{p} V}
$$

where

$$
\begin{aligned}
& \epsilon_{s} \quad-\text { solids volume fraction } \\
& W_{p} \quad \text { - weight of the powder added to the cell } \\
& \rho_{p} \quad-\text { particle density } \\
& V \quad \text { - powder volume which is fixed. This volume was } \\
& \text { measured at the factory before shipment. }
\end{aligned}
$$

f. Once a stable layer is obtained, the compaction weight and cell extension tube are removed. The motor is then turned on, and the movable cell is freed by releasing the securing knob very gently.

g. The motor then pulls against the movable half of the cell. At some point the powder layer is broken. At this point the $x-y$ recorder shows a peak similar to that in gas chromatography (Figure 10). The height of this peak is proportional to the tensile strength. The tensile strength represents the cohesive force holding the powder together.

$h$. Once the powder layer is broken, the motor is switched off, the powder is removed from the cell and the cell is cleaned.

\section{Calibration of Cohetester}

Several tests were first conducted with wheat flour to compare the results with those obtained by the Hosokawa Micron Corporation. The tests consisted of measuring the cohesive force of wheat flour as a function of solids volume fraction. A comparison of the data obtained on the cohetester with data supplied by the Hosokawa Corporation is given in Figure 11 . Both sets of data show the same trend of the variation of tensile strength with solids volume fraction. However, the data from the Hosokawa Corporation indicated a more cohesive flour. This can easily be attributed to different experimental conditions. The flour was not the same flour, and surface moisture was undoubtedly different. In addition, the particle size may not have been the same. However, the tensile strengths varied with solids volume fraction in essentially the same manner. Therefore it was concluded that the instrument was functioning correctly. 


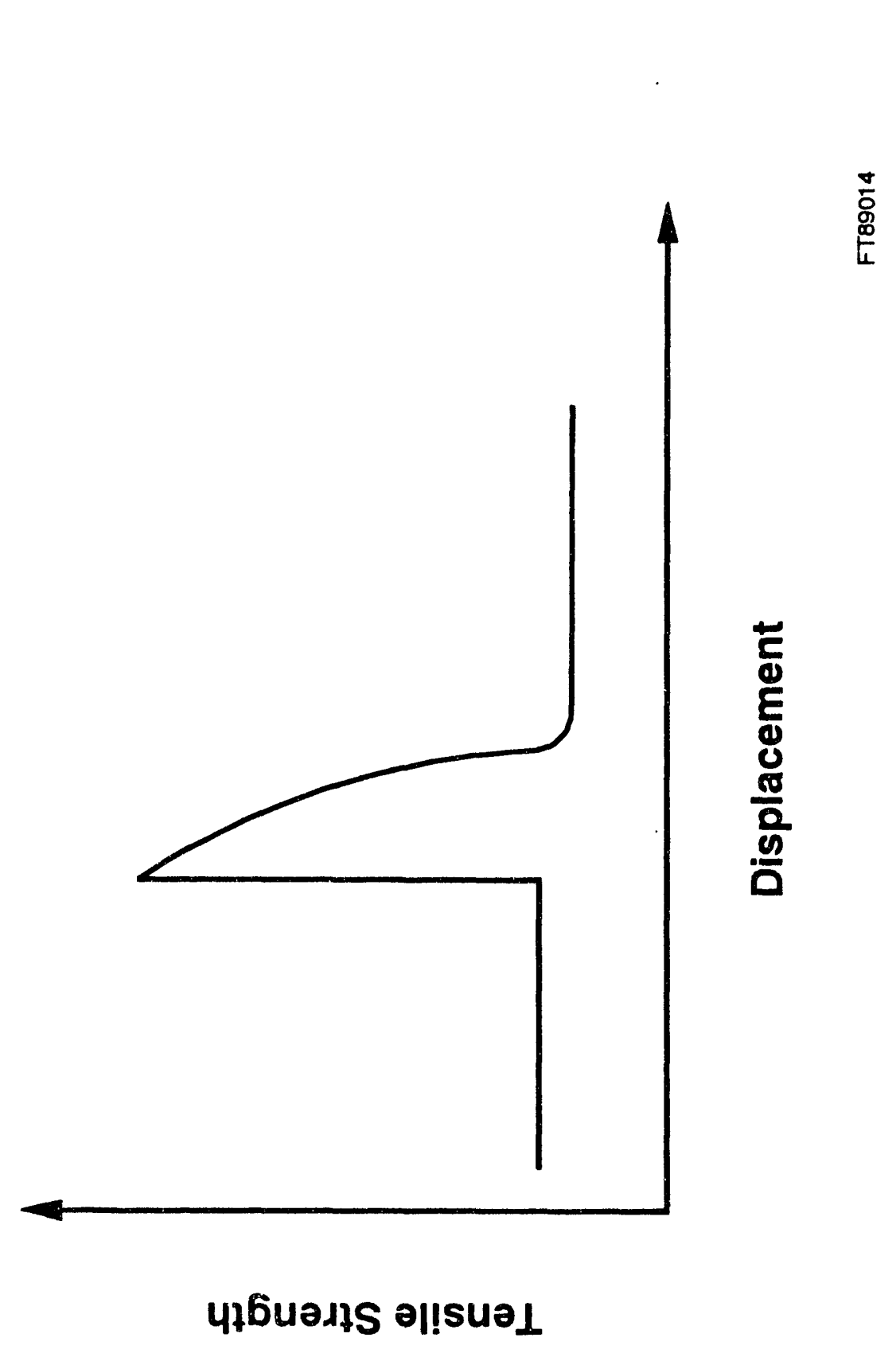

善

옹

$\ll$

号

品

雚

is

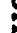

㛑

哭

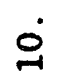

点

G A S

TE C H N O L O G Y 


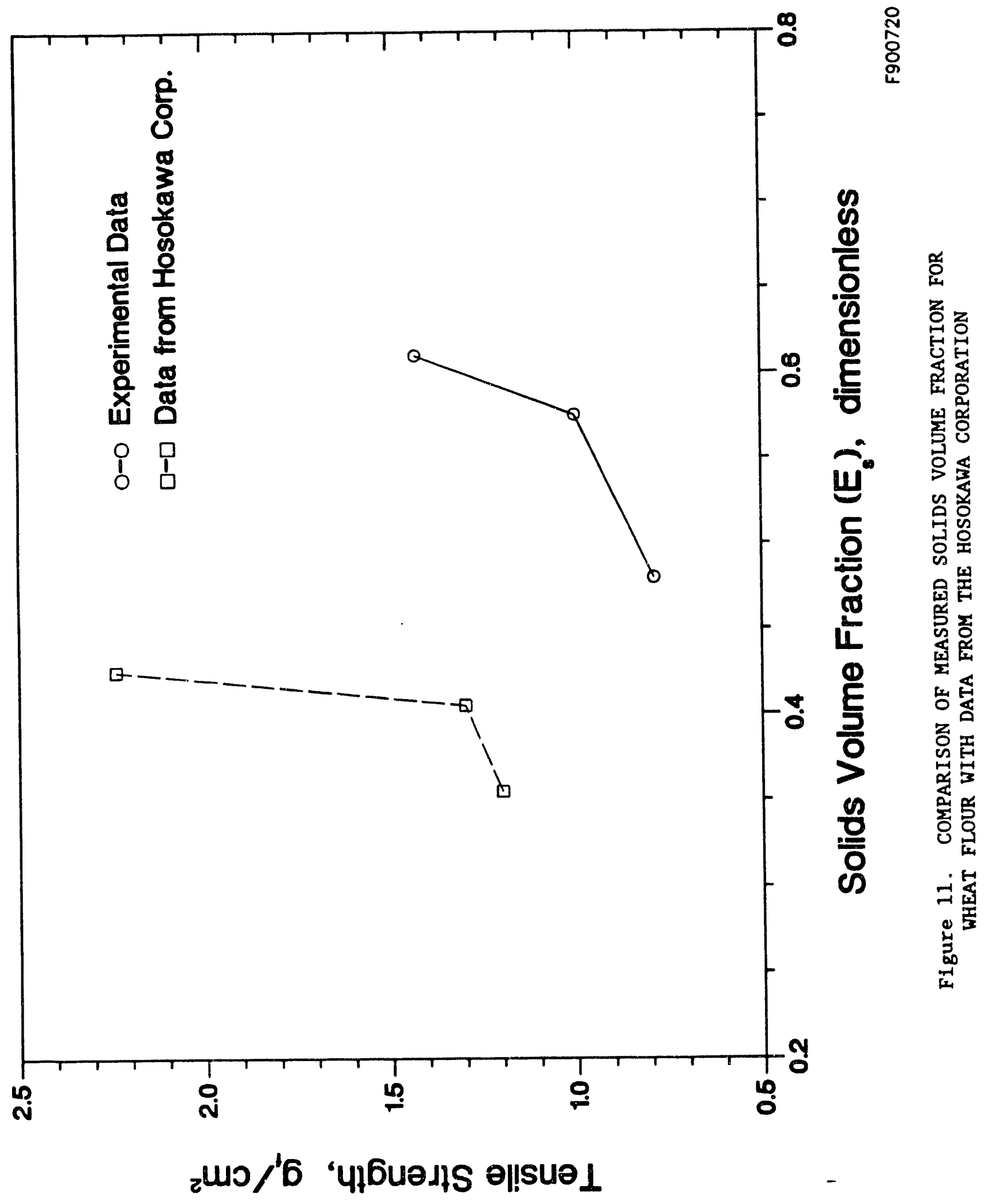




\section{Experimental Results}

After calibrating the Instrument with the wheat flour, several oil shale samples were tested. The first ofl shale sample tested was Indiana-New Albany eastern oil shale. This shale was first ground in a jet mill to an average particle size of 5 microns. Four measurements of tensile strength were taken to cover a range of solid void fractions. The experimental data for all four tests are shown in Table 2 .

Table 2. COHETESTER MEASUREMENT

Sample Name Particle Size Specific Gravity

Ambient Temperature, ${ }^{\circ} \mathrm{C}$

Powder + Tare Weight, $\mathbf{g}$

Tare Weight, $g$

Powder Weight, $g$

Void Fraction

Bulk Density, $\mathrm{g} / \mathrm{cm}^{3}$

Tensile Strength, $g f / \mathrm{cm}^{2}$

\begin{tabular}{c}
$\begin{array}{c}\text { Indiana-New Albany Oil Shale } \\
-5 \mu \mathrm{m} \\
2.1\end{array}$ \\
\hline
\end{tabular}

Test No, 1 Test No, 2 Test No, 3 Test No, 4

20

20

20

20

24.4925

28.5025

26.0625

25.5485

0.8625

0.8625

0.8625

0.8625

23.63

27.64

25.20

24.686

0.5598

0.6548

0.5970

0.5848

1.1756

1. 3752

1. 2537

1. 2282

8.132

14.766

10.379

9.309

Note: Tensile Strength $=$ Helght of Peak $(\mathrm{cm}) \times 0.1070$.

0.1070 is the amplifier gain.

The volume of the cell in the cohetester was $20.1 \mathrm{~cm}^{3}$.

Tensile strength is proportional to the peak height produced on the $x-y$ recorder. A plot of tensile strength and solid void fraction obtained in these tests is shown in Figure 12. Tensile strength increased with increasing solid volume fraction. The rate of increase of tensile strength was less at the looser packings, but it increased rapidly as the powder packing increased. 


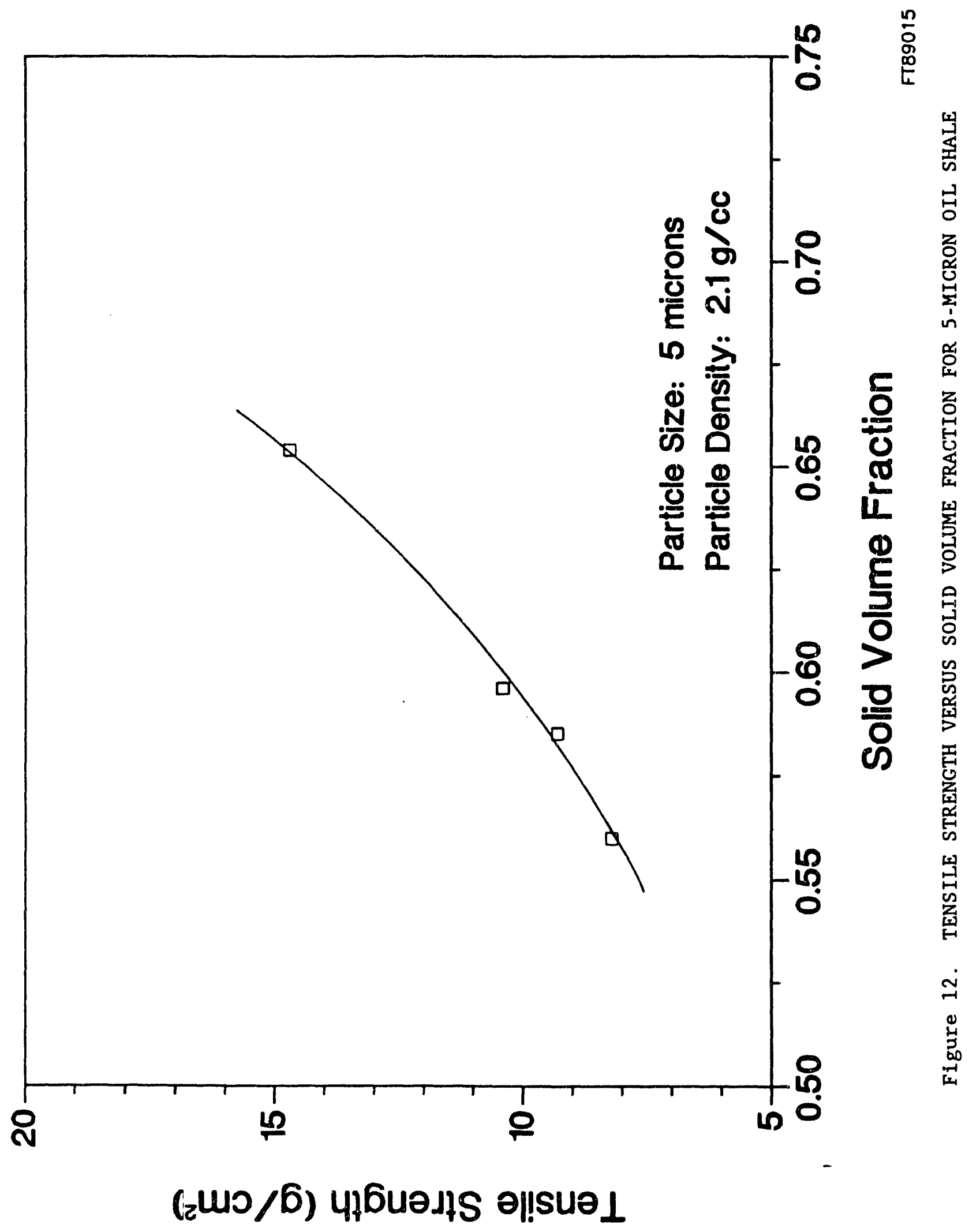

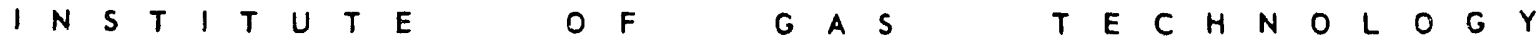


The relationship between tensile strength and solids volume fraction was fitted mathematically as:

$$
\tau_{c}=10^{2.75 \epsilon,+2.36}
$$

This equation was incorporated into the hydrodynamic model developed in Task 2.

Cohesive oil shale fines of the same Indiana New-Albany eastern shale obtained from a bag filter were also tested. This material had a kerogen content of approximately 138. The particle size distribution of this material is given in Table 3 . The tensile strength of this material was again observed to increase with an increase in the solids void fraction as shown in Figure 13.

The third sample tested was beneficlated oil shale, which had a higher kerogen content (approximately 28\%). The tensile strength of this material also was found to increase with an increasing solids volume fraction as shown in Figure 13. As can be seen in Figure 13, the tensile strength of the beneficiated shale was higher than that for the bag filter fines.

A plot comparing the tensile strengths of the wheat flour and bag filter shale fines is given in Figure 14. The shale was much more cohesive than the wheat flour.

\section{Subtask 3.2 Fluidization and Flow Testing}

A sample of the bag filter fines cohesive test material to be used in Task 5 was placed into a four-inch-diameter column and a fluidization test conducted. The results of the fluidization test are shown in Figure 15 . In this test, nitrogen gas was passed throught a bed of fine oil shale. The particle size distribution of the oil shale material is the same as that shown in Table 3 . 


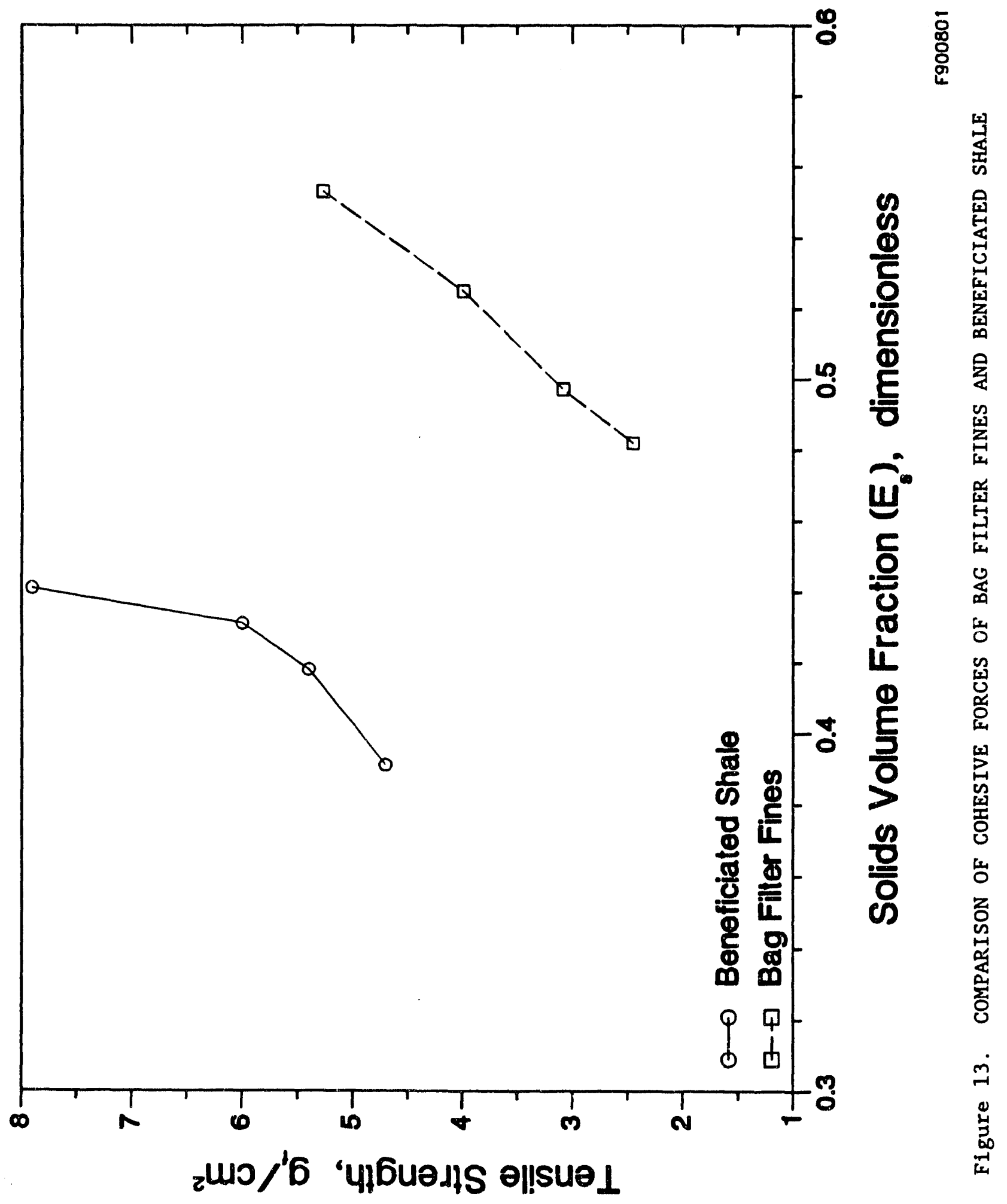




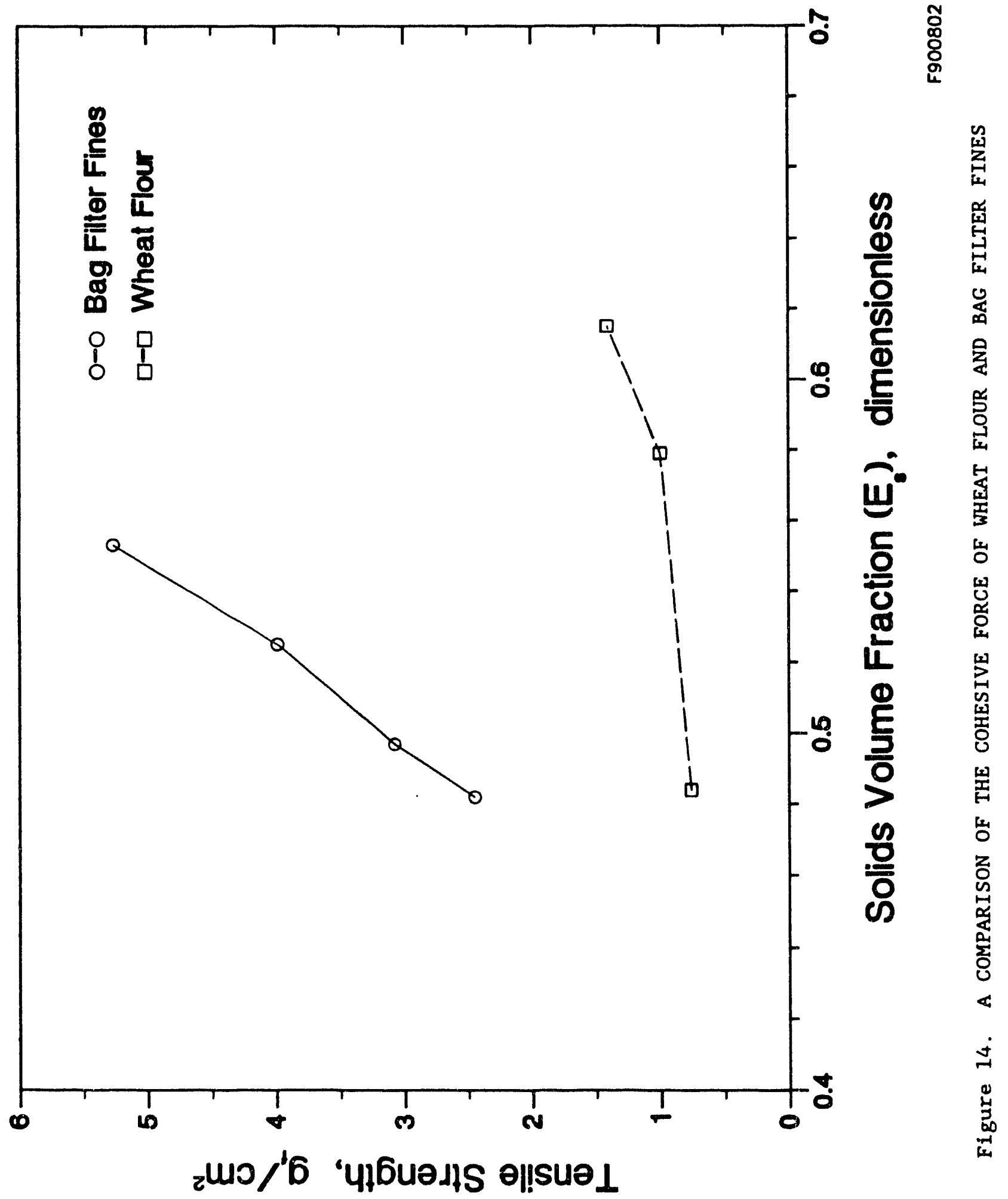

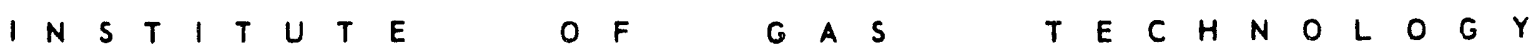




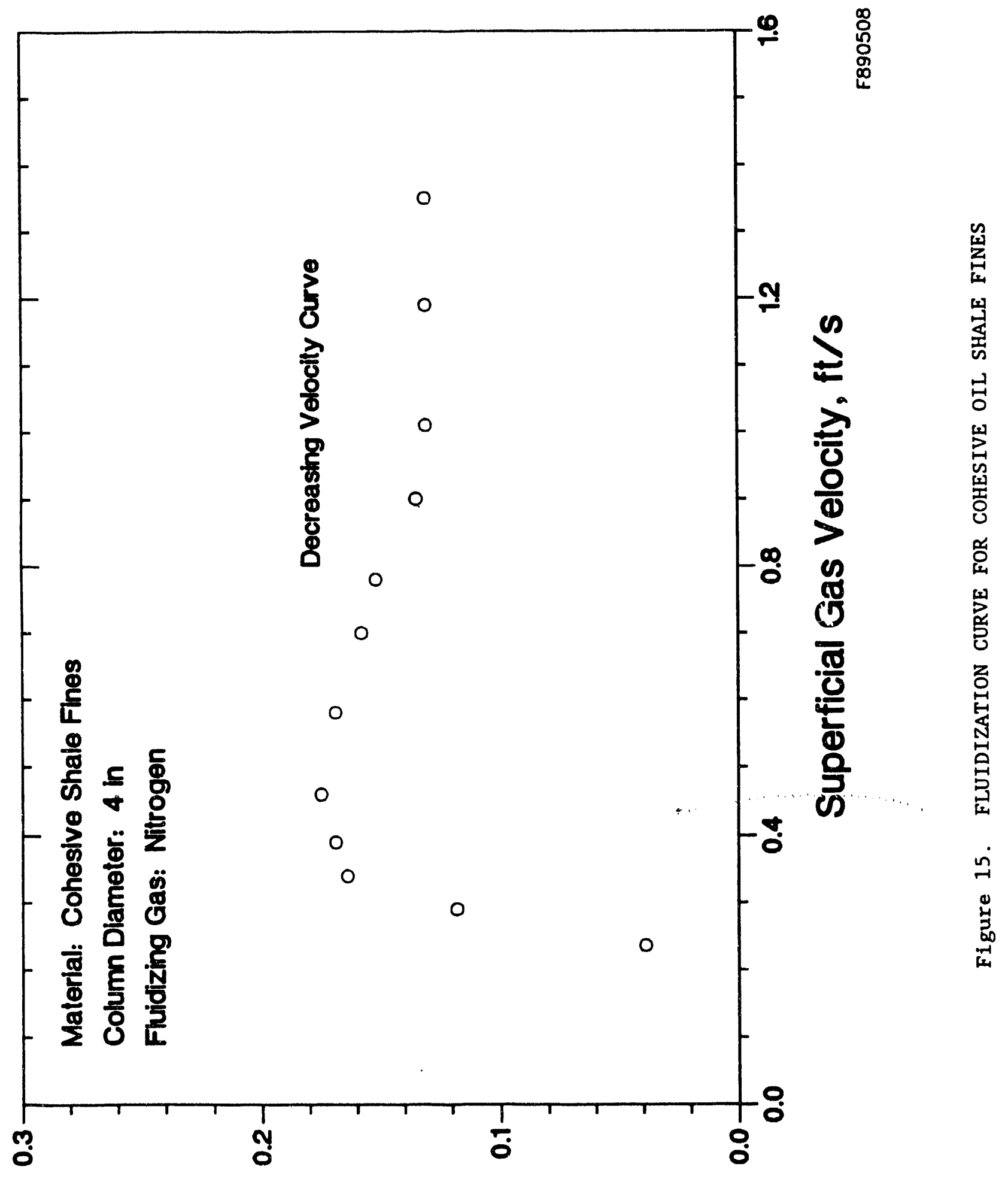

H/Isd ' ר/dV 'doda өנnssedd peg
I N S S T I T U T E
O F
G A S
TE C H N O L O G Y 
Table 3. OIL SHALE PARTICLE-SIZE ANALYSIS

\section{Particle \\ Size, \\ Microns}

40.3

32.0

25.4

20.2

16.0

12.7

10.1

8.0

6.4

5.0

4.0

3.2

2.5

2.0

1.6

1.3

1.0

0.8

0.6

0.5

$<0.5$

\section{Weight 8}

7.3

3.1

5.2

7.5

8.0

8.6

8.9

8.0

7.2

7.1

6.6

6.6

4.4

3.7

2.8

2.0

1.2

0.8

0.4

0.3

0.2

40 
When the nitrogen was initially passed through the solids very little pressure drop through the bed was noticed initially. This was because most of the gas was "channeling" through open cracks in the bed. After a gas velocity of approximately $0.25 \mathrm{ft} / \mathrm{s}$ was attained, the pressure drop across the bed began to build. This pressure drop increase was accompanied by the formation of spherical agglomerates which were much larger than the individual shale particles. The maximum pressure-drop-per-unit-length through the bed $(0.18 \mathrm{psi} / \mathrm{ft})$ was reached at a superficial gas velocity of about $0.5 \mathrm{ft} / \mathrm{s}$. This pressure-drop-per-unit-length was equivalent to a density of approximately $26 \mathrm{lb} / \mathrm{ft}^{3}$.

At a gas velocity of $0.5 \mathrm{ft} / \mathrm{s}$, only approximately one-third of the bed was fluidized. The bottom portion of the bed was still not moving. The entire bed became fluidized only when the gas velocity was increased above about $1.3 \mathrm{ft} / \mathrm{s}$.

When the bed became fluidized, the motion of the bed was different than a bubbling fluidized bed composed of larger particles. The bed had a "rolling" type of motion to it which is not generally seen in fluidized beds.

As noted above, the small oil shale particles agglomerated into much larger spheres. The high velocity needed to fluidize the shale is due to the presence of these spheres. Using the Wen and Yu Equation for the minimum fluidization velocity, it was calculated that a velocity of $1.3 \mathrm{ft} / \mathrm{s}$ would minimally fluidize particles 1300 microns in size. Thus, because of the agglomeration occurring in the bed, the cohesive oil shale eventually behaved more like a large Geldart Group B material than a Geldart Group C material.

The aggglomerates that were formed in the bed were very soft aggomerates. They were easily broken up by hand. It appears that they are held together only by interparticle forces.

A 6-inch-diameter hopper was then modified to accept a 1-inch-diameter screw feeder, and was tested to determine its suitability to feed cohesive oil shale. A schematic drawing of the modifled hopper/screw-feeder system is shown in Figure 16. A gas distributor was added to the bottom of the hopper to assist the screw feeder in discharging Geldart Group C solids. 


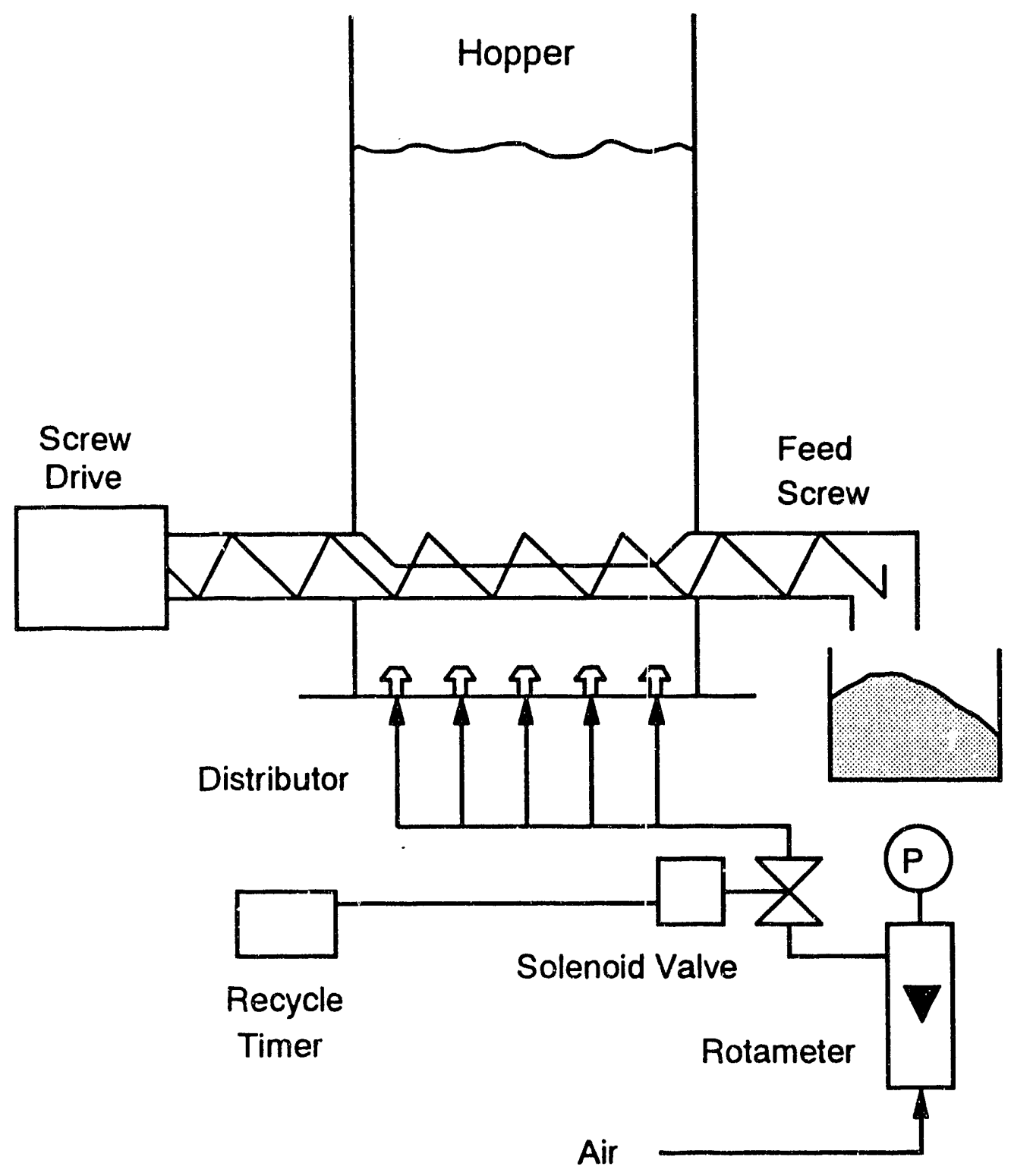

F900115

F1gure 16. SCHEMATIC DRAWING OF TEST' HOPPER AND DISTRIBUTOR 
The distributor was constructed so that gas could be passed through the hopper in controlled pulses. Nineteen gas-distribution holes were drilled into the distributor plete. A brass, porous filter vent was screwed into each hole. This construct un prevented the solids from weeping through the holes.

A section of $1 / 4$-inch-diameter tubing was attached to each distributor port, and was in turn connected to a pipe plenum. A solenoid valve actuated by a timer controlled the flow rate of gas into the distributor.

The hopper was filled with cohesive oil shaie fines and tested to determine if the device could feed the cohesive oil shale accurately and reliably. The particle-size distribution of these solids is shown in Table 4 . Solids were added to the hopper to a height approximately 60 inches above the feed screw. The upper section of the hopper was constructed of plexiglas so that the flow of solids in the hopper could be visually observed.

\begin{tabular}{ccc} 
Table 4. PARTICLE-SIZE DISTRIBUTION OF COHESIVE OIL SHALE PARTICLES \\
$\begin{array}{ccc}\text { Sesh } & \text { Microns } & \text { Wt \& Retained on } \\
\text { Stated Mesh Size }\end{array}$ \\
\cline { 2 - 3 } 120 & 125 & 6.4 \\
140 & 105 & 4.3 \\
170 & 88 & 23.4 \\
200 & 74 & 19.3 \\
230 & 63 & 22.7 \\
270 & 53 & 15.2 \\
325 & 44 & 3.5 \\
Pan & $\ldots$ & 5.2
\end{tabular}

The first test with the hopper was conducted with no pulsing of air through the distributor. Solids initially flowed through the screw feeder, but then stopped completely as the solids bridged across the hopper near the screw outlet. The test was repeated and the solids bridged again. Therefore, it was concluded that this method of operation was unsatisfactory with this material. The second test was conducted with air pulsed into the hopper through the distributor. Several different pulse times were tested in conjunction with different gas pressures at the rotameter. 
Initially, the feed screw was started and different pulse times and pressures were tried to obtain a flow that appeared to be steady. The first set of on/off pulse times were 5 seconds on and 5 seconds off. At a rotameter pressure of $30 \mathrm{psig}$, the solids in the hopper were fluidized, and the solids flow out of the hopper was not controllable by the screw. The same uncontrollable flow was observed at a rotameter pressure of $15 \mathrm{psig.}$

The rotameter pressure was then lowered to $7 \mathrm{psig.} \mathrm{The} \mathrm{hopper} \mathrm{still}$ appeared to be fluidized with an on/off pulse time of 5 seconds on and 5 seconds off. Therefore, the on/off times were changed to 2 seconds on and 8 seconds off. This setting appeared to still fluidize the bed during the 2-second pulse. The solids could be controlled with the feed screw, however.

The on/off pulse times were changed systematically until an on/off time of 0.2 seconds on and 9.8 seconds off was used. This combination appeared to give good control for the least amount of gas used.

Visual observation of the hopper showed that the solids appeared to bridge and stop flowing unless air was pulsed into the hopper. The air pulse prevented bridge formation in the hopper and allowed the solids to flow freely into the screw.

During the pulse of air into the hopper, a slight upward motion of the bed was observed at 7 psig. At pressures of 15 and $30 \mathrm{psig}$ at the rotameter, the solids in the hopper were observed to move upward as much as 6 to 12 inches.

It was concluded that the best combination of on/off pulse times and pressure at the rotameter was 0.2 seconds on and 9.8 seconds off, with a pressure of $7 \mathrm{psig}$ at the rotameter. Therefore, tests were conducted to determine if the solids flow through the screw was repeatable and controllable.

Two tests were conducted with the screw rpm set at 20. The solids were fed into a container over a certain time interval and then weighed. In the first test, two solid rates were measured at the 20 -rpm setting. The first rate measured was $82.5 \mathrm{~g} / \mathrm{min}$ and the second rate was $81.0 \mathrm{~g} / \mathrm{min}$.

The feed screw was then shut off and adjusted to the 20-rpm setting again. The next two rates obtained were $78.3 \mathrm{~g} / \mathrm{min}$ and $77.7 \mathrm{~g} / \mathrm{min}$. Two more 
readings were then obtained without shutting the screw off, but waiting approximately 5 minutes between readings. These two readings were $77.7 \mathrm{~g} / \mathrm{min}$ and $75.9 \mathrm{~g} / \mathrm{min}$.

The results of the testing show that the pulsed hopper in conjunction with a screw feeder can feed the cohesive ofl shale reliably and controllably. Task 4. Smal1-Scale Flow Tests

\section{Riser Test Unit}

A small-scale (3-inch-diameter) riser test unit was constructed to provide additional information on the nature of dilute-phase flow in risers, and to evaluate instrumentation to measure the radial distribution of the solids density and solids mass flux in the large-scale test unit. A schematic drawing of the small-scale test unit is shown in Figure 17. Systematic testing was conducted to determine mass flux, particle velocity, and solids volume fraction as a function of radial position in the riser in the smallscale test unit. The radial mass flux profile was measured using an extraction probe, whereas the solids volume fraction was measured using an $x$-ray densitometer. Because the particle velocity, solids volume fraction, and mass flux are related, knowing any two of the three parameters enables the calculation of the other parameter. Therefore, the radial particle velocity profile was calculated from the measured radial mass flux and the solids volume fraction data.

The tests in this unit were conducted with FCC catalyst to ensure that the instrumentation was operating correctly, and to compare the results with those of Bader et al. (1988) who conducted similar tests using the same material.

The FCC catalyst used in the testing had an average particle size of approximately 75 microns. The actual particle-size distribution of the catalyst as tested is given in Table 5. The catalyst had a vibrated bulk density of $68.4 \mathrm{lb} / \mathrm{ft}^{3}$, and a loose bulk density of $63.4 \mathrm{lb} / \mathrm{ft}^{3}$. The particle density of the material (as determined by mercury porosimetry) was determined to be $103.2 \mathrm{lb} / \mathrm{ft}^{3}$.

A description of the equipinent and techniques used to determine the solid volume fraction, mass flux, and particle velocity is given below. 


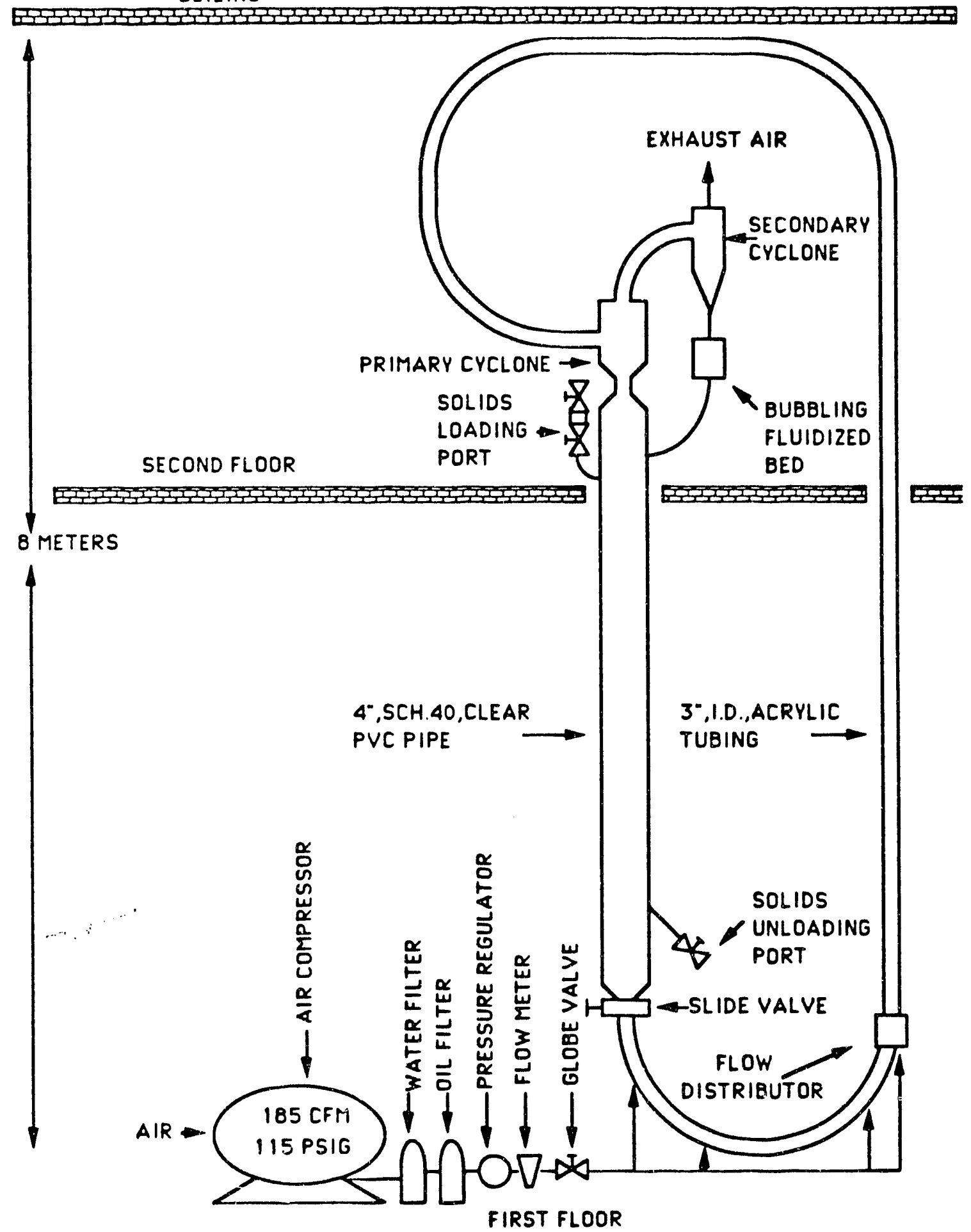

Figure 17. SCHEMATIC DRAWING OF SMALL-SCALE TEST UNIT 
Table 5. PARTICLE-SIZE DISTRIBUTION OF FCC CATALYST MATERIAL

$\begin{array}{cc}\begin{array}{c}\text { Particle Size Range, } \\ \text { microns }\end{array} & \begin{array}{c}\text { Weight, } \\ \end{array} \\ 3 / 4 & \\ 4 / 6 & 0.28 \\ 6 / 8 & 0.71 \\ 8 / 10 & 0.31 \\ 10 / 20 & 0.50 \\ 20 / 40 & 4.55 \\ 40 / 50 & 50.67 \\ 50 / 70 & 27.21 \\ 70 / 100 & 12.31 \\ 100 / 200 & 1.41 \\ 200 / 286 & 1.40 \\ & 0.65\end{array}$

\section{X-Ray Densitometer}

The radial solids volume fraction profile in the test unit was determined with radially traversing $x$-ray densitometer. A schematic drawing of this device is shown in Figure 18. The probe contained a 200-mCi Curium 244 source centered at the capped-off outlet of a $2.66-\mathrm{cm}-\mathrm{I}$.D. pipe. The cap of the pipe was covered with lead, $1.27-\mathrm{cm}$ thick, to prevent X-ray scatter. A $0.635 \mathrm{~cm}$ tube that is approximately $15 \mathrm{~cm}$ in length extends through the lead to the center of the X-ray source. A collinear X-ray beam travels through the pipe. Because the outlet of the tube is inserted into the CFB, it is capped off to prevent particles from flowing into it. A $0.635-\mathrm{cm}$-diameter plug of Karvex (jeweler's) wax was used to accomplish this objective. To fix the wax into position, the inside surface of the tube was roughened before the wax was melted into place. Karvex wax was used because it does not severely attenuate the $X$-ray beam. Also, the wax is robust and has a high $\left(121^{\circ} \mathrm{C}\right)$ melting point.

The tube extends through a male run tee into the riser. Plastic ferrules were used in the tee so that the tube could continuously be repositioned. When positioning the tube, air was continuously purged through the tee to prevent particles from causing the tube to bind.

A block diagram of the $X$-ray spectrometer is shown in Figure 19. The collinear $X$-ray beam traversed from the tip of the $X$-ray probe, through the 


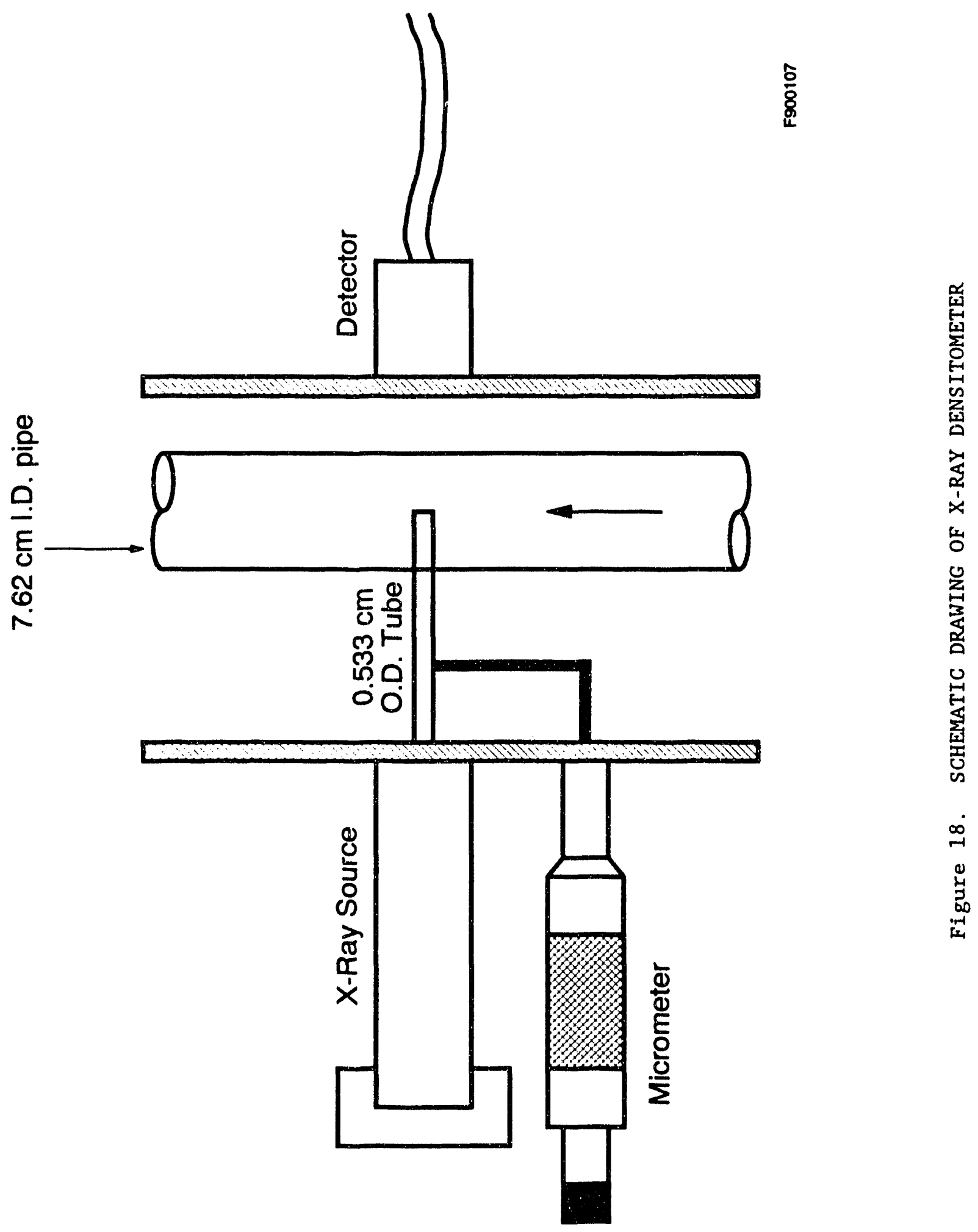




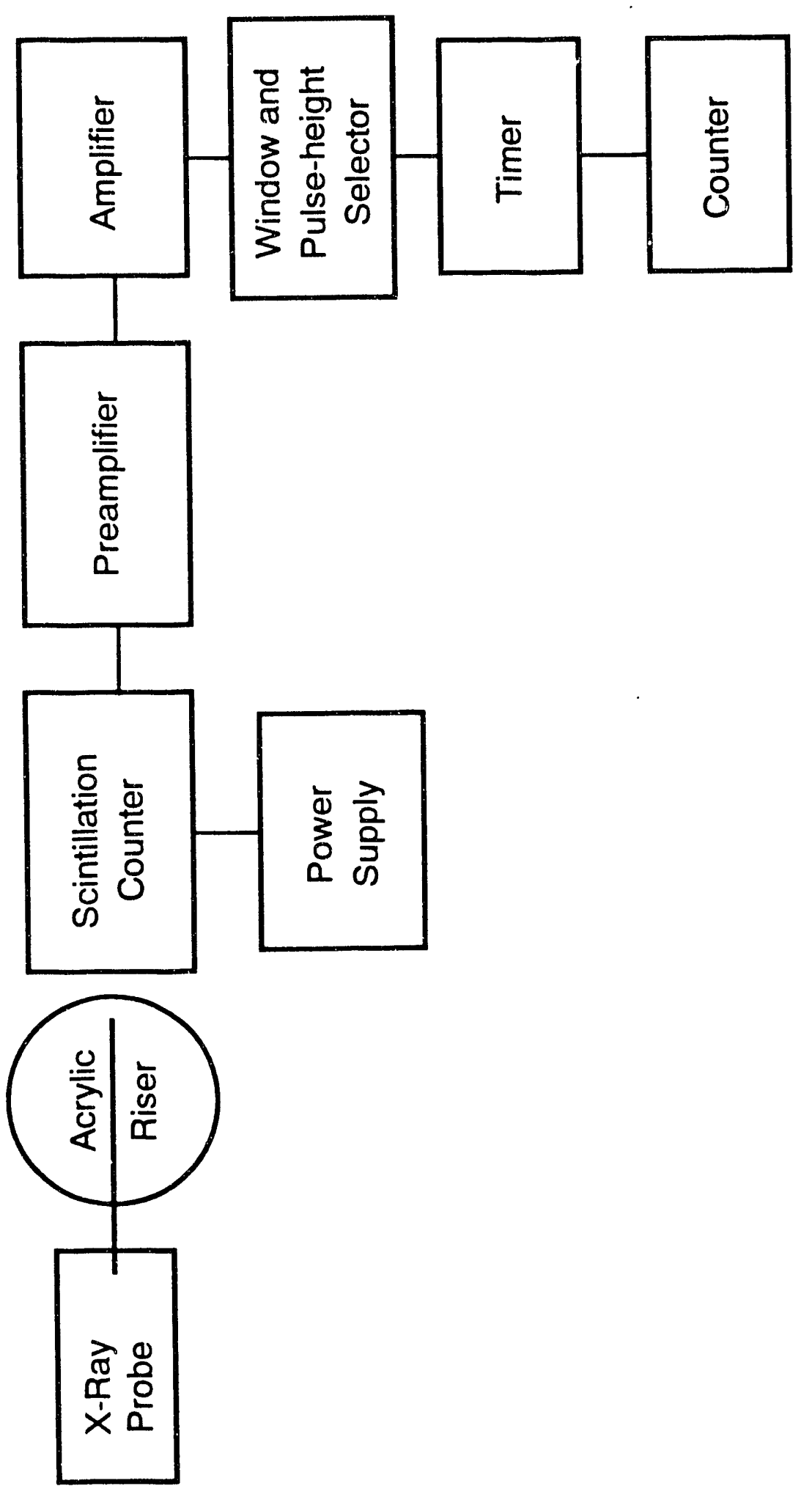

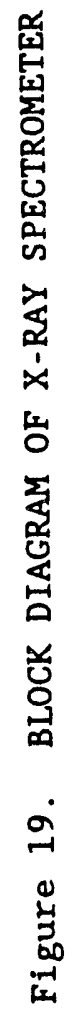
I A S T I T U T E
OF
G A S
TECHNOL 
absorbing material (particles and gas stream) and acrylic pipe, to a thalliumactivated, sodium lodide scintillation counter. The $\mathrm{X}$-rays were absorbed in the scintillator, which was powered by a regulated dc potential of $960 \mathrm{~V}$. Each X-ray photon transferred its energy to a photoelectron, which in return, expended its energy producing 4100- $\AA$ light photons. The more energetic the $\mathrm{X}$-ray photon, the more light photons were produced. Thus, detector output was proportional to X-ray photon energy. A preamplifier and amplifier were used to amplify the detector output pulse to potentials high enough to pass through the window of the pulse-height selector. The window for the selector was set as narrowly as possible to eliminate noise that distorted the final count rate. Output from the selector was fed to a counter and timer that provided a readout and display of the $\mathrm{X}$-ray intensity data in an accumulative digital mode over a selected time interval.

\section{Theory of Operation}

The Beer-Lambert law was the mathematical basis used to analyze the experimental data obtained with the $\mathrm{X}$-ray densitometer. It can be expressed as :

$$
I=I_{0} \exp (-\delta t)
$$

where $I$ is the radiation intensity, $I_{0}$ the initial radiation intensity, and $\delta$ and $t$ are the linear-absorption coefficient and thickness of the absorber, respectively. The negative sign indicates that the radiation intensity always decreases (that is, the $X$-rays are attenuated as they pass through solids). A more useful form of this equation is:

$$
I=I_{0} \exp (-\mu d t)
$$

where

$$
\mu=\delta / d
$$

and $\mu$ is the mass-absorption coefficient $\left(\mathrm{cm}^{2} / \mathrm{g}\right)$ of the absorber, and $d$ the absorber density $\left(\mathrm{g} / \mathrm{cm}^{3}\right)$. The mass-absorption coefficient is an intrinsic property of materials, and is a measure of their X-ray opacity. For the same wavelength $(\alpha), \mu$ is different for every element; and for the same element, $\mu$ is different at every wavelength. The wavelength is related to the photon energy $\left(E_{x}\right)$ by the equation:

$$
\alpha=12.396 / E_{x}
$$


where $E_{x}$ and $\alpha$ are in $\mathrm{keV}$ and angstroms, respectively. The principal photon energy of the $200-\mathrm{mCi} \mathrm{X}$-ray source used in this experiment is $18 \mathrm{keV}$.

The mass-absorption coefficient of a mixture of elements of weight fractions $W_{a}, W_{b}, W_{c}, \ldots$ is given by:

$$
\mu_{\operatorname{mix}}=\Sigma W_{1} \mu_{1}
$$

The weight fraction of a component 1 is related to its volume fraction by:

$$
W_{1}=\epsilon_{1} d_{1} / d_{m 1 x}
$$

where $\epsilon_{1}, d_{1}$, and $d_{m 1 x}$ are the volume fraction and density of component 1 , and the density of the mixture, respectively. Substituting Equation 62 into Equation 61 yields:

$$
\mu_{\operatorname{mix}}=\Sigma \epsilon_{1} \mathrm{~d}_{1} \mu_{1} / \mathrm{d}_{\operatorname{mix}}
$$

For a mixture, the Beer-Lambert law is expressed as:

$$
I=I_{0} \exp \left(-\mu_{m 1 x} d_{m i x} t\right)=I_{0} \exp \left(-\Sigma \epsilon_{1} d_{1} \mu_{1} t\right)
$$

For a mixture consisting of air and solids, the Beer-Lambert law becomes:

$$
I-I_{0} \exp \left(-\left(\epsilon_{s} d_{s} \mu_{s}+\epsilon_{a} d_{a} \mu_{A}\right) t\right)
$$

and

$$
\operatorname{lnI}=\ln I_{0}\left(-\left(\epsilon_{\mathrm{s}} \mathrm{d}_{\mathrm{s}} \mu_{\mathrm{s}}+\epsilon_{\mathrm{a}} \mathrm{d}_{\mathrm{a}} \mu_{\mathrm{a}}\right) t\right)
$$

where

$$
\epsilon_{\mathrm{a}}+\epsilon_{\mathrm{s}}=1
$$

Differentiating Equation 66 with respect to $t$ and solving for $\epsilon_{s}$ explicitly results in:

$$
\epsilon_{\mathrm{s}}=\left(\mathrm{d} \ln I / \mathrm{dln} t+\mu_{\mathrm{a}} \mathrm{d}_{\mathrm{a}}\right) /\left(\mu_{\mathrm{a}} \mathrm{d}_{\mathrm{a}}-\mu_{\mathrm{s}} \mathrm{d}_{\mathrm{s}}\right)
$$

From this equation the solid volume fraction can be obtained from the experimental values of $I(t)$, because all other components in the expression are constant.

\section{Experimental Techniques}

To apply Equation 68 in the test unit operating with air and FCC catalyst, the absorption coefficients for FCC catalyst and air were first determined. The catalyst coefficient was determined by adding catalyst into 
the riser of the test section in a packed-bed mode. Intensity measurements were obtained every $0.15875 \mathrm{~cm}$ across the pipe. The natural $\mathrm{log}$ of the measured intensity versus distance for the catalyst is shown in Figure 20.

The slope of Figure 20 was nearly linear for radiation intensities resulting in counts exceeding 190 counts/s. It was over this range that the curve obeyed Beer-Lambert's law. The Iinear-absorption coefficient of the catalyst was equal to the negative of the slope and had a value of $2.372 \mathrm{~cm}^{-1}$. The mass-absorption coefficient of the catalyst is equal to the linearabsorption coefficient divided by the density of the solids. The coefficient was determined to be $2.335 \mathrm{~cm}^{2} / \mathrm{g}$.

It is important that the Beer-Lambert Law hold over the range of applicability. Because the largest and smallest values of the intensity over the range of applicability are, respectively, 975 counts/s and 190 counts/s, the area density $\left(d_{s} t\right)$ should be less than:

$$
d_{s} t-\ln (975 / 190) / 2.335=0.7 \mathrm{~g} / \mathrm{cm}^{2}
$$

to avoid significant error in the calculations. A higher energy radiation source should be used for the measurement of particle area densities that are greater than this value.

A curve similar to that of Figure 20 was also obtained for air. This curve is shown in Figure 21. The curve in Figure 21 is linear and obeys the Beer-Lambert Law. The linear and mass-absorption coefficients for air were determined to be $0.0096 \mathrm{~cm}^{-1}$ and $6.79 \mathrm{~cm}^{2} / \mathrm{g}$, respectively.

\section{Extraction Probe}

Mass flux profiles in the riser were monitored with the extraction probe shown in Figure 22 using the equipment schematically depicted in Figure 23. The probe consisted of a brass tube that had an outside diameter of $0.635 \mathrm{~cm}$ and a $0.472-\mathrm{cm}$ inside diameter. The tube was bent at a 90 -degree angle to align its opening parallel to the flowing solids-gas mixture. Unfortunately, because of its 90 -degree bend, the probe could not be pulled back completely flush with the near riser wall. Therefore, flux measurements spanned only $6.985 \mathrm{~cm}$ of the $7.5 \mathrm{~cm}$ riser inside diameter.

Two circular levels were attached to the probe to align its inlet with the wall of the riser. Radial probe alignment was accomplished by measuring 


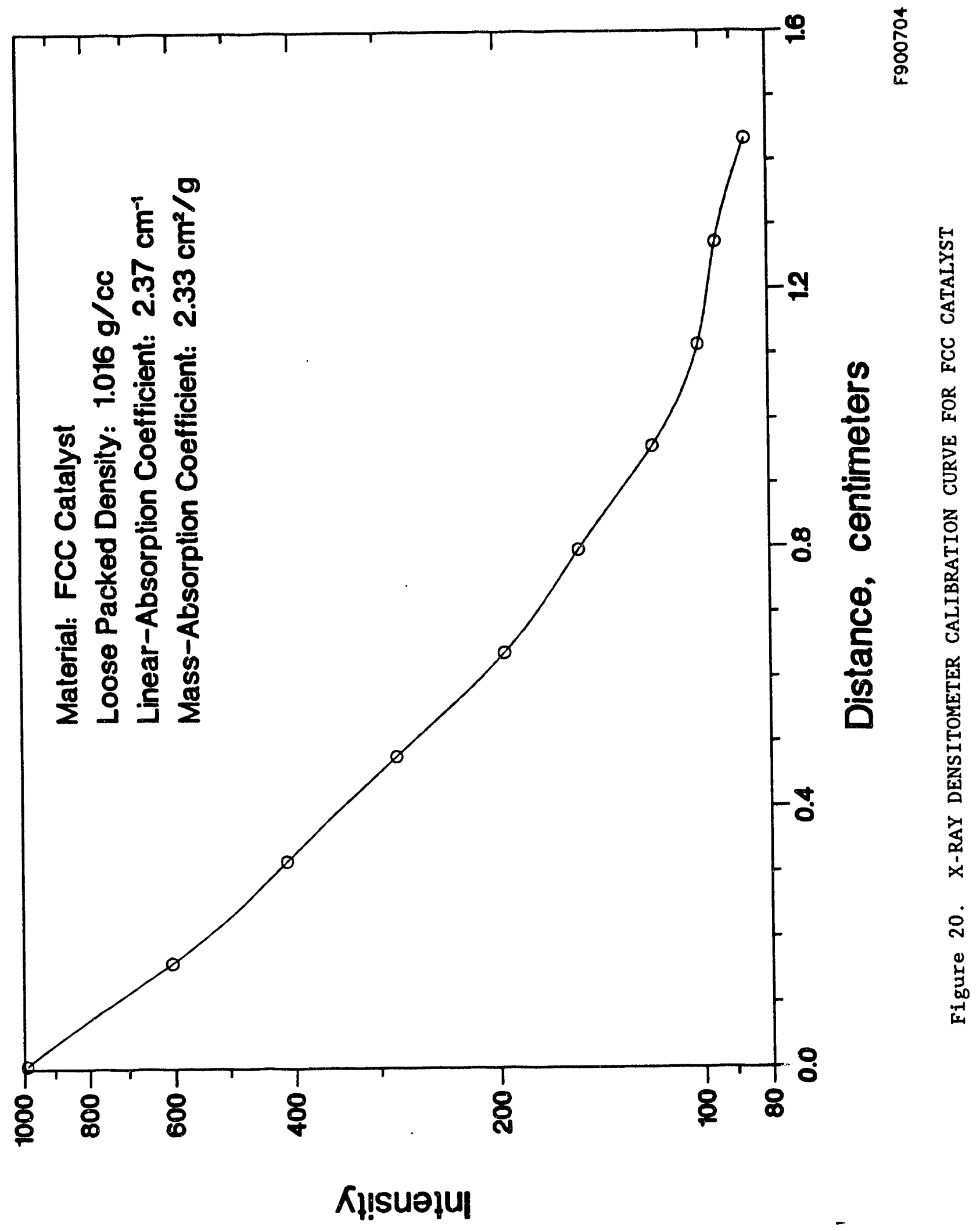




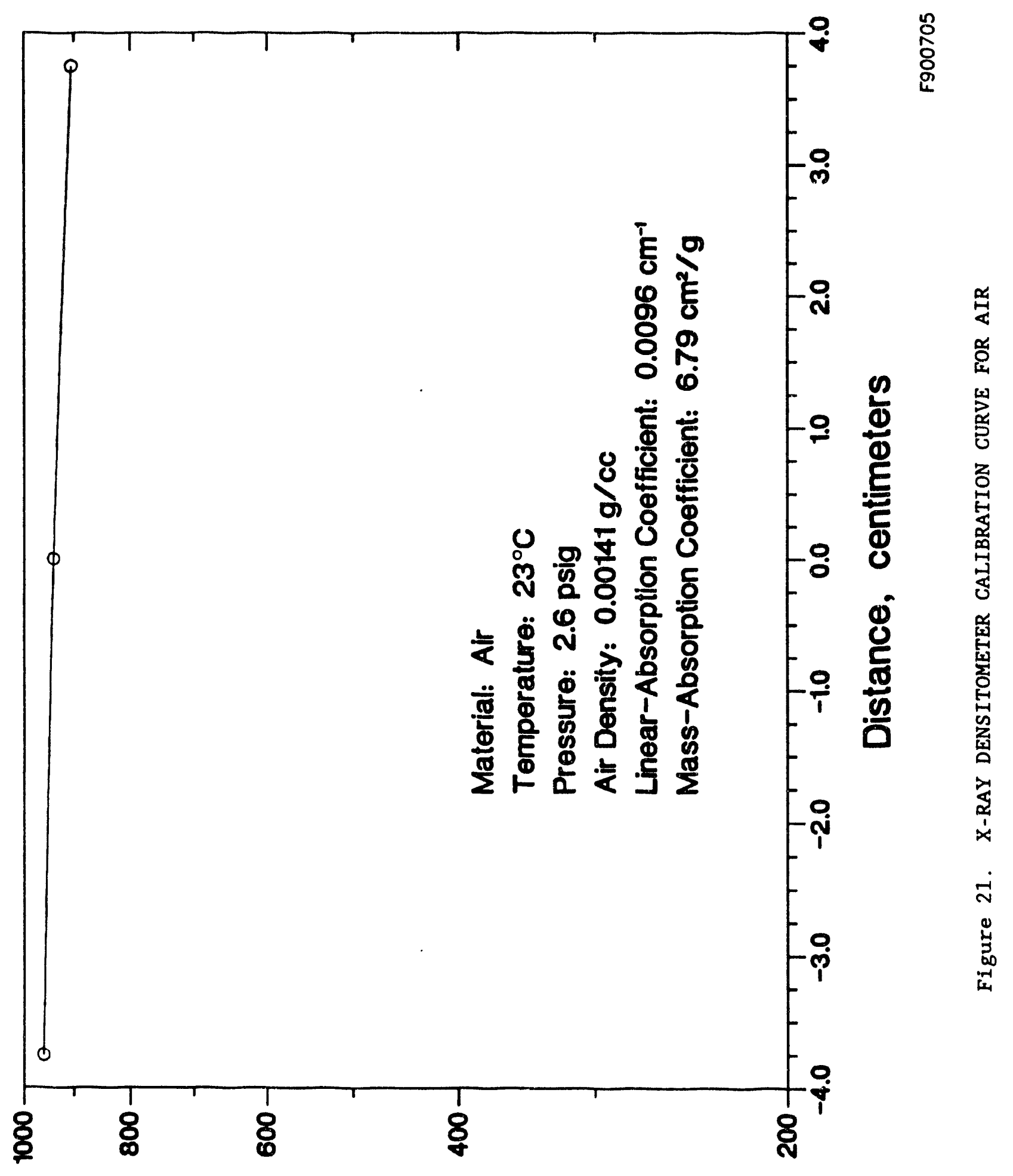

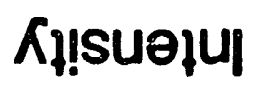




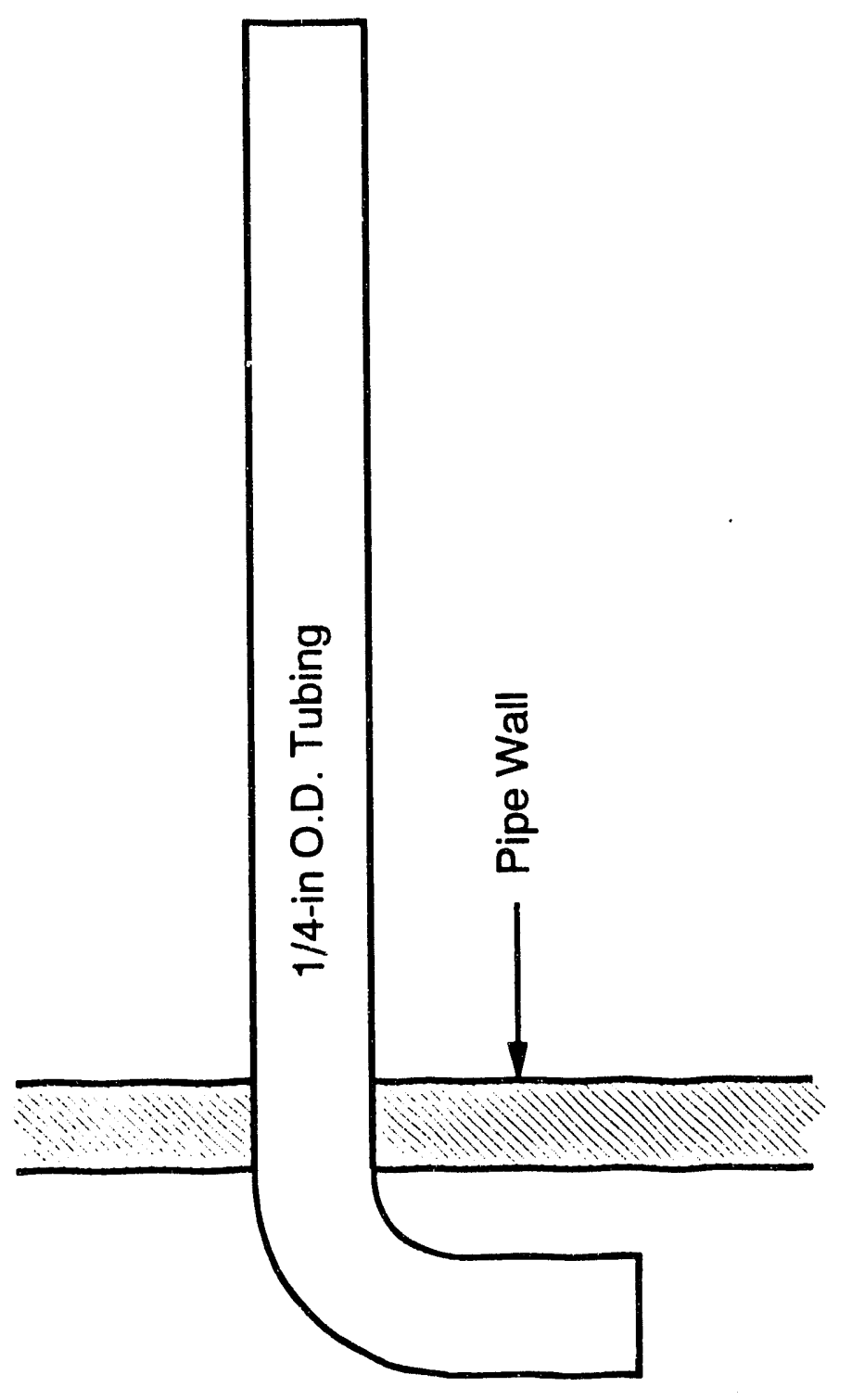

\section{뚱}

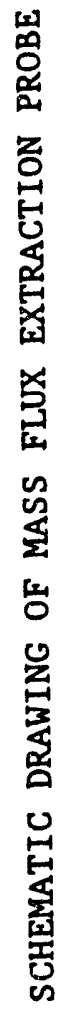

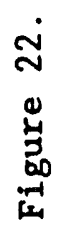




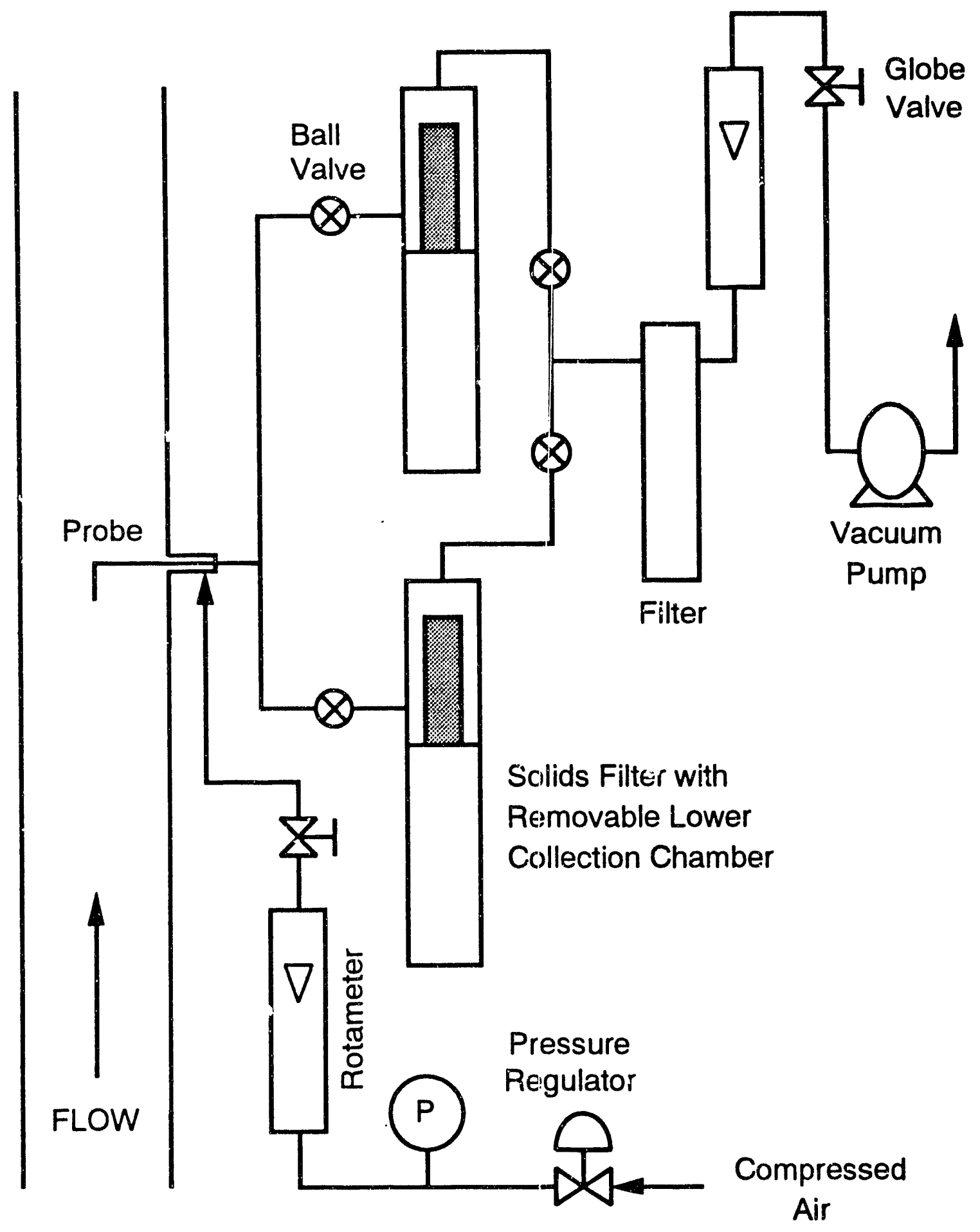

F900706

Figure ?'. SCHEMATIC DRAWING OF MASS FLUX COLLECTION EQUIPMENT

IN S T I T U T E


the distance between a marker on the probe and the male run tee. When aligning the probe, compressed air was passed through the male run tee to prevent binding of the probe.

After extraction of the solids by the probe, the solids/gas mixture was separated by a filter. The filter was equipped with a removable solids collection chamber fabricated of clear PVC for visual observation. Air leaving the filter flowed through a finer secondary filter to protect the downstream rotameter and vacuum pump. The flow of air exiting the extraction probe was regulated by a globe valve located downstream of the rotameter used to measure the extraction gas flow rate.

\section{Theory of Operation}

At any particular position within the riser, the time-averaged mass flux consisted of both an upward and downward component. The magnitude of the upward mass flux minus the magnitude of the downward mass flux was equal to the net upward mass flux. Both components of the mass flux were measured with the extraction probe. The upward and downward mass flux components were measured with the inlet of the extraction probe pointing in the upstream and downstream directions, respectively. Because the solids flow in the riser fluctuates, all flux measurements were time-averaged over periods that ranged from 1.5 to 6 minutes. Mass flux components were calculated by dividing the weight of solids recovered in the filtration collection chamber by the area of the tip of the probe and sample time.

The magnitude of both mass flux components appeared to be a linear function of the flow of gas through the extraction probe; however, the net mass flux does not. That is, the difference between the upward and downward components of the mass flux does not vary with extraction gas flow when the extraction gas flow rate is the same for both components. An exception to this rule was when the gas extraction rate was low enough for slugging to occur in the line between the probe and the filter.

Other investigators have assumed that the components of net mass flux are the flux axis intercept of the gas flow versus mass flux curve, because this is the hypothetical zero gas extraction velocity (that is, where there is no influence of gas velocity on the rate of solids extraction). This method 
is labor intensive in that it requires several ( 3 to 5 ) data points to correctly determine the mass flux axis intercept. In this investigation, the net mass flux was taken to be the difference between the two components of the mass flux measured at the same gas extraction rate. To compensate for experimental error, the readings were averaged over two gas extraction rates. Measurements were obtained at gas flows that were nigh enough to prevent line plugging. Relatively low gas flows were used, so that the measured mass flux components would be as close as possible to their zero gas extraction velocity values.

\section{Experimental Results}

Tests to determine the radial variation of solids mass flux, solids volume fraction, and solids velocity were obtained in two ways. First, the solids mass flux was held constant and the gas velocity was varied. Then, the gas velocity was held constant while the mass flux was varied. Tests were also conducted to determine the effect of riser height on these profiles.

In the first case, the solids mass flux was held constant at a value of $20.4 \mathrm{~kg} / \mathrm{s}-\mathrm{m}^{2}$ while three different superficial gas velocities were tested $(2.61,2.89$, and $3.48 \mathrm{~m} / \mathrm{s})$. In the second case, the superficial gas velocity remained constant at $2.89 \mathrm{~m} / \mathrm{s}$ while three different mass fluxes were studied $\left(12.0,19.7\right.$, and $\left.32.8 \mathrm{~kg} / \mathrm{s}-\mathrm{m}^{2}\right)$. The mass flux, solids velocity, and solids volume fraction radial profiles were also measured at riser heights of 1.86 , 4.18 , and $5.52 \mathrm{~m}$ above the solids inlet.

The extraction probe was used to obtain mass flux profiles as a function of radial position in the riser. The results of the testing when the solids mass flux was held constant while the superficial gas velocity in the riser was varied are shown in Figure 24. This figure shows that the mass flux profiles are parabolic, with higher mass fluxes in the center of the column and lower at the wall. At the highest superficial gas velocity tested (3.48 $\mathrm{m} / \mathrm{s}$ ) the profile was flattest, with mass fluxes in the center of riser of approximately $40 \mathrm{~kg} / \mathrm{s}-\mathrm{m}^{2}$. At the wall the mass flux decreased to a value of approximately $10 \mathrm{~kg} / \mathrm{s}-\mathrm{m}^{2}$.

At the lower superficial gas velocities of 2.61 and $2.89 \mathrm{~m} / \mathrm{s}$, the mass flux distribution in the center in the riser was approximately $80 \mathrm{~kg} / \mathrm{s}-\mathrm{m}^{2}$. 


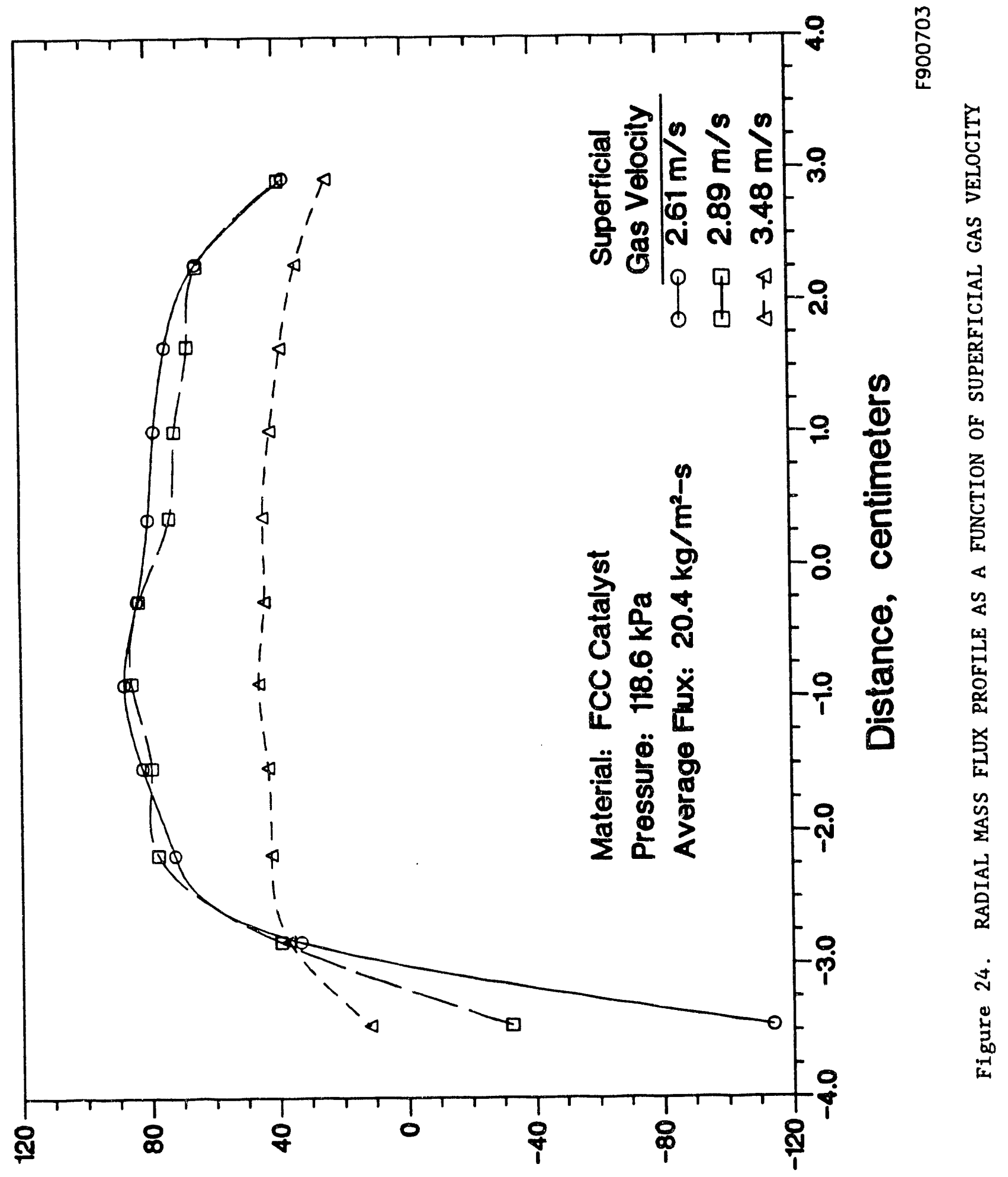

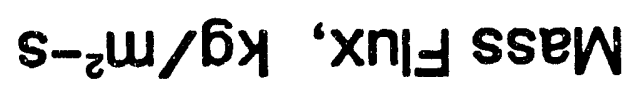


This is approximately twice as high as the mass flux measured for the higher gas velocity of $3.48 \mathrm{~m} / \mathrm{s}$.

Conversely, the mass fluxes measured near the wall were "lower" than those measured for the higher gas velocity. At the wall, the solids were actually flowing down the column. For the lowest gas velocity tested, the mass flux near the wall was approximately $120 \mathrm{~kg} / \mathrm{s}-\mathrm{m}^{2}$ downward. This overall mass flux flow pattern was also observed by Bader et al. (1988).

The effect of gas velocity on the radial distribution of solids volume fraction was measured using the $\mathrm{X}$-ray densitometer, and is given in Figure 25 . Measurements of the solids volume fraction were made at a constant mass flux of $20.4 \mathrm{~kg} / \mathrm{s}-\mathrm{m}^{2}$, and at the same three gas velocities that were used in the mass flux measurements $(2.61,2.89$, and $3.48 \mathrm{~m} / \mathrm{s})$.

The results of these tests showed that the overall solids volume fraction in the riser increased as the gas velocity was decreased. The concentration of solids in the center of the riser varied from approximately 0.5 percent at the highest superficial gas velocity to approximately 1.2 percent at the lowest superficial gas velocity. Near the wall, the solids volume fraction varied from approximately 2.5 percent at the highest superficial gas velocity tested to approximately 7 percent at the lowest superficial gas velocity tested.

The solids volume fraction was essentially constant in the center of the column. In the wall region (within $1 \mathrm{~cm}$ of the wall), the solids volume fraction rose to approximately 5 to 6 times the value in the center. These results are also consistent with the results obtained by Bader et al. (1988).

The radial solids velocity distribution was determined by calculation from the experimental values obtained for the solids volume fraction and the mass flux. The relationship between solids velocity, solids volume fraction, and mass flux is given by -

$$
v_{p}=G /\left(\rho_{p} \epsilon s\right)
$$

The variation of solids velocity with superficial gas velocity is given in Figure 26. These calculated results were obtained for a constant mass flux of $20.4 \mathrm{~kg} / \mathrm{s}-\mathrm{m}^{2}$, and for the three superficlal gas velocities of $2.61,2.89$, and $3.48 \mathrm{~m} / \mathrm{s}$. 


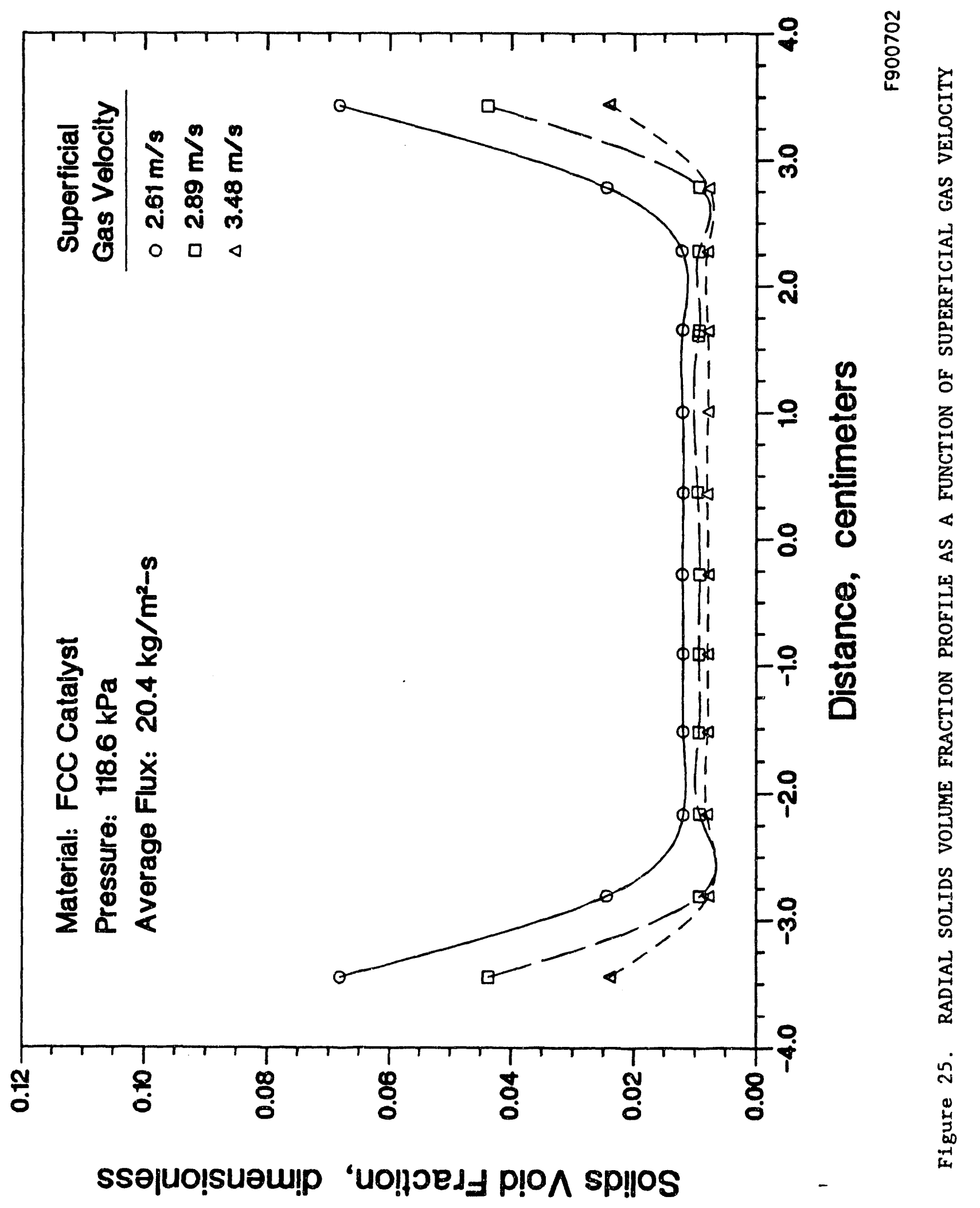

I NSTITUTE OF GAS T T C H NOL L G Y




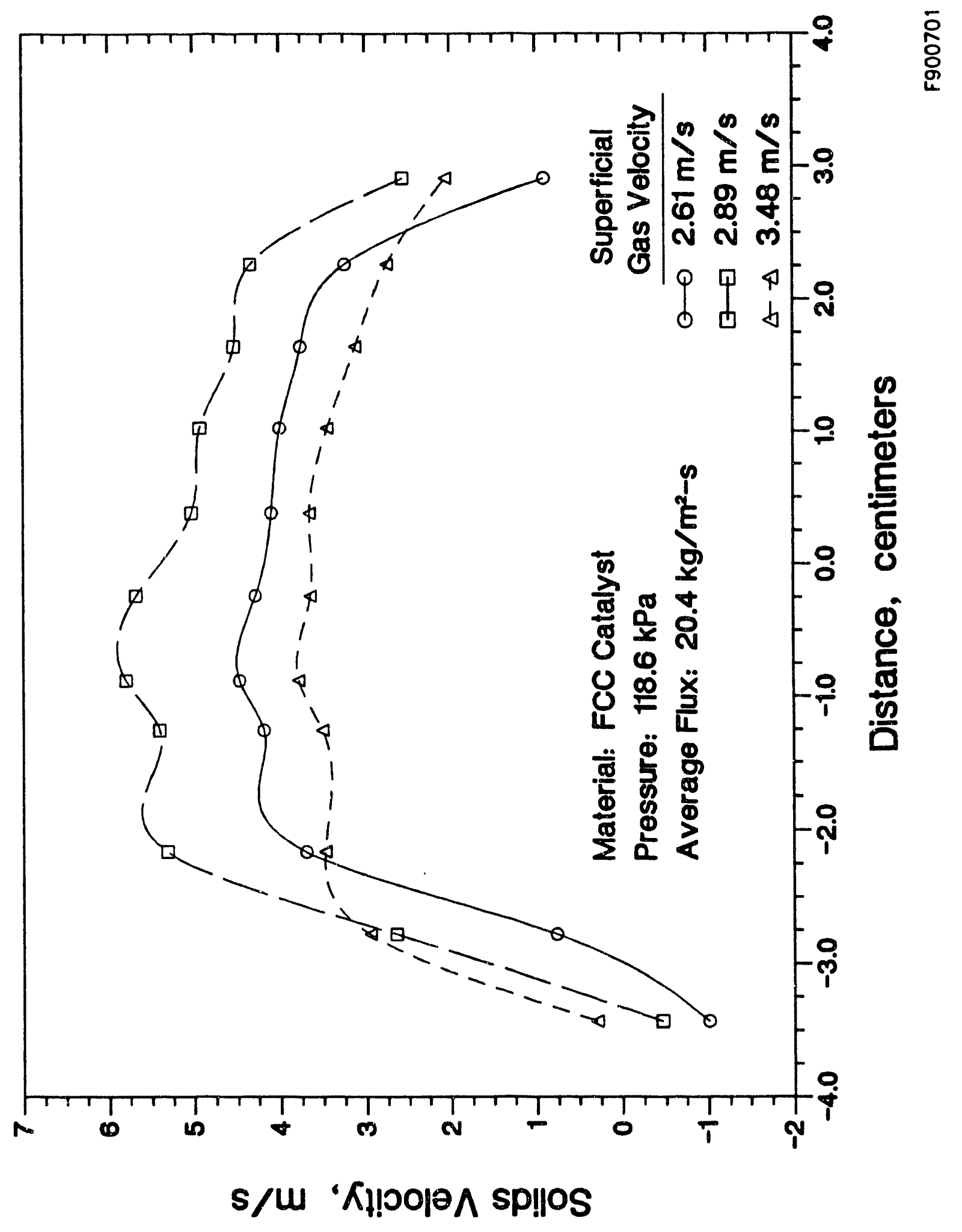

焉 
The calculated solids velocity profiles were parabolic, with the highest velocities in the center of the column and the lowest velocities near the wal1. Counterintultively, the particle velocities were highest in the center at the lowest gas velocity tested, and lowest for the highest gas velocity tested. At this mass flux, the particle velocities in the center of the column were of the order of 1.5 to 2 times the superficial gas velocity.

At the wall of the column, the particle velocities were either near zero, or were negative. This reflects the fact that solids are flowing downward at the wall as indicated in Figure 24. The shape of the calculated solids velocity profile is also similar to the profile obtained by Bader et al. (1988) for the same material.

As described above, radial mass flux, solids volume fraction, and solids velocity measurements were made at three different mass flux values (12.0, 19.7 , and $32.8 \mathrm{~kg} / \mathrm{s}-\mathrm{m}^{2}$ ) while maintaining the superficial riser gas velocity constant at a value of $2.89 \mathrm{~m} / \mathrm{s}$. The results of this testing are presented in Figures 27,28 , and 29.

In Figure 27, the radial mass flux profile across the riser obtained with the extraction probe, is shown as a function of solids mass flux at a constant riser gas velocity of $2.89 \mathrm{~m} / \mathrm{s}$. As found in the previous tests, the profiles are parabolic, with higher fluxes measured in the center of the riser than at the wall. The highest mass fluxes in the center were measured for the highest average mass fluxes in the riser as would be expected. However, the lowest local mass fluxes measured (at the wall), were also obtained with the highest average solids mass fluxes.

The measured mass flux values in the center of the riser were approximately three times the average mass flux. At the wall, the measured mass fluxes were negative, indicating that the solids were flowing downward in the vicinity of the wall.

The measured radial solids volume fraction profiles in the riser obtained with the $\mathrm{X}$-ray densitometer are shown in Figure 28 . The curves have an inverted parabolic shape. In general, the higher the mass flux, the higher the solids volume fraction at any point in the riser. 


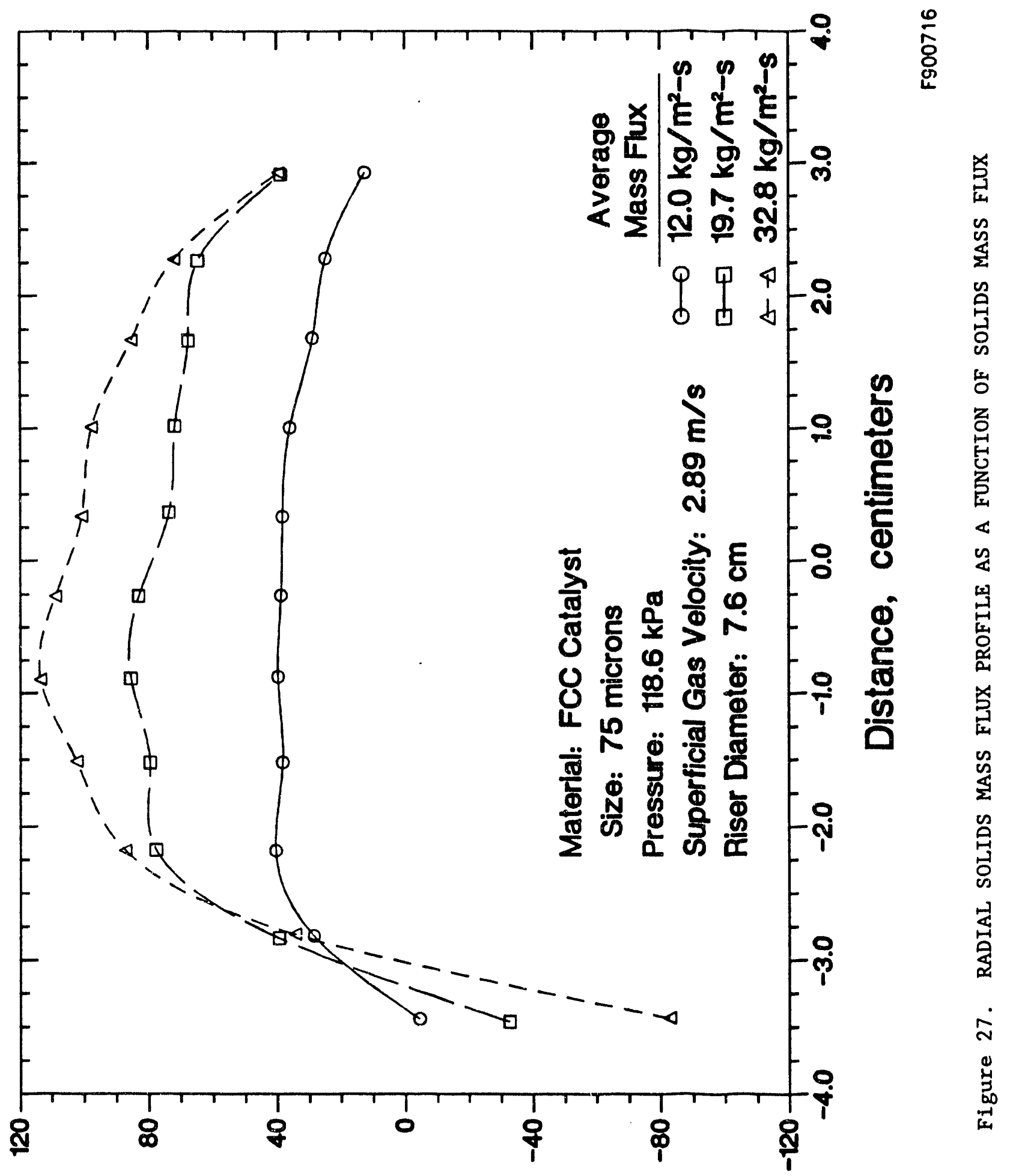

\section{s-zس/6ry 'xn]」 ssew}




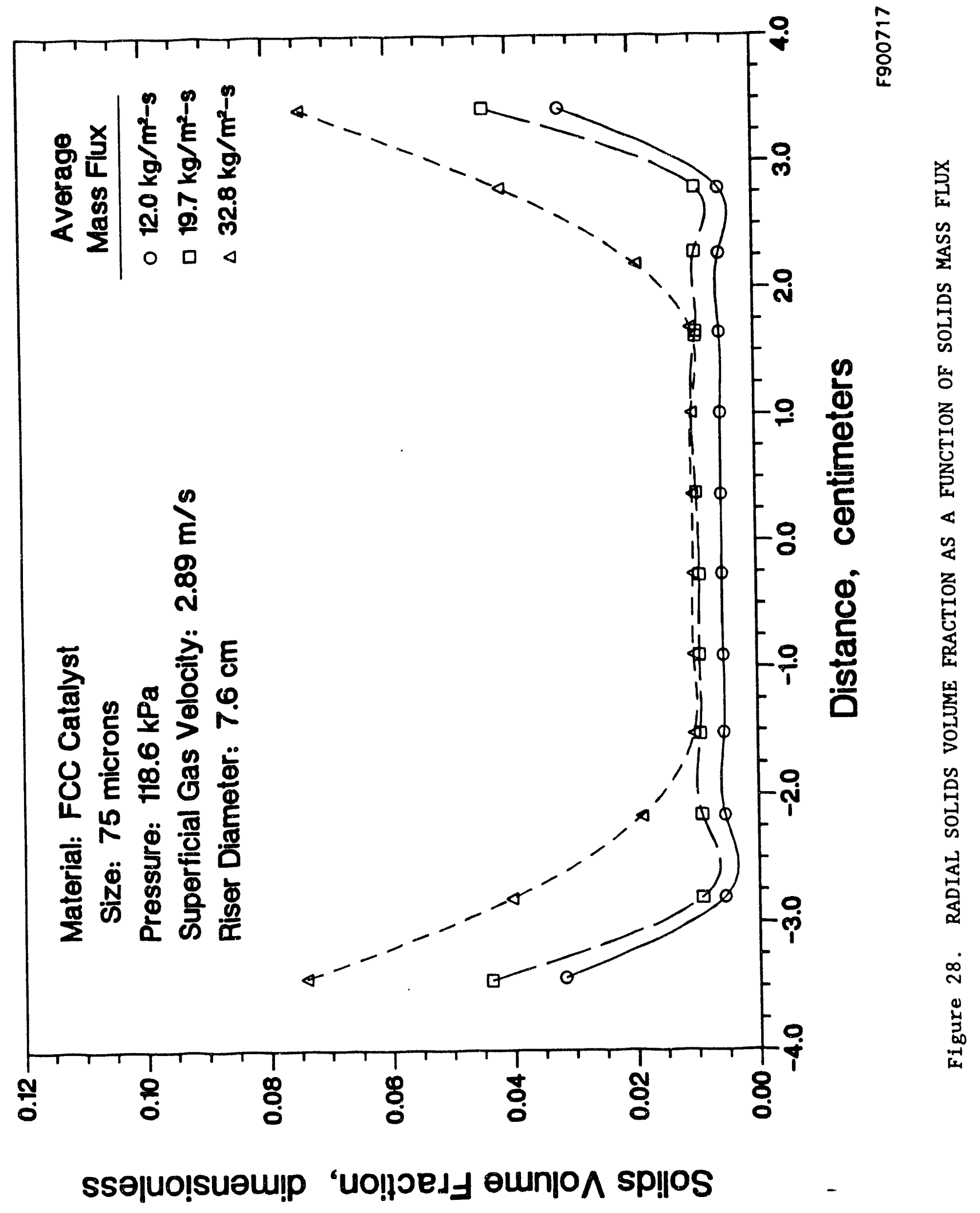




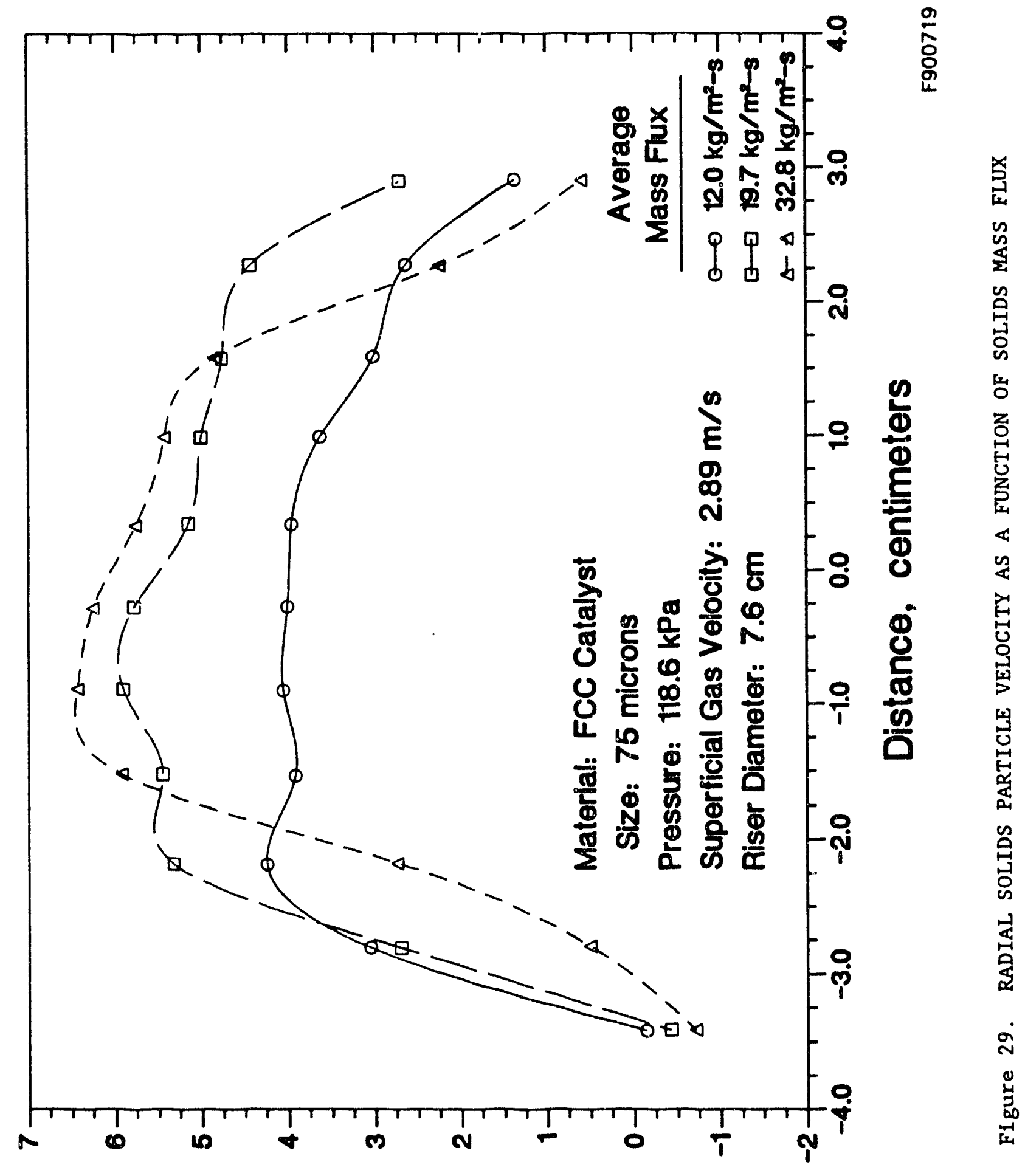

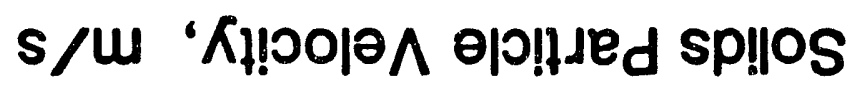


At the center of the riser, the solids volume fraction was very low, and essentially constant for all of the solids mass fluxes. The values ranged from 0.68 at the lowest solids mass flux, to approximately 1.18 at the highest solids mass flux.

Near the wall of the riser (within $1 \mathrm{~cm}$ of the wall), the solids concentration rose rapidly. The measured solids volume fraction near the wall of the riser appeared to be approximately 5 to 6 times the solids volume fraction in the center. Thus, it appears that the solids are flowing downward near the wall in a relatively dense state. These results are consistent with those reported by Bader et $\underline{\text { al. }}$ (1988), and the mass flux curves obtained previously.

The radial solids particle velocity profile across the riser was determined by calculation from the experimental values obtained for the solids volume fraction and the solids mass flux. This relationship was given above in Equation 69.

The variation of solids velocity with solids mass flux is given in Figure 29. These calculated results were obtained for a constant superficial gas velocity in the riser of $2.89 \mathrm{~m} / \mathrm{s}$, and for solids mass fluxes of 12.0 , 19.7 , and $32.8 \mathrm{~kg} / \mathrm{s}-\mathrm{m}^{2}$.

The calculated solids particle velocity profiles were also parabolic, with the highest velocities in the center of the column and the lowest velocities near the wall of the riser. The particle velocities in the center of the riser were proportional to the solids mass flux in the riser. The calculated particle velocities in the center of the riser were approximately 1.5 to 2 times greater than the superficial gas velocity through the riser. This indicates that when solids are being transported, the gas is flowing rapidly through the center of the riser in essentially dilute-phase plug flow, while the solids are flowing down the wall of the riser in a much denser phase. This type of flow is often referred to as core-annular flow.

The data described above, were obtained at a height of $4.18 \mathrm{~m}$ above the solids feed point in the riser. The radial profiles of mass flux, particle velocity, and solids volume fraction were also determined at riser heights of 1.86 and $5.52 \mathrm{~m}$ above the solids feed point. The results of this testing are presented in Figures 30, 31, and 32 . 


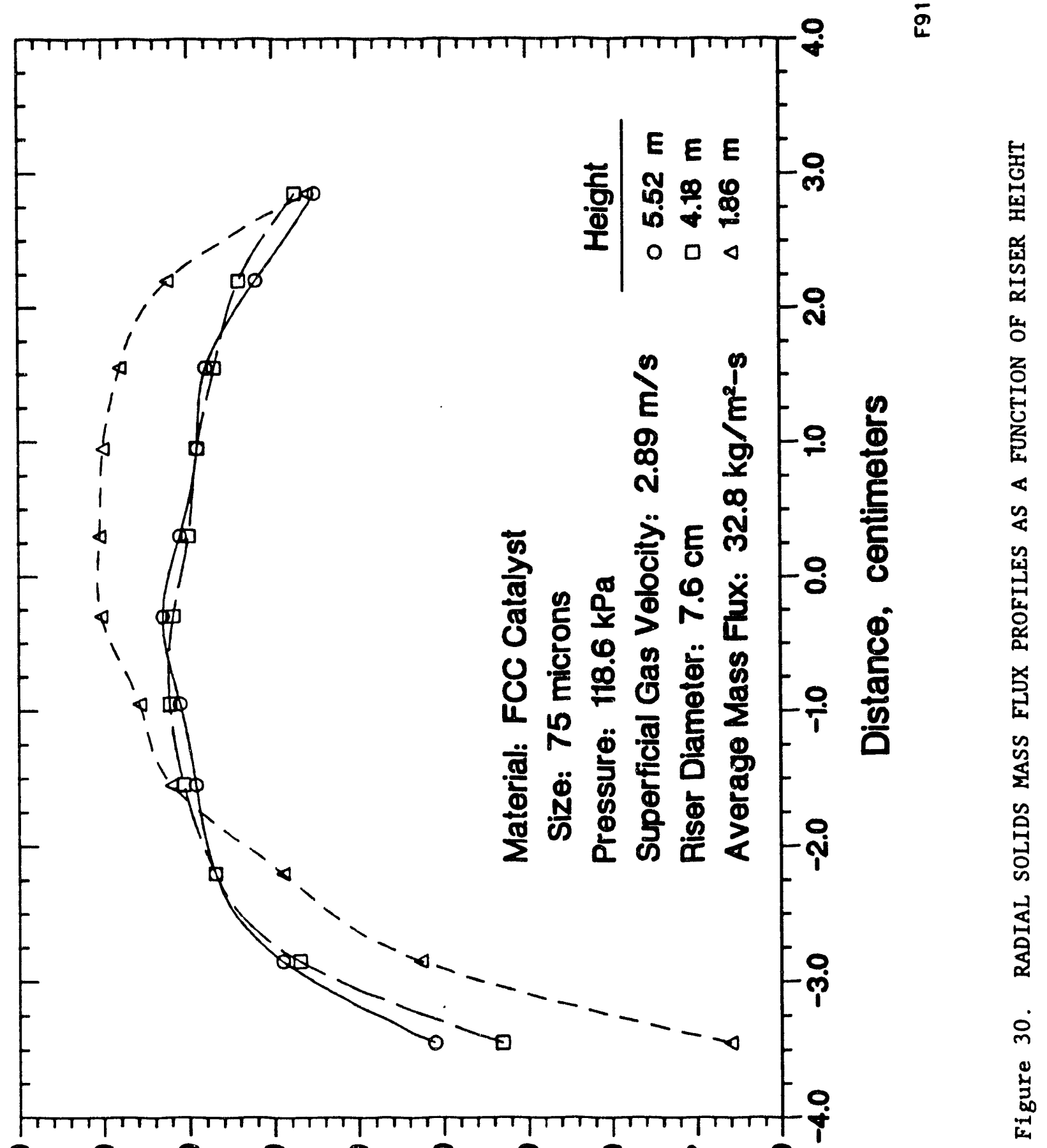

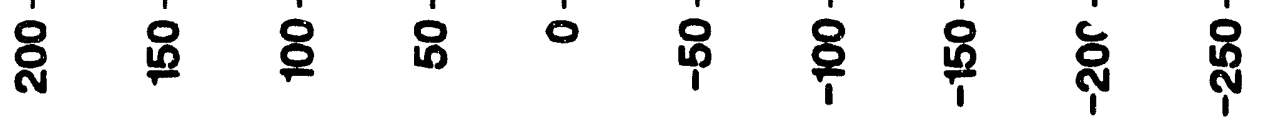

s-zس/6x ' $x n \mid \exists$ ssew

INSTITUTE OF GAS TE CH NOL O O G Y 


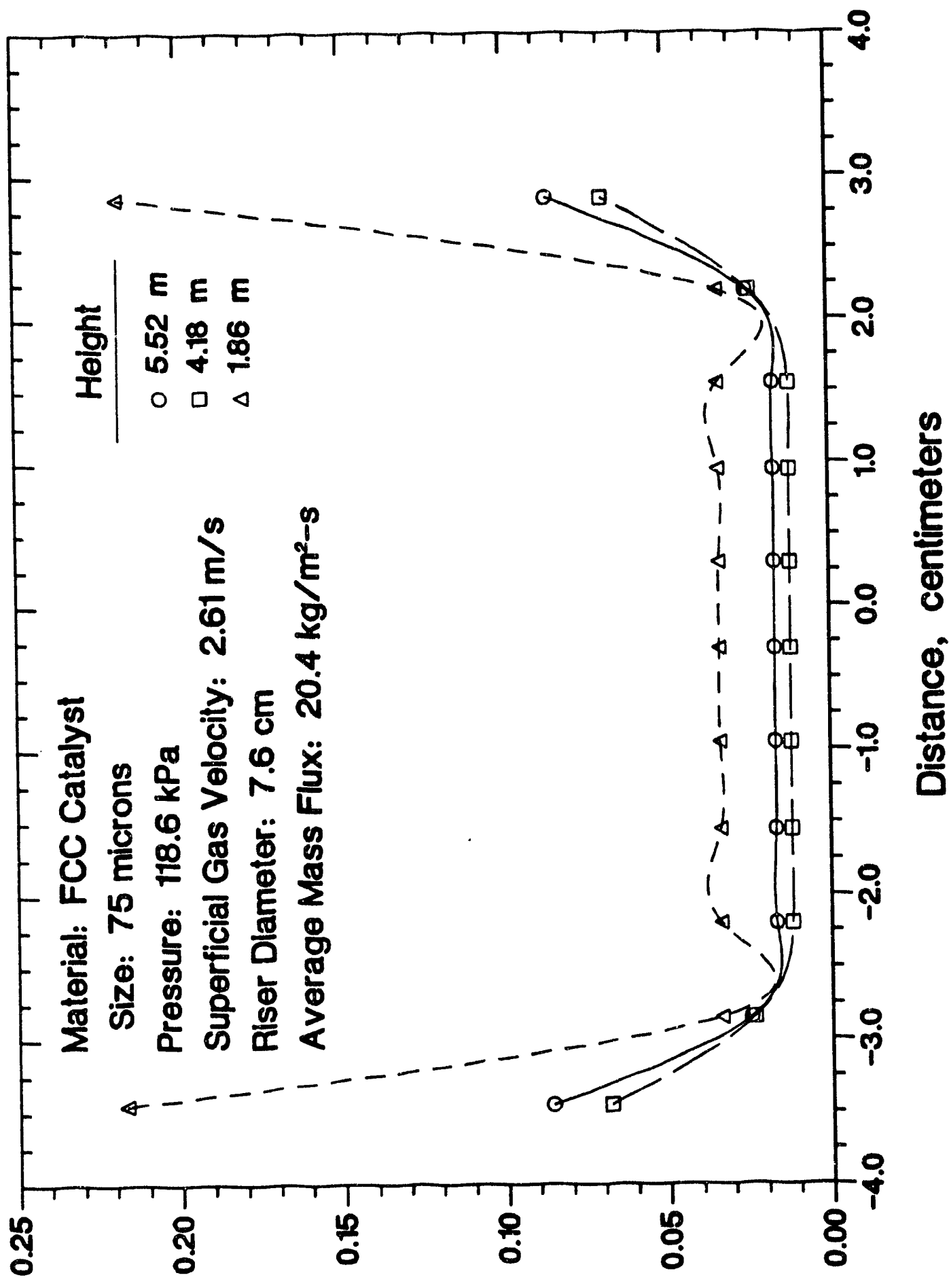

$\frac{\frac{7}{8}}{\frac{0}{4}}$

星

装

芯

s

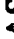

品

幽

点

$\dot{m}$

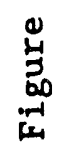

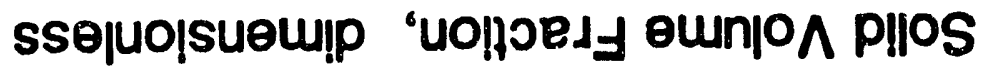

I NSTITUTE O OF G A S T TE C H N O L O G Y 


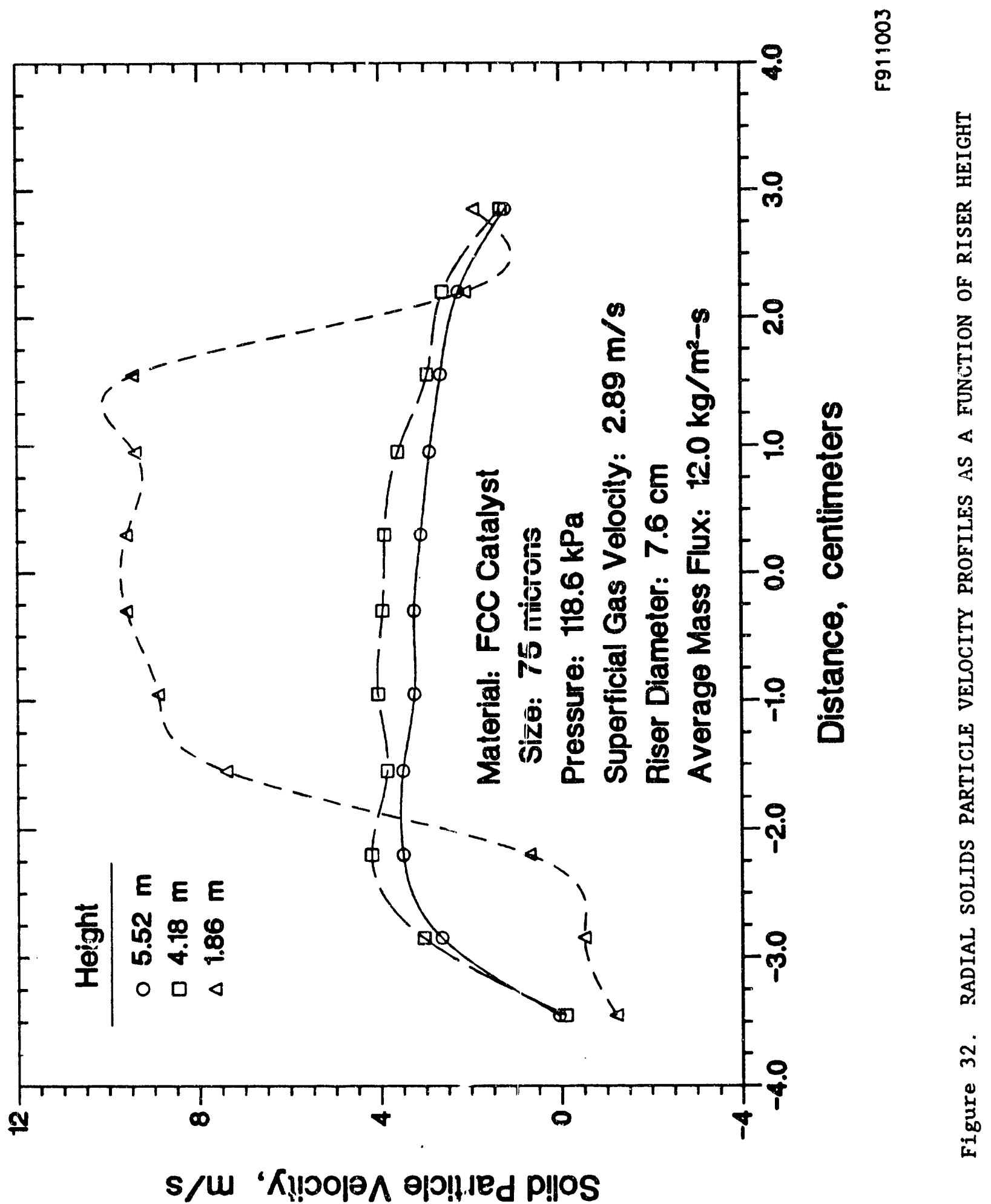


In Figure 30, radial profiles of solids mass flux are shown as a function of riser height at a constant riser superficial gas velocity of 2.89 $\mathrm{m} / \mathrm{s}$, and a constant solids mass $f 1 \mathrm{ux}$ of $32.8 \mathrm{~kg} / \mathrm{s}-\mathrm{m}^{2}$. The radial mass flux profiles obtained at the two higher riser locations, were "flatter" than the profile obtained at the lower location. The data also indicate that the annulus layer of downward flowing solids at the wall is thicker near the bottom of the riser, and then thins out at greater heights.

The measured radial profiles of solids volume fraction in the risex as a function of height are shown in Figure 31. These data were obtained at a constant superficial gas velocity of $2.61 \mathrm{ft} / \mathrm{s}$ and a constant solids mass flux of $20.4 \mathrm{~kg} / \mathrm{s}-\mathrm{m}^{2}$.

The curves in Figure 31 show that the solids volume fraction is highest along the wall (in the annular region) and lowest in the center of the riser. The solids volume fraction radial profile obtained at the lowest riser height $(1.86 \mathrm{~m})$ was more parabolic than the curves obtained at the two higher riser levels. Also, the values of the solids volume fraction were higher at the lower riser location than at the higher riser locations. This difference was especially pronounced near the wall.

As describud above, the radial profile of solids velocity across the riser was determined by calculation from the experimental values obtained for the solids volume fractior and the solids mass flux. The effect of riser axial location on the radial solids velocity profiles are given in Figure 32 . These curves were obtained at a constant superficial gas velocity of $2.89 \mathrm{~m} / \mathrm{s}$, and a constant solids mass flux of $12 \mathrm{~kg} / \mathrm{s}-\mathrm{m}^{2}$. As with the mass flux and solids volume profiles, the particle velocity radial profiles were significantly "flatter" at the higher axiel positions.

It is apparent from the data oltained at the different riser heights, tilat the radial profiles for mass flux, solids volume fraction, and solids velocity tend to become "flatter" at higher axial locations. This implies that the central core of the riser expands with height. This causes the various riser parameters to vary less with radial position.

Laser-Doppler Velocimeter Experimental Unit

Tests with a Laser-Doppler Velocimeter (LDV) were conducted to gain information about the flow of dilute suspensions of cohesive solids. The LDV 
was also tested as a potential tool to measure the density of cohesive solids in a dilute suspension. During the investigation, a technique was developed to measure both particle size and particle velocity distributions of the cohesive ofl shale simultaneously. A description of the operating principle of the LDV, and the test results obtained are presented below.

\section{Theory of Operation}

Light scattered by a moving particle is "Doppler" shifted in frequency. By measuring the amount of this shift, the velocity of the particle may be determined. The high intensity and monochromaticity of laser light is well suited for this type of measurement. The method is non-intrusive, and can measure particle velocities accurately and with high spatial resolution.

The principal advantages of this method of measurement are the lack of probes, which could otherwise disturb the flow, and the ability to measure a wide range of velocities (from a few millimeters per second to supersonic flow), without the need for calibration. The drawback, however, is that optical access is a necessity, and thus, applying the method to complex geometries is difficuit. A schematic diagram of the Laser Doppler Velocimeter is shown in Figure 33.

In a dual-beam LDV, the laser beam is split by a beam splitter into two beams of equal intensity, both of which are focused at the measuring point. The LDV used in this study utilized a beam from a Helium-Neon Laser ( $15 \mathrm{~mW}$ at a wavelength of $6328 \mathrm{~A}^{\circ}$ ). The two beams were $50 \mathrm{~mm}$ apart, and passed through a focusing lens of $250 \mathrm{~mm}$ focal length. Inside the focusing volume, the two light beams intersect, and interfere with each other to form a fringe, where Iight intensity varies periodically in space (Figures 34 and 35 ).

The fringe space, $d_{f}$, is given by -

$$
d_{f}=\frac{\lambda}{2 \sin x}
$$

where $\lambda$ is the wavelength of the laser light, and $\alpha$ is the half angle between the two beams.

When a moving particle passes through this fringe area, the intensity of the scattered light reflected from the particle surface varies in time to 


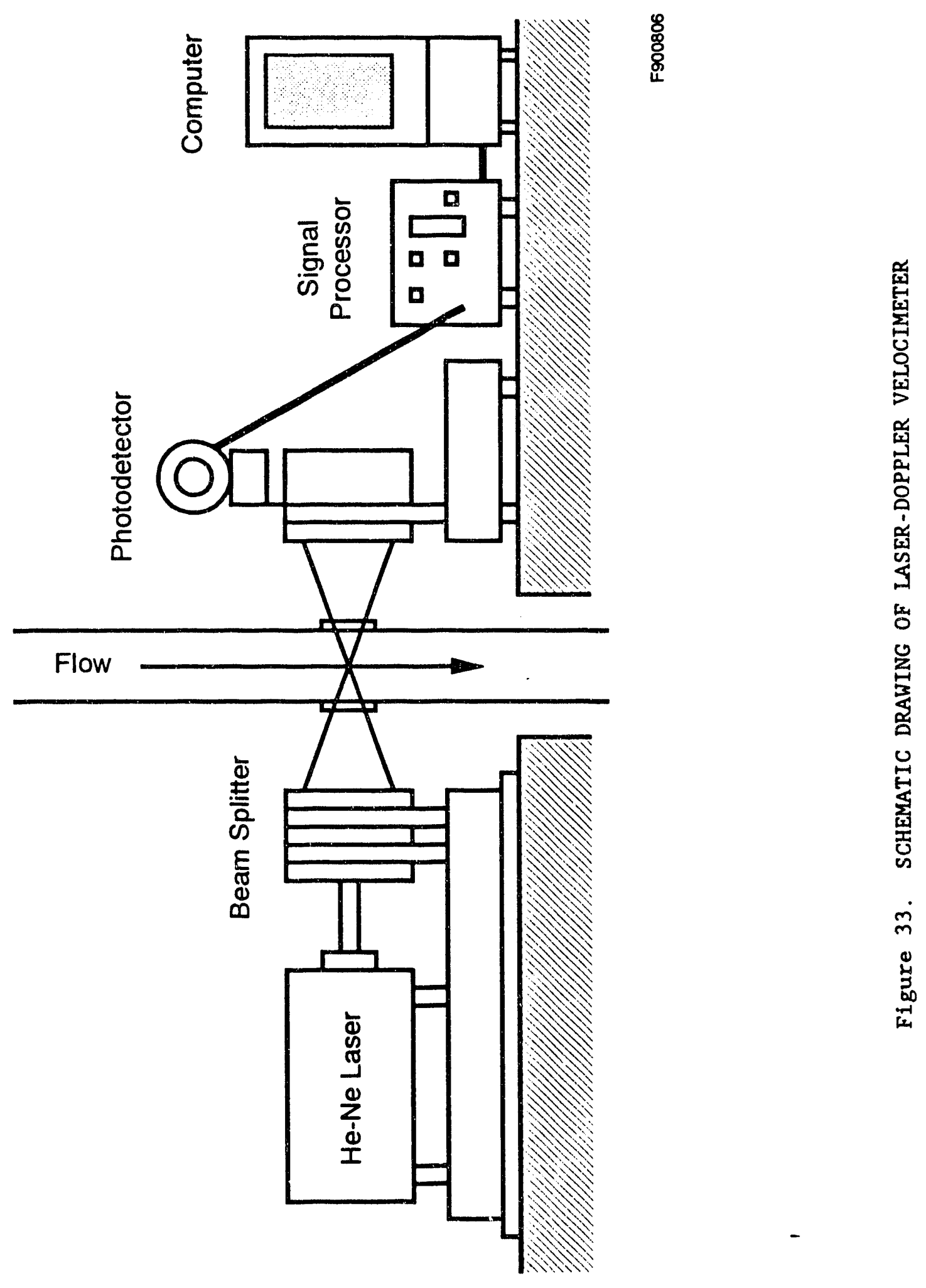

73

INST I T U T E 

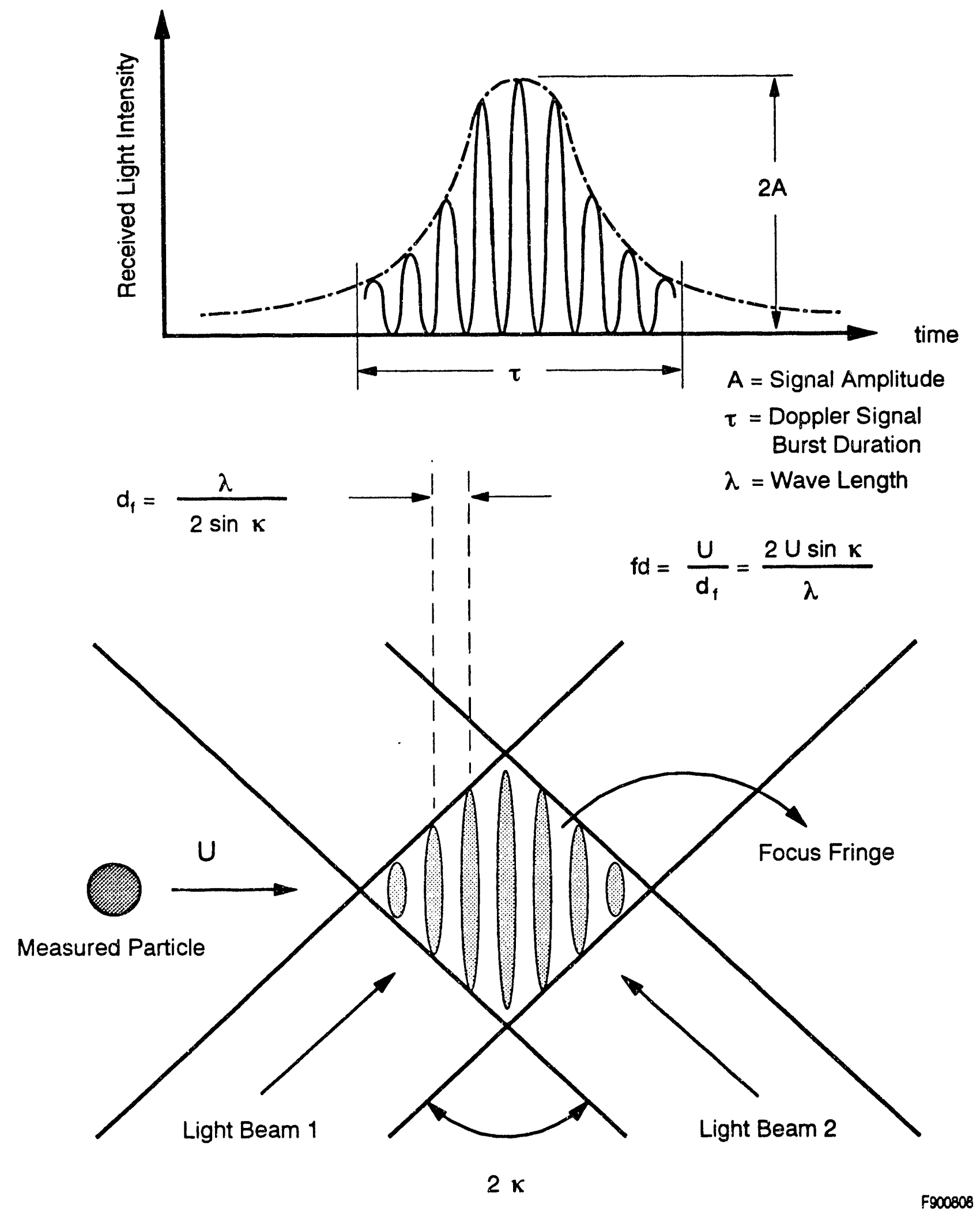

Figure 34. SCHEMATIC DRAWING OF LASER-DOPPLER VELOCIMETER OPERATING PRINCIPLE
I N S T I T U T E
O F
G A S
T E C H N O L O G Y 


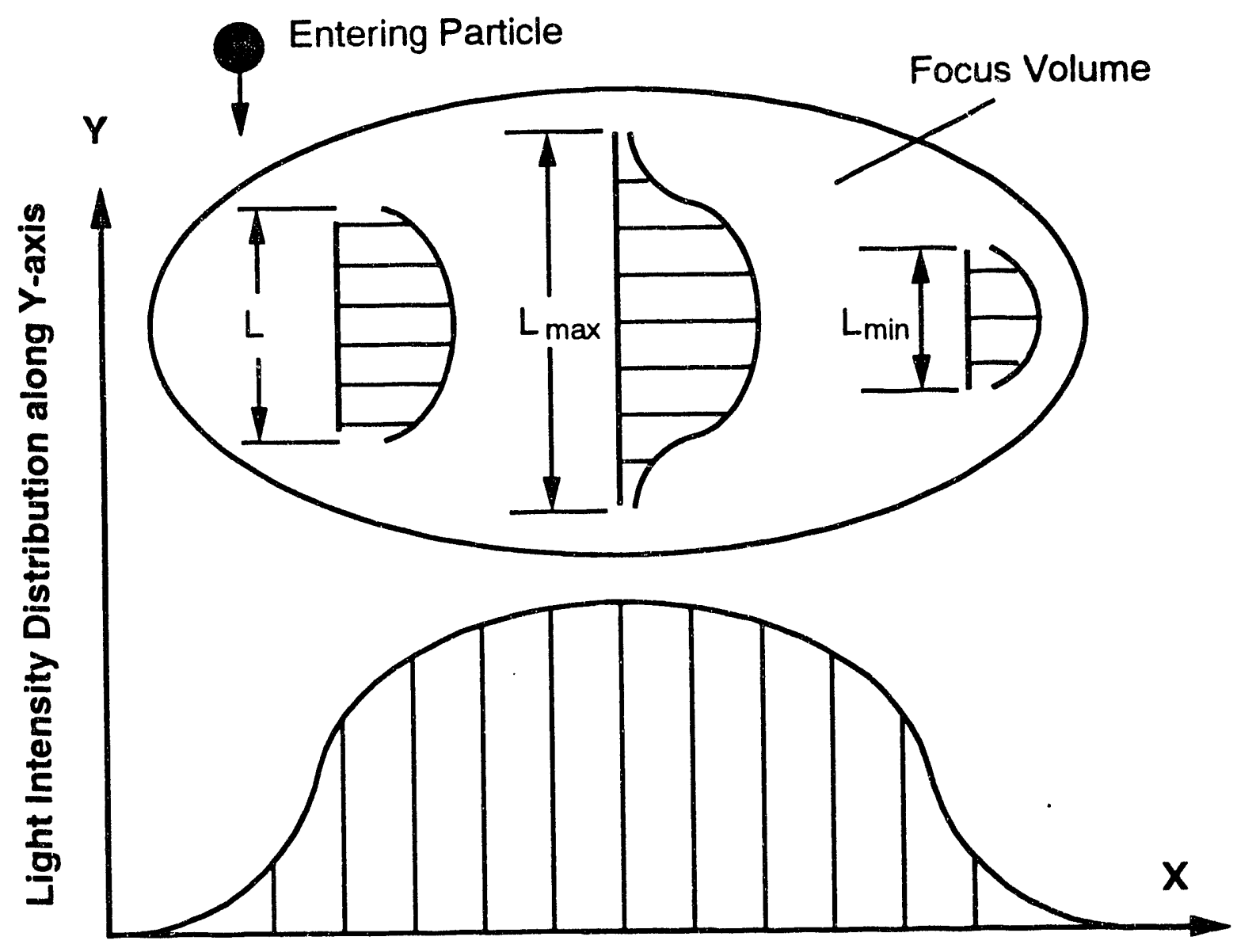

Light Intensity Distribution along $X$-axis

F900809

Figure 35. LIGHT INTENSITY VARIATION IN THE LDV - 
form the Doppler Burst Signal. This Doppler burst is received by the photodetector, and its frequency, $f_{d}$, is proportional to the velocity of the moving particle. The frequency is given by the relation,

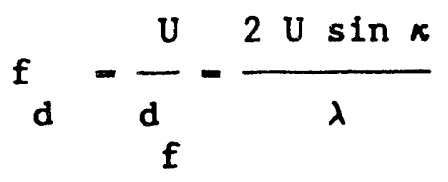

where $U$ is the particle velocity component perpendicular to the optical axis. The Doppler signal output from the photomultiplier tube typically has a Gaussian envelope. The mean value, which also has a Gaussian shape, is referred to as the pedestal, and is usually filtered out.

Thus, by measuring the Doppler frequency, it is possible to determine the particle velocity without any calibration. When measuring the velocity of gas flowing through a pipe, the gas must be seeded with small particles, since the LDV actually measures a particle velocity. The particles must be small enough (usually less than 1 micron) in order to ensure that its velocity is essentially the same as the gas velocity.

\section{Measurement of Particle Size with an LDV}

There have been several attempts to measure the particle-size distribution simultaneously with measuring particle velocity with the LDV. It can be demonstrated theoretically, that the shape of the Doppler Burst signal is determined by the size, shape, and the surface properties of the particles, the optical system alignment, the optical properties of the particle, and the actual path that the particle takes while passing through the focusing volume.

For a fixed cptical system alignment, the Doppler signal still depends on the individual particle size in a complex way. There are two approaches discussed in the literature which deal with the attempt to obtain the relationship between the particle size and certain signal characteristics: 1. the visibility of the Doppler-Burst signal (Farmer, 1972, 1978), and 2. the amplitude of the Doppler-Burst signal (Lee et al, 1978).

In this work, a new theory was developed to interpret the Doppler signal which is based on obtaining particle-size information from the amplitude of the Doppler-Burst signal. 
It is assumed that no more than one particle can pass through the focus ing volume at any time. This means that each Doppler-Burst will correspond to only one particle in the focusing volume at the precise measuring moment. When several particles appear in the focusing volume, they are considered to be moving as clusters, and are treated as one big particle. This assumption should be true in the case of very dilute gas-solid flows, and when the optical focusing volume very small.

The dual-beam LDV used in this work has an oval-shaped focusing volume, with a short-axis length of 184 microns and a long-axis length of 1890 microns. The fringe space length, $d_{f}$, is 3.2 microns. Light intensity is distributed across the focusing volume in a Gaussian distribution.

In a system with a fixed optical alignment, the amplitude of the Doppler-Burst, $A_{d}$, then depends only on the particle size, Dp, and the position of the path as it travels through the focusing volume. Let 1 be the effective path-length. Then different path-lengths will represent a different position of the path (Figure 35 ). Therefore,

$$
A_{d} \text { - function }\left(D_{p}, 1\right)
$$

In general, a larger particle will generate a stronger signal than a smaller particle. When a particle travels through the exact center of the focusing volume, a stronger signal will be generated than when the particle travels off-center through the focusing volume. Farmer (1972) obtained an expression for the light intensity distribution in the focusing volume based on the Mie Scatter Theory. It is given below:

$$
I_{0}=2 I \exp \left[-2\left(\frac{x^{2}}{b_{0}^{2}}+\frac{y^{2}}{b_{0}^{2}}+\frac{z^{2} \kappa^{2}}{b_{0}^{2}}\right)\right]\left[\cosh \left(\frac{A y z \kappa}{b_{0}^{2}}\right)+\cos \left(2 \pi \frac{y}{d_{f}}\right)\right]
$$

where $b_{o}$ is the $e^{-2}$ dimension of the focusing volume in the direction perpendicular to the light axis.

If it is assumed that the velocity component of the particle perpendicular to the laser-beam plane can be neglected, the expression above results in the following expression for $A_{d}\left(D_{p}, 1\right)$

$$
A_{d}\left(D_{p}, 1\right)=A_{d 0}\left(D_{p}\right) \exp \left[-2\left(1-\frac{1^{2}}{1_{\max }^{2}}\right)\right]
$$


where $A_{d 0}\left(D_{p}\right)$ is the Doppler signal amplitude generated by a particle with diameter, $D_{p}$, passing through the center of the focusing volume. Because the effective path length, 1 , is proportional to the actual number of peaks within one Doppler-burst, $N$, the equation above may be written as:

$$
A_{d 0}\left(D_{p}\right)=A_{d}\left(D_{p}, 1\right) \exp \left[2\left(1-\frac{N^{2}}{N_{\max }^{2}}\right)\right]
$$

Thus, for any Doppler-Burst, $A_{d o}$ calculated from this burst will be proportional to the size of the particle which caused the burst.

\section{Noise Rejection}

Even after implementing the techniques described above, there is substantial noise (from the various electronic devices employed in the testing) among the received Doppler signals. Two criteria (time and period discrimination) are used to discriminate the electronic noise.

\section{Time Discrimination}

Reasonable Doppler signals should last longer than a certain minimum time duration, i. e.,

$$
r_{\min } \leq r
$$

where $r$ is the duration of the individual Doppler burst, and $\tau_{m i n}$ is the required minimum time duration to minimize noise. $\tau_{\min }$ is determined from the experimental measurements.

\section{Period Discrimination}

All Doppler bursts oscillate at the same frequency. Therefore, they all have the same period. For accelerating particles, the relative standard deviation of the periods of each Doppler burst should be less than some critical value (determined from measurements). If not, the bursts are treated as noise. Thus,

$$
\left.\frac{\left[1 / \mathrm{N} \mathbb{i}_{1}^{\mathbb{N}}\left(\Delta \tau_{1}-\overline{\Delta T}\right)^{2}\right.}{\Delta T}\right]^{1 / 2} \leq \text { Critical value }
$$

where $\Delta r_{i}$ is the ith period in the Doppler burst, and $\overline{\Delta r}$ is the average period in the Doppler burst. 
Only after both the time and the period criteria are satisfied can a particular Doppler burst be considered as a reasonable signal.

In actual testing, an HP 5404 digitizing oscilloscope was used to record the Doppler signals. The signals were then stored and transferred to an IBM 386-type computer for data processing.

\section{Particle-Size Calibration Curve}

It is nearly impossible to determine the particle-size versus electric signal voltage curve theoretically. This is because the light intensity/voltage signal relationship is unknown, and the electric signals have been amplified before they are recorded. Therefore, the following procedure was used to obtain a calibration curve for particle-size analysis:

1. The actual particle-size distribution of the particles being used in the experiment were determined using a Coulter Counter or other particle. size analyzer.

2. A reference flow condition was then chosen, and a large number of random Doppler signals were recorded with solids flowing through the experimental pipe, to make data processing statistically significant.

3. An electronic filter was used to remove the very high frequency components of the signal which are considered as noise, as well as the low-frequency components (pedestals).

4. The time and period criteria were then used to discriminate the remaining signal to remove further noise.

5. The burst amplitude of each Doppler burst, $A_{d 0}$, was then calculated using Equation 75.

6. A statistical analysis was then performed to determine the accumulative signal number distribution as a furction of signal amplitude.

7. The signal-amplitude distribution was then compared with the reference particle-size distribution obtained in Step 2.

8. The particle-size calibration curve was then constructed by choosing the signal amplitude and particle size values corresponding to the same accumulative signal number distribution (signal number percentage).

The resulting calibration curve allows the determination of the size of particle which causes a particular Doppler burst.

A TSI photodetector and frequency counter amplified the signals and filtered out the high and low frequency components of the raw signals. 
However, waveforms on the HP 5404 digitizing oscilloscope showed that some high and low frequency components still existed after filtering. Therefore, a computer program was developed to further filter the signals. After being filtered via the computer, the resulting signals were acceptable.

\section{Solid Concentration Measurement Using the IDV}

As well as obtaining the particle size distribution, it is also possible to obtain information about the solid-phase volume (number) concentration at the measuring point. Because the particle velocity and the particle size are measured, it is possible to calculate the solid flux and then obtain the solid volume concentration from the solid flux and velocity.

Within the sampling time period, $T_{s}$, the total volume of solids passing through the intersection area, $A_{f}$, of the focusing volume is $\Delta V$,

$$
\Delta V-\sum_{i=1}^{N} s \frac{\pi}{6} D_{p i}^{3}
$$

where $\mathrm{N}_{S}$ is the total number of sample bursts received within the sampling time period, $T_{s}$. Thus, tha solids flux through $A_{f}$ is

$$
F \operatorname{lux}=\frac{\Delta V}{T_{s}} A_{f}
$$

During this period, the average solid velocity is $\mathrm{U}_{\text {ave }}$,

$$
U_{\text {ave }}=\frac{1}{N_{s}} \quad \sum_{i=1}^{N_{s}} U_{p i}
$$

Therefore,

$$
\epsilon_{s}-1-\epsilon_{f}-\frac{F l u x}{U_{\text {ave }}}-\frac{N_{s}}{T_{s} A_{f}} \frac{\sum_{i=1}^{N_{s}} \frac{\pi}{6} D_{p i}^{3} \underbrace{N_{s}}_{i=1} U p i}{U_{p i}}
$$

where $\epsilon_{S}$ is the solid volume concentration, and $\epsilon_{f}$ is the void fraction. 


\section{Experimental Equipment}

A schematic drawing of the experimental test unit is shown in Figure 36. The test unit consists of five major parts: 1) the primary gas flow inlet, 2) the solids feed section, 3) the solids/gas mixing chamber, (4) the measurement (test) section, and 5 ) the cyclone and solids recirculation section.

The primary gas flow inlet section consisted of four filters to remove water and oil droplets from the compressed air, a pressure regulator to lower the high-pressure air ( 80 to $120 \mathrm{psig}$ ) to the desired operating pressure (20 to $30 \mathrm{psig}$, and a flow meter to measure the total air flow rate.

In the solids feed section, solid particles from a storage hopper were fed into the test unit via a feed screw. A Penberthy jet-pump eductor (Figure 37) was used to create the pressure gradient required to overcome the cohesiveness of the particles and cause the solids to flow. The jet pump created a negative pressure zone after the nozzle, which caused the particles to flow into the test unit.

The mixing chamber consisted of a 2-foot-long section of 2 -inch-diameter pipe. The mixing section was added to the test unit to allow the solids to mix well with the gas before the mixture entered the test section.

A 10-foot-long section of 2-inch-dlameter clear PVC pipe oriented vertically, served as the test section in the unit. The test section was located after a 3.5-foot-long section which allowed the solids and the gas to accelerate to their steady-state value. A pair of optical-glass windows 180 degrees apart were mounted in the test section after the acceleration section, to allow the laser beam to penetrate into the test section. The $20-\mathrm{mm}$ diameter window was designed to prevent accumulation of particles in front of the window. Differential pressure transmitters and gauges were distributed along the riser to measure the axial pressure distribution and pressure fluctuations during the tests. Near the bottom of the riser, spherical polystyrene tracer particles ( 0.96 microns in size) were added to the riser by a TSI atomizer, to allow the measurement of the gas velocity.

Following the test section, the sollds were collected in two cyclones connected in series. A cloth filter captured the extremely fine particles which escaped through the cyclone. The solids collected by the cyclones were

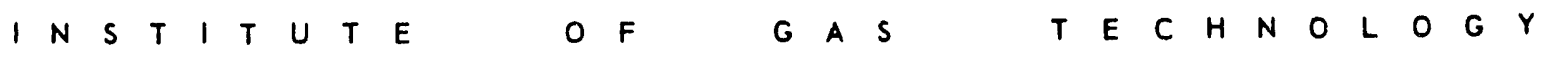




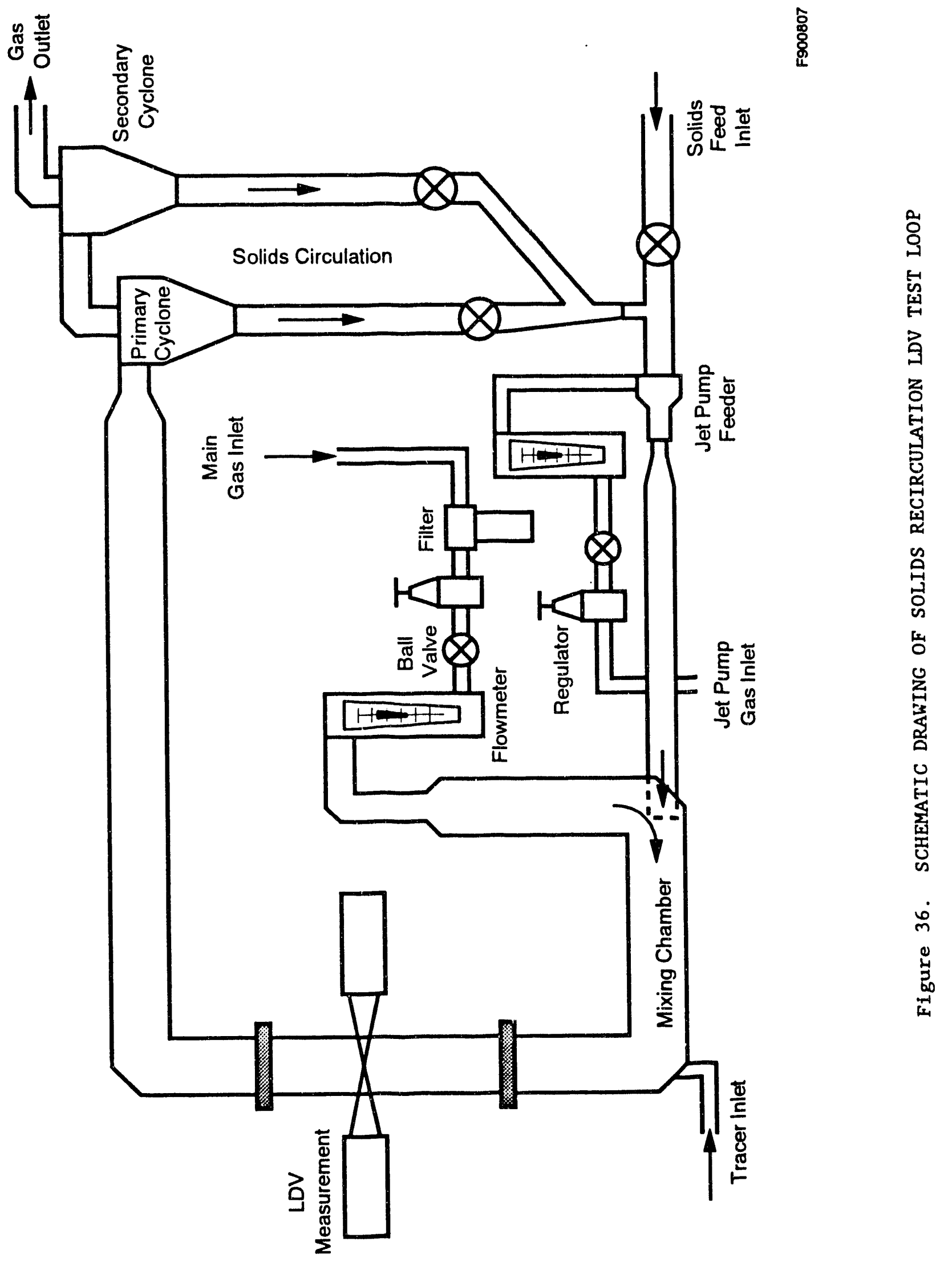
I NST I T U T E
O F
G A S
T E C H N O L O G Y 


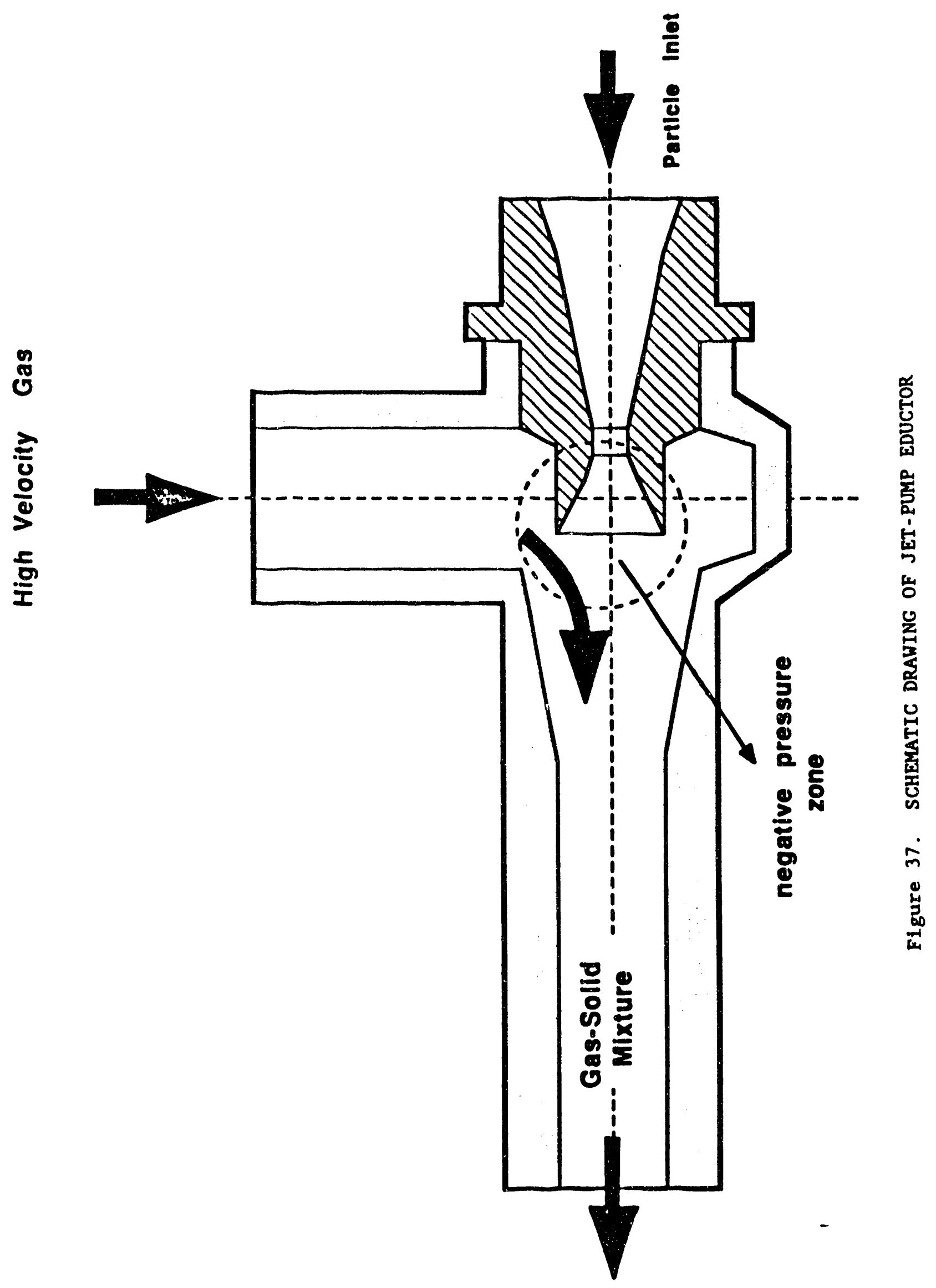


recirculated back to the feed system through two standpipes. Ball valves in the standpipes enabled the solids circulation rate to be controlled.

In a typical test, both ball valves in the recirculation standpipes were opened completely, and the oil shale particles were loaded into the system. of the nine tests conducted, three tests were conducted with 75 grams of oil shale in the system, while six tests were conducted with 750 grams of oil shale in the unit. The frequency shift of the laser beam was set at $0.5 \mathrm{MHz}$. After this adjustment was completed, all of the settings on the photodetector and the frequency counter were set. The gas volumetric flow rate was then adjusted to the desired value. The IDV was then used to measure the particle velocity and the particle size. The axial pressure profile and the pressure fluctuations in the riser were also measured.

Different steady-state gas and solid flow rates were obtained by adjusting the gas flow rate through the system or by adjusting the ball valves in the cyclone recirculation standpipes.

\section{Experimental Results}

As described above, the calibration of the LDV to measure particle size distribution required a reference flow condition. It was assumed that the reference particle-size distribution obtained using a Coulter Counter was the same as that obtained at a gas flcw rate of 0.4 SCFM.

It was found that the shale particle-size ranged from 0.3 microns to 70 microns. The calibration curve (Figure 38 ) showing the relationship between particle size and the amplitude of the signal from the LDV, was obtained using the technique described above.

Due to different mixing characteristics near the wall compared to the center of the pipe, the particle-size distribution was not uniform across the diameter of the pipe. Therefore, the particle-size distribution and the particle velocity were measured with the LDV at twelve different radial positions in the 2-inch-diameter test section: $0,0.133,0.267,0.4,0.533$, $0.667,0.8,0.867,0.9,0.933$ and 0.99 Inches from the centerine of the pipe. At each location, 500 Doppler bursts were collected for a statistical analysis

of the data. Experimental particle-size distributions as a function of radial 


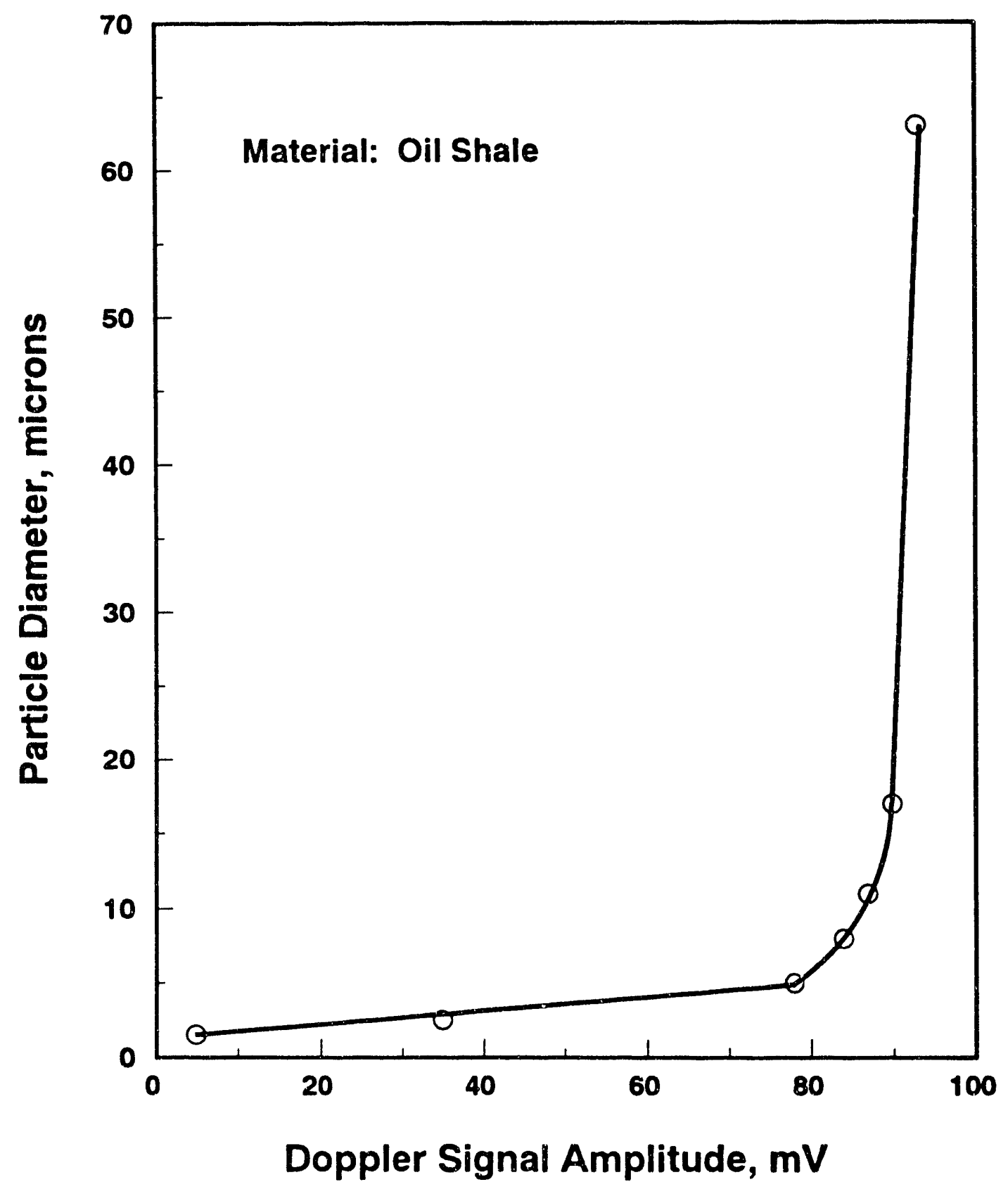

CalCurvA

Figure 38. PARTICLE SIZE CALIBRATION CURVE FOR THE LDV 
position were obtained at gas flow rates of $0.4,4,8,10$, and 12 SCFM at each radial location. The shale particle size distribution was divided into five different particle size ranges. The ranges used were:

Group 1: Less than 0.45 microns

Group 2: From 0.45 to 0.8 microns

Group 3: From 0.8 to 1.1 microns

Group 4: From 1.1 to 3.0 microns

Group 5: Greater than 3 microns

The particle-size distributions for dimensionless radial positions of $0,0.4$, 0.8 , and 0.99 from the centerline are shown in Figures 39, 40, 41, and 42 for a gas flow rate of 0.4 SCFM, and in Figures $43,44,45$, and 46 for a gas flow rate of 12 SCFM. Simultaneously, pressure drops were also measured at eight different axial locations: $16,23.7,30.6,62.8,69.9,78$, and 86.8 inches above the entrance of the solids.

In general, the particle size distribution was wider at the higher gas flow rates. This was primarily due to the extensive particle agglomeration observed to occur at the higher gas flow rates. However, for all gas flow rates, more large particles were formed at the wall where the local gas velocity was lowest.

Radial profiles of average particle size obtained at gas flow rates of 0.4 SCFM and 12 SCFM are given in Figures 47 and 48 , respectively. At both gas flow rates, the average particle size is seen to be much greater near the wall. This is because the mean and fluctuating gas velocities are always lowest in the wall region.

The particle size distribution in the pipe at steady state is a result of a balance between: 1) agglomeration due to interparticle collision and 2) de-agglomeration due to shearing, turbulent interaction, and impacts with the wall. In general, when the mean and fluctuating gas velocities in the pipe were high, the average particle size at the same location was small.

Figure 49 shows the variation in average particle size with gas flow rate for two different solids inventories in the system - 75 and $750 \mathrm{~g}$. For 


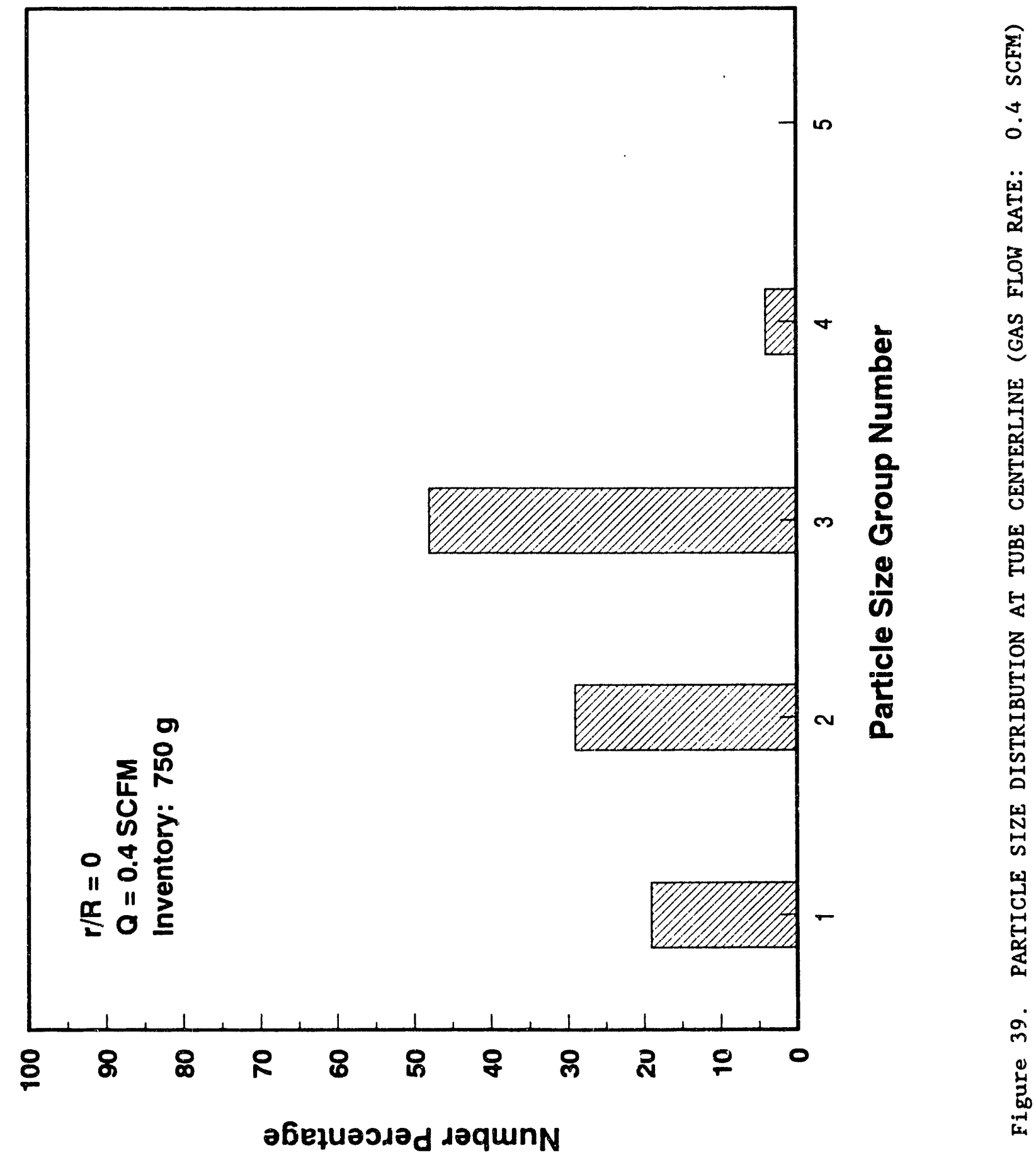




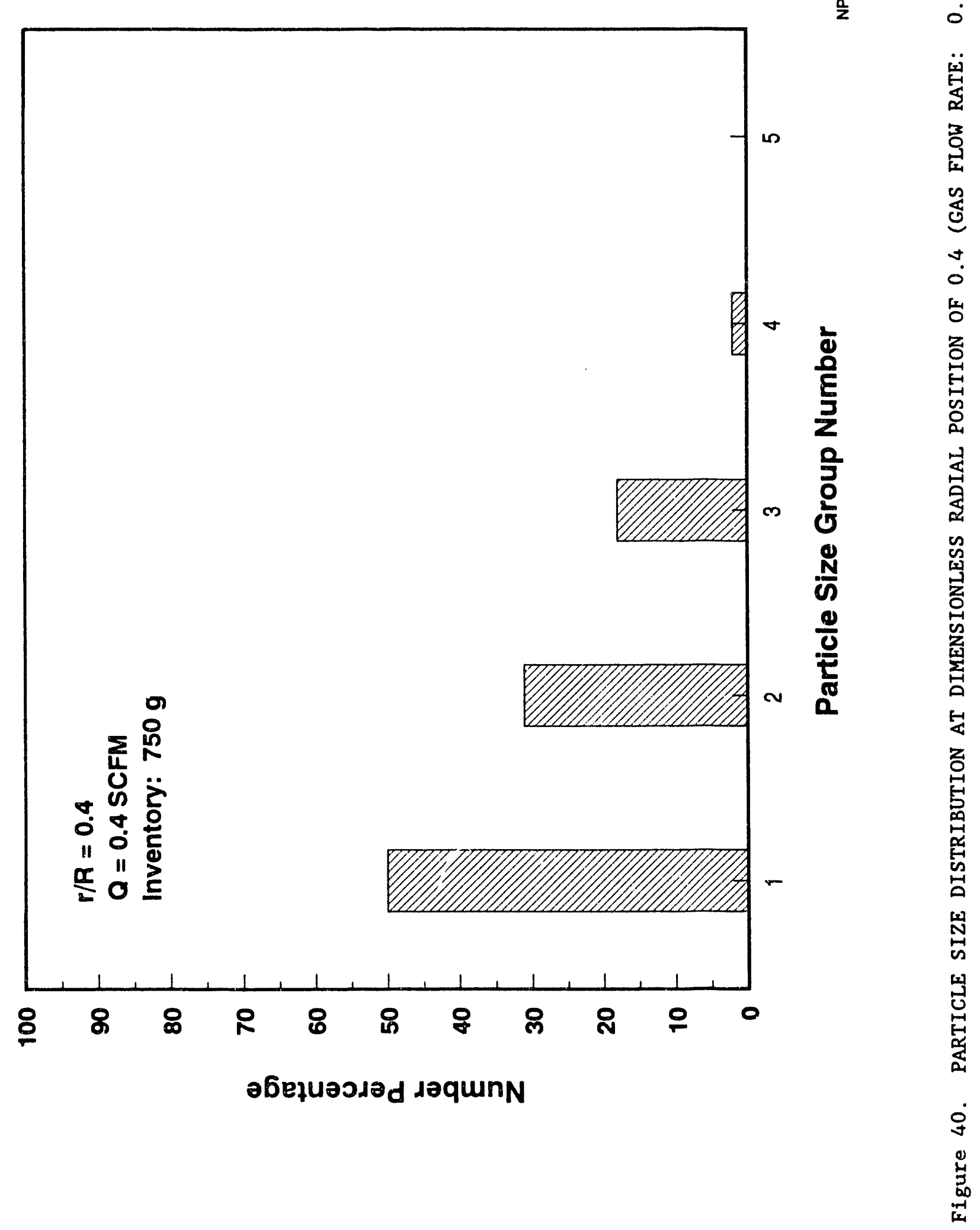




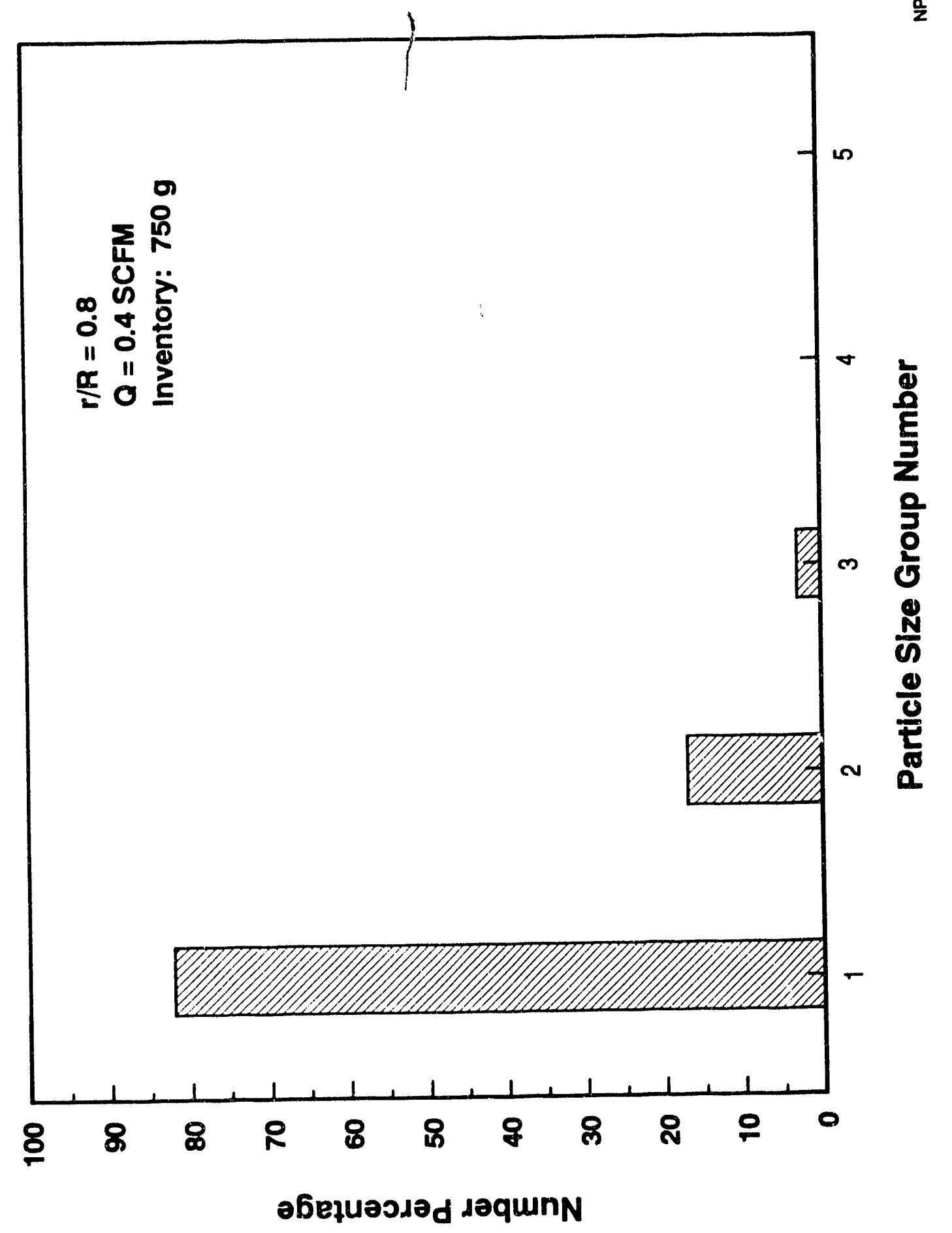

这
v
$\dot{0}$
$\dot{0}$

in

$\frac{2}{8}$

赵

$\infty$

$\dot{0}$

동

ż

密

م.

崫

正

傜

号

武

(x)

법

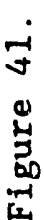




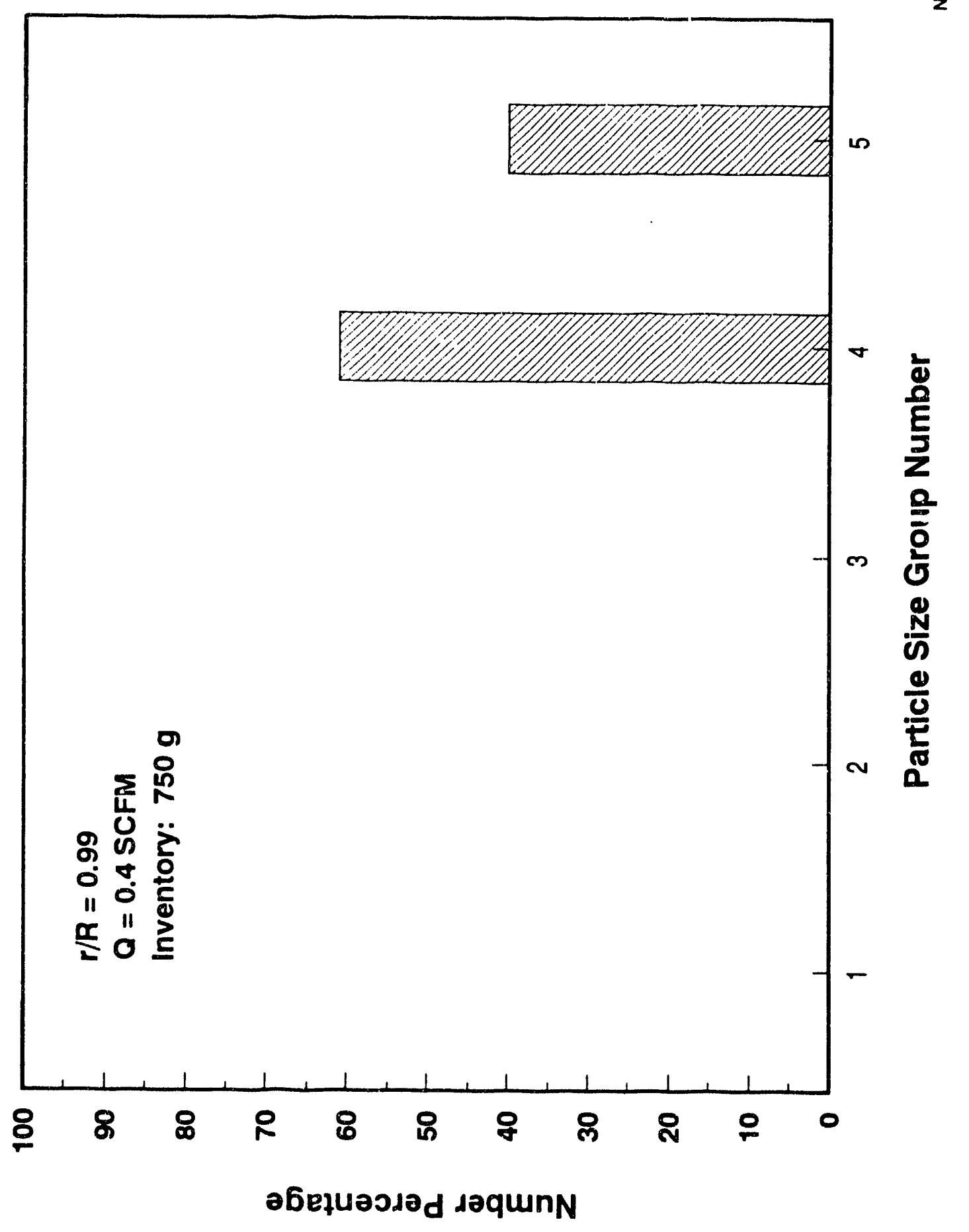

疍
s
t.
0

突

옴

త్ర

a)

o.

㗘

은

点

宠

告

娄

zㅇ

品

I N S T I T U T E

O F

G A S

T E C H NOL 


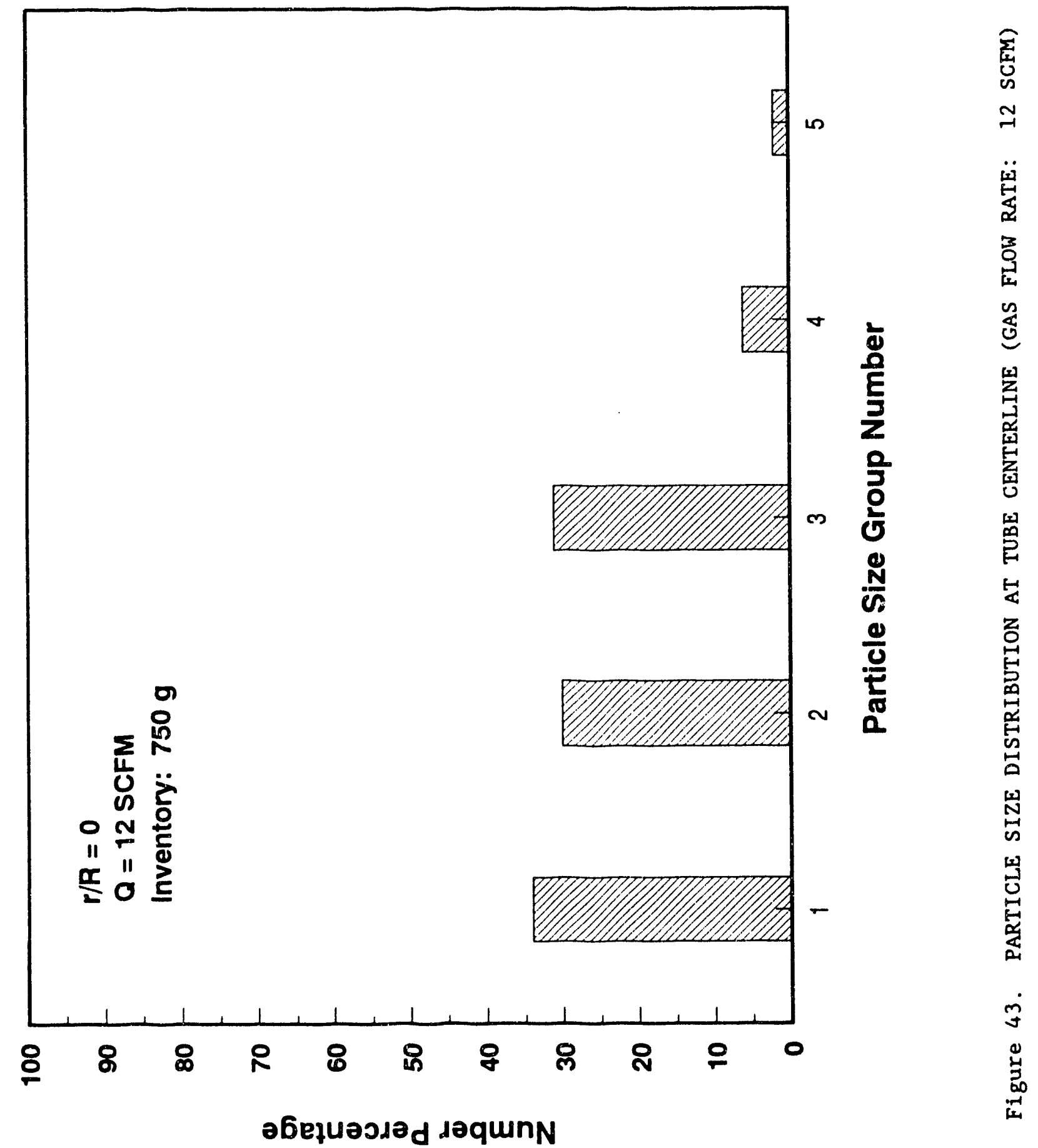

O F OA S

TE C H N O L O 


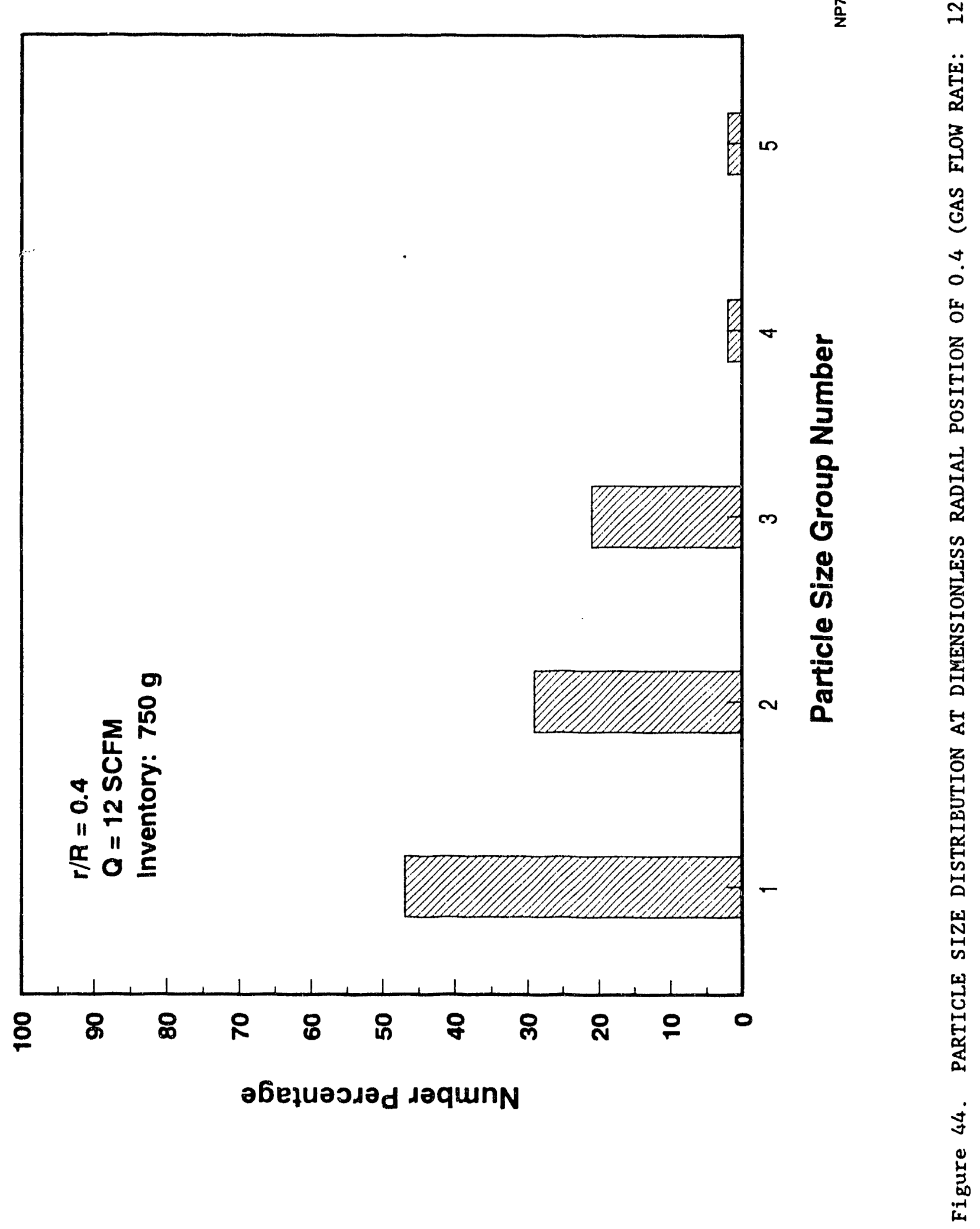




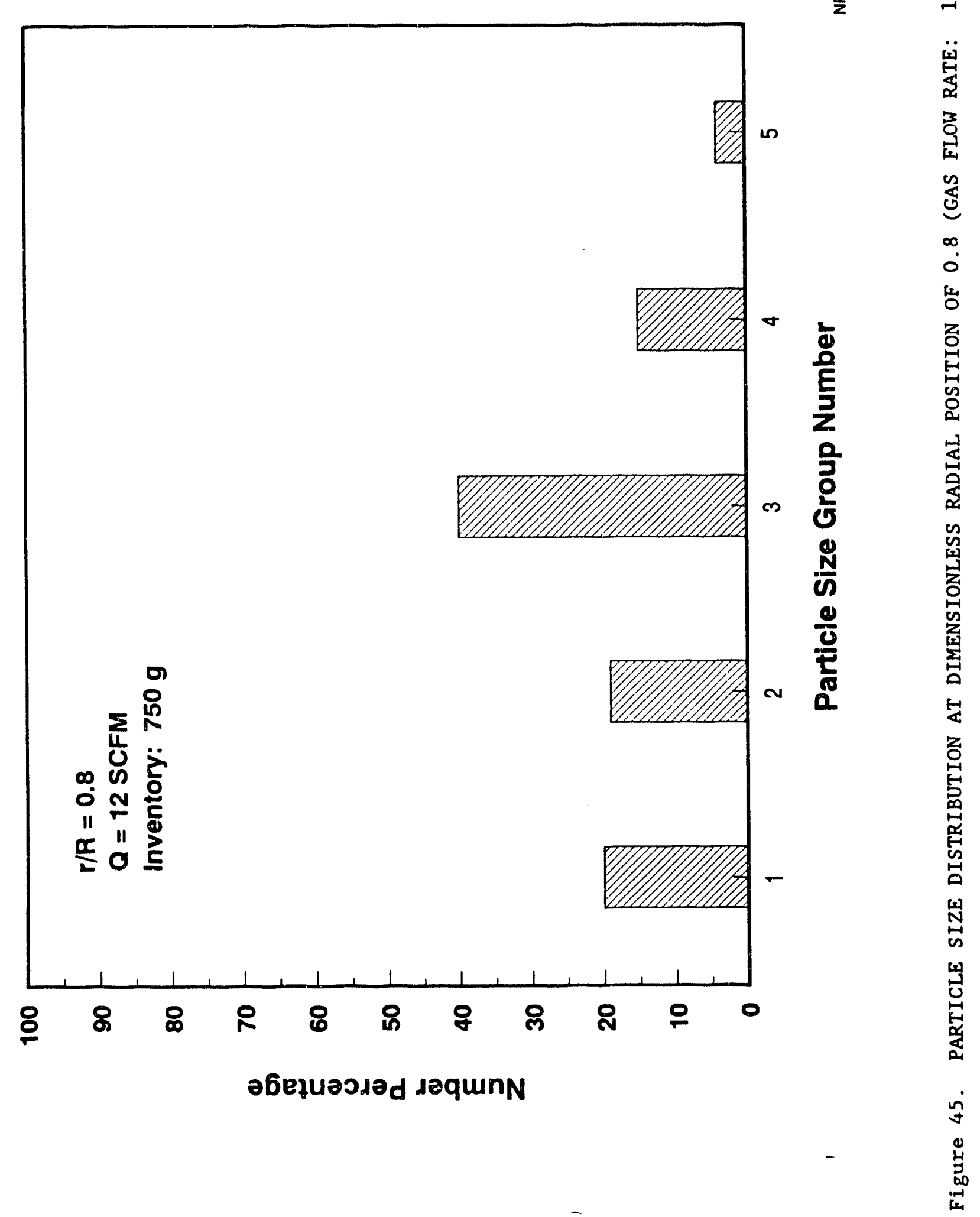

I N S T I T U T E O F G A S T E C H NOL L G Y 


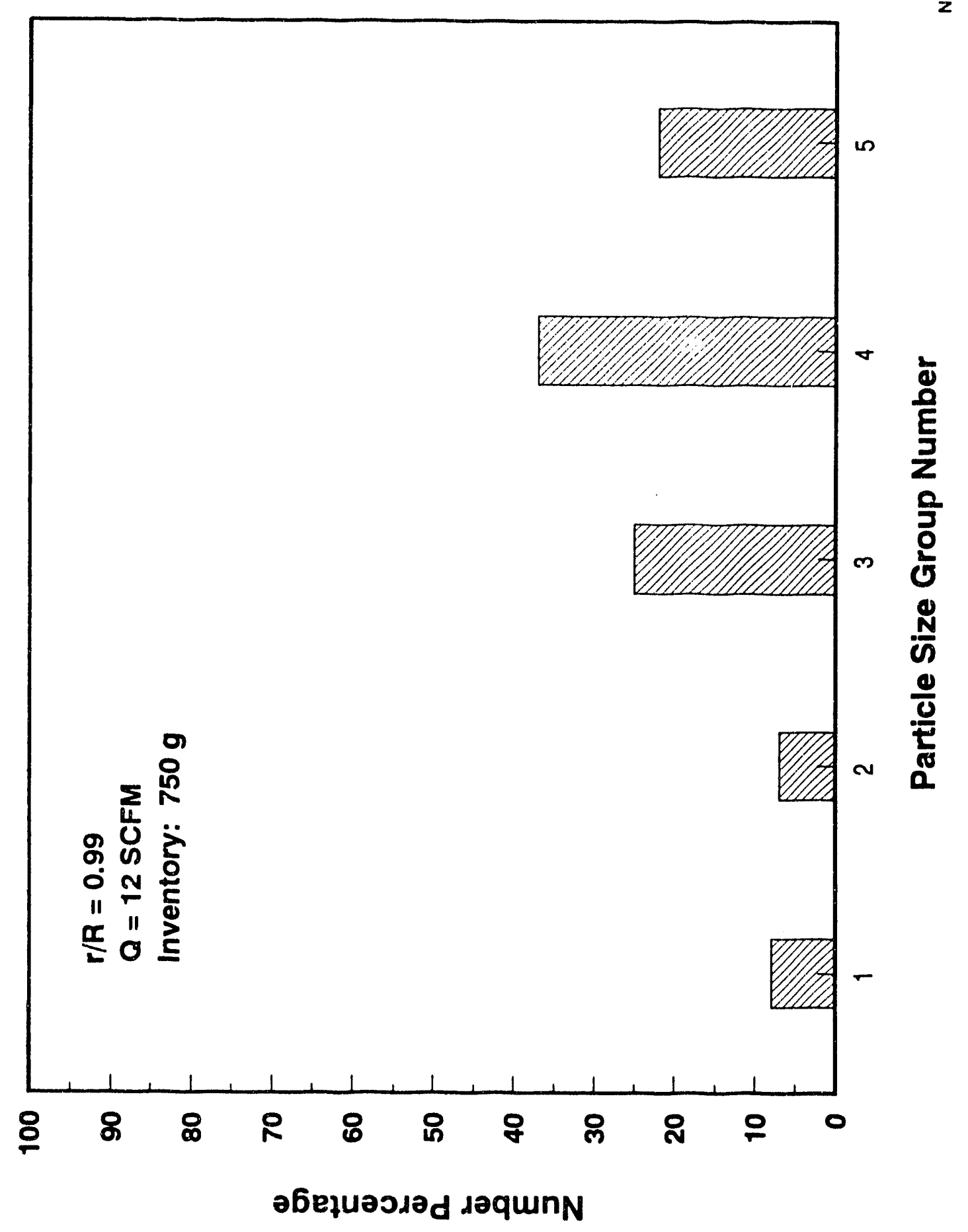

证

N

:

娄

跑

a

$\circ$

趗

zo

c

4

$z$

5

黛

照

$\stackrel{9}{9}$

虫 


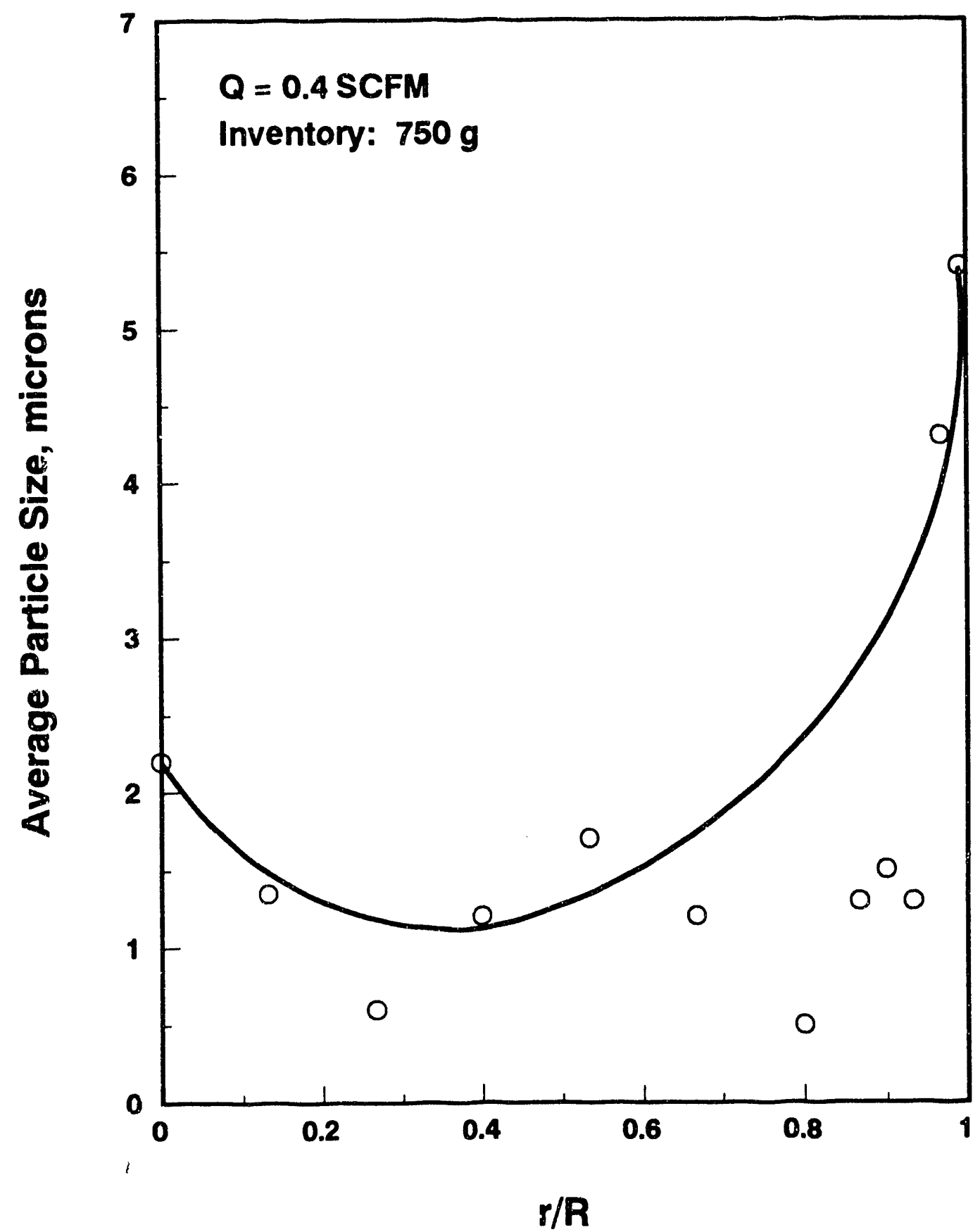

PSVSR.4

Figure 47. AVERAGE PARTICLE SIZE VERSUS DIMENSIONLESS RADIAL POSITION (GAS FLOW RATE: 0.4 SCFM)

95

I N S T I T U T E

O F

G A S

T E C H N O L O G 


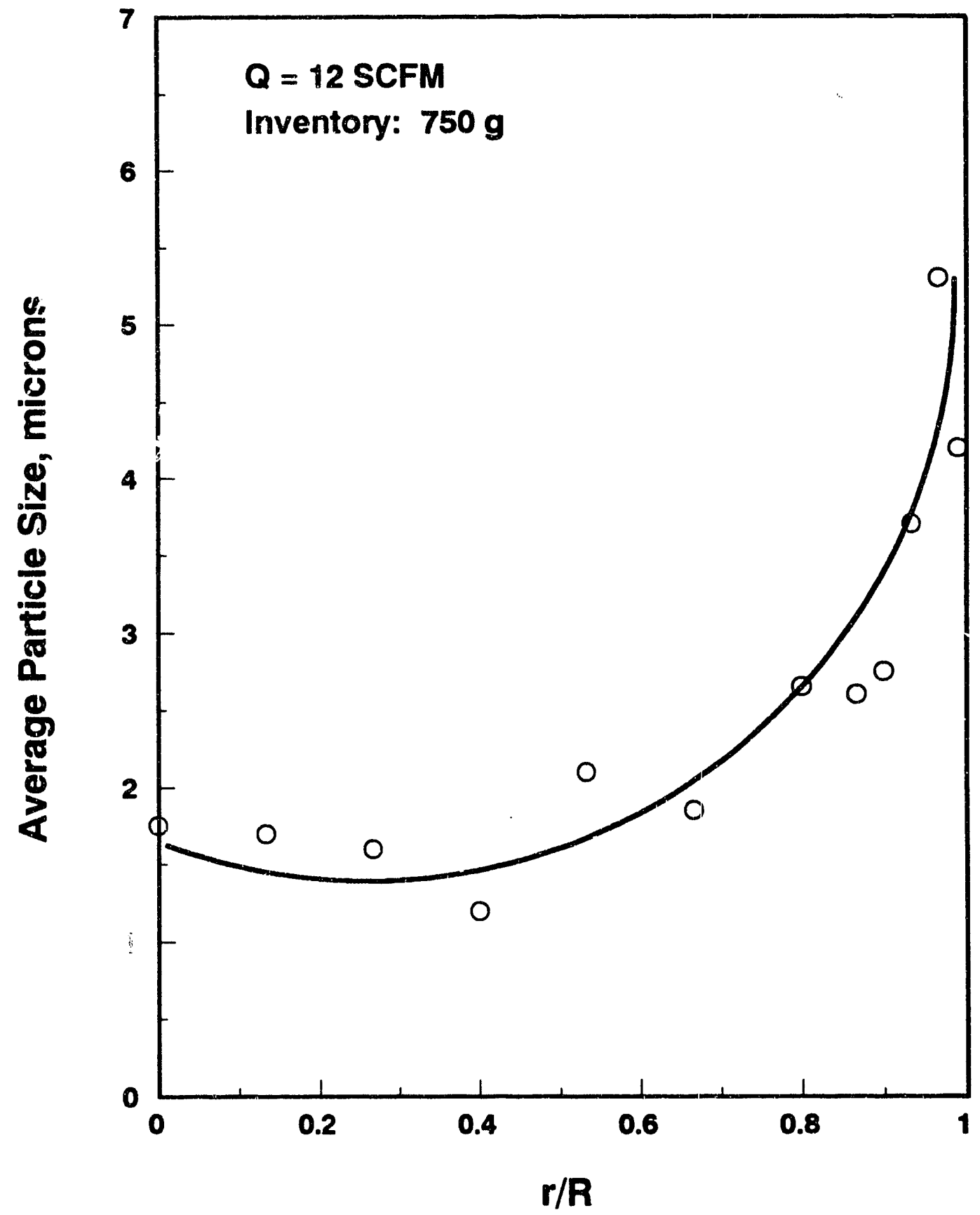

PSVSA12

Figure 48. AVERAGE PARTICLE SIZE VERSUS DIMENSIONLESS RADIAL POSITION (GAS FLOW RATE: 12 SCFM)

96

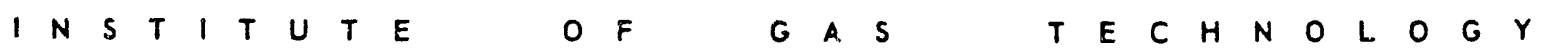




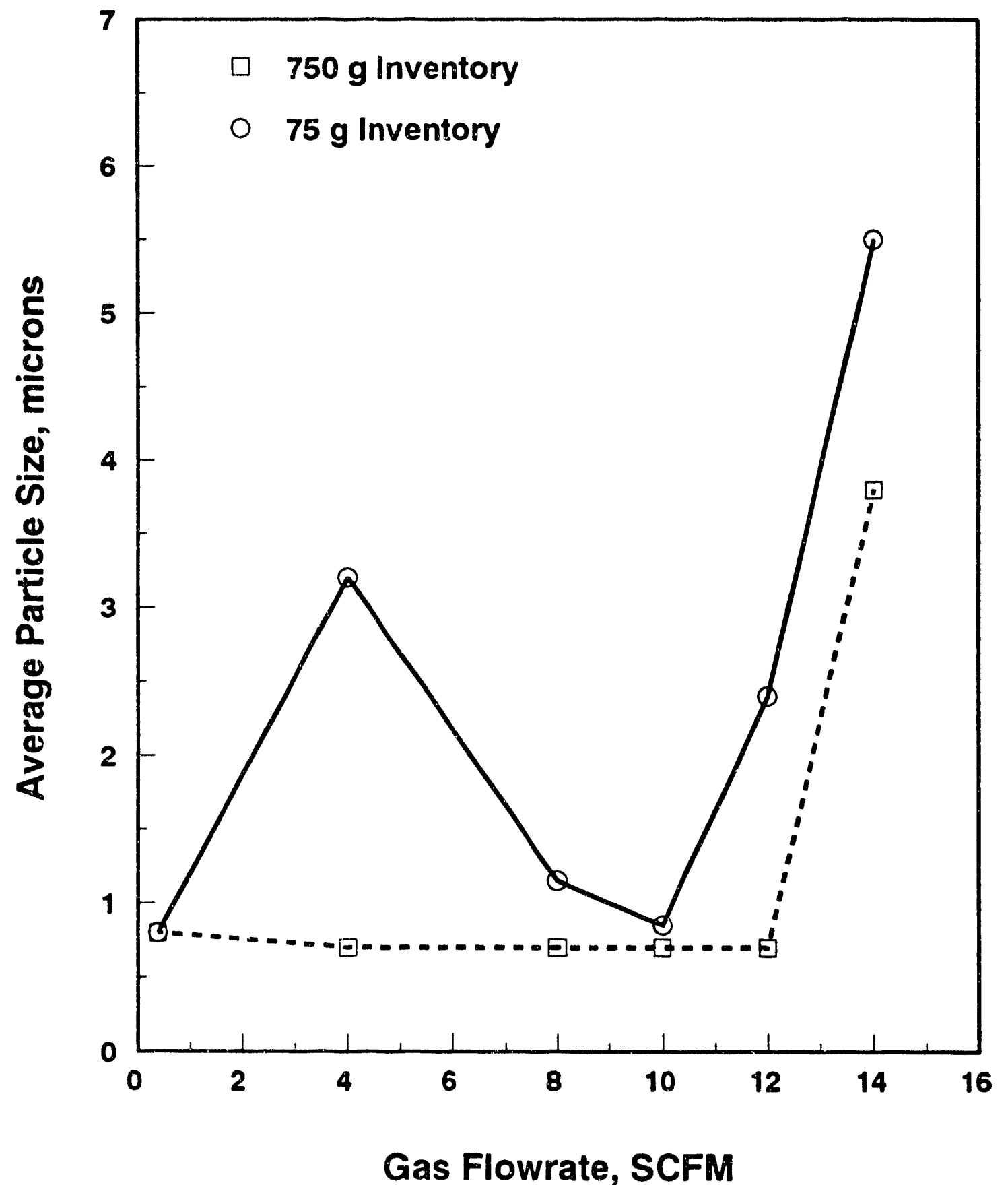

PSVSQ

Figure 49. VARIATION IN AVERAGE PARTICLE SIZE WITH GAS FLOW RATE (75 g AND $750 \mathrm{~g}$ INVENTORY) 
the $75 \mathrm{~g}$ inventory, average particle size first increased with increasing gas flow rate, then decreased before increasing again. For the $750 \mathrm{~g}$ inventory case, the particle size distribution was constant with gas flow rates until the particle size distribution increased at a gas flow rate near 10 SCFM.

Radial profiles of mean particle velocity as a function of particle size for a solids inventory of $750 \mathrm{~g}$ are shown in Figures 50 and 51 for gas flow rates of 0.4 and 12 SCFM, respectively. It can be seen that an annular boundary region adjacent to the wall exists wherein mean particle veloclties are extremely low. This variation of mean particle velocity with radial position was also observed with the $75 \mathrm{~g}$ inventory.

Radial profiles of fluctuating particle velocity as a function of particle size for a $750 \mathrm{~g}$ inventory are shown in Figures 52 and 53 for gas flow rates of 0.4 and 12 SCFM, respectively. The fluctuating particle velocities were also found to be lower near the wall.

The radial profiles of void fraction for both the $750 \mathrm{~g}$ and the $75 \mathrm{~g}$ solid inventory tests were nearly identical. The void fraction was nearly 1 in the center of the riser, and decreased to a lower value at the wall. However, even near the wall the void fraction was very high (greater than $0.997)$. A plot of void fraction versus radial position is given in Figure 54 for the $750 \mathrm{~g}$ inventory case.

\section{Verification of Maxwellian Velocity Distribution Assumption}

In recent years, the research in the field of granular flow using the kinetic theory approach has been very active. However, all the investigators used a very important assumption which has not been verified experimentally, that is, the particle velocity probability distribution function is a Maxwellian distribution. Experiments conducted with the LDV provided validation of this assumption in the dilute-phase region.

The one-dimensional Maxwellian velocity distribution is described in terms of the following equation.

$$
f \text { Maxwell }(u)=\frac{1}{2 \pi T_{\text {granular }}{ }^{1 / 2}} \exp \left[-\frac{\left(u-U_{\text {mean }}\right)^{2}}{2 T_{\text {granular }}}\right]
$$

\begin{tabular}{|c|c|}
\hline & $N$ \\
\hline
\end{tabular}




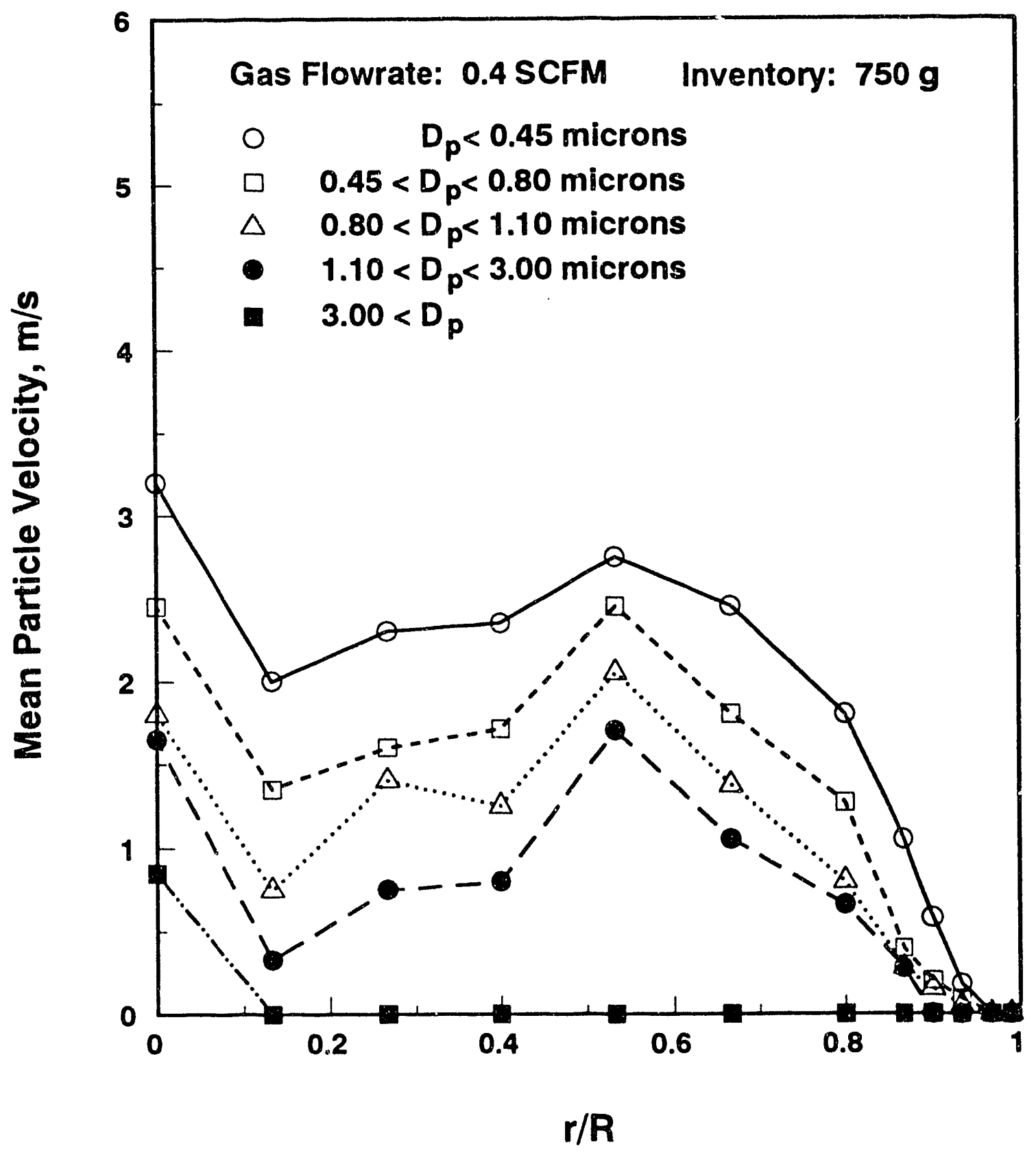

MVISH.4

Figure 50. RADIAL PROFILES OF MEAN PARTICLE VELOCITY AS A FUÑCTION OF PARTICLE SIZE (GAS FLOW RATE: 0.4 SCFM) 


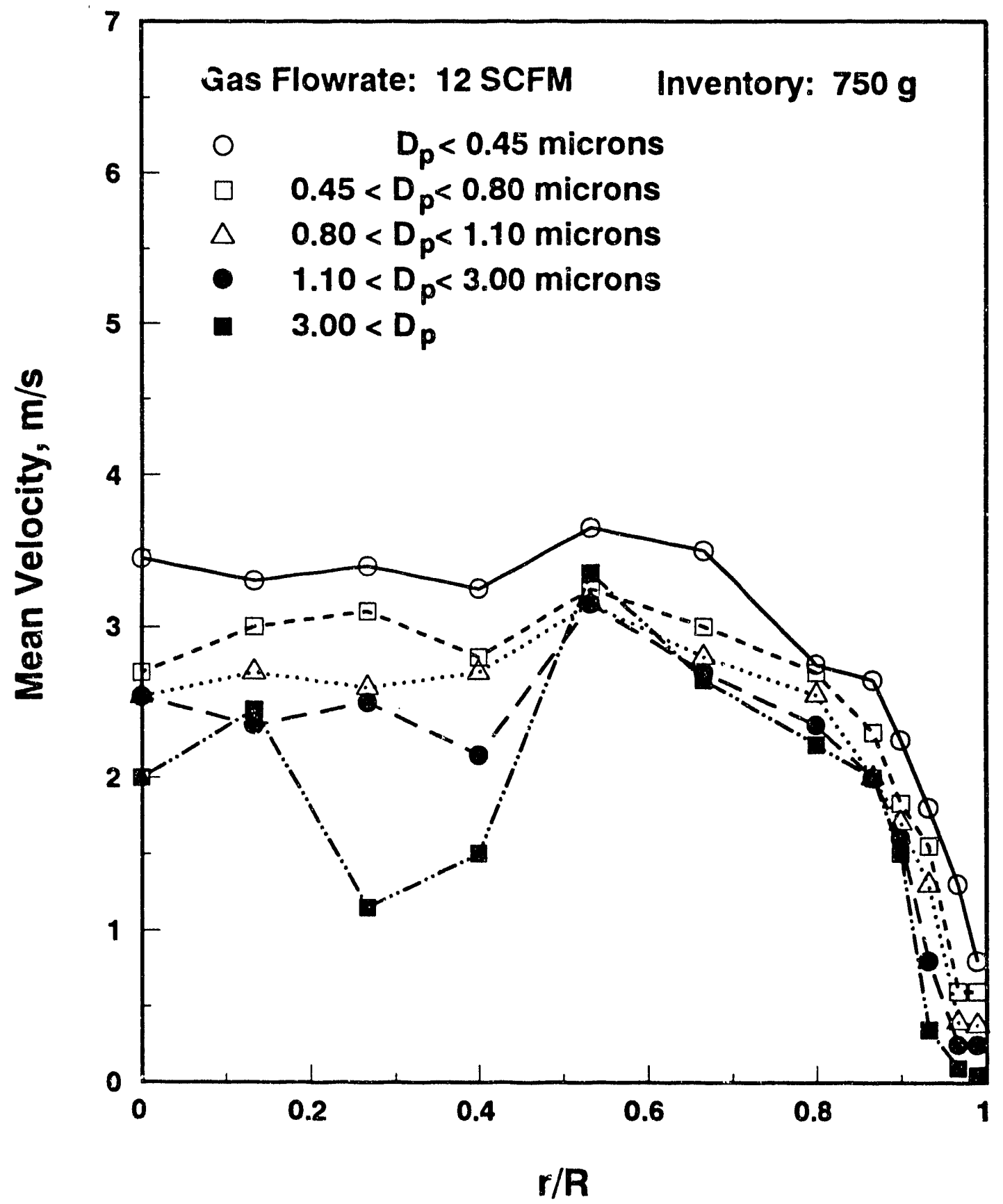

MVVSR12

Figure 51. RADIAL PROFILES OF MEAN PARTICLE VELOCITY AS A FUNCTION OF PARTICLE SIZE (GAS FLOW RATE: 12 SCFM) 


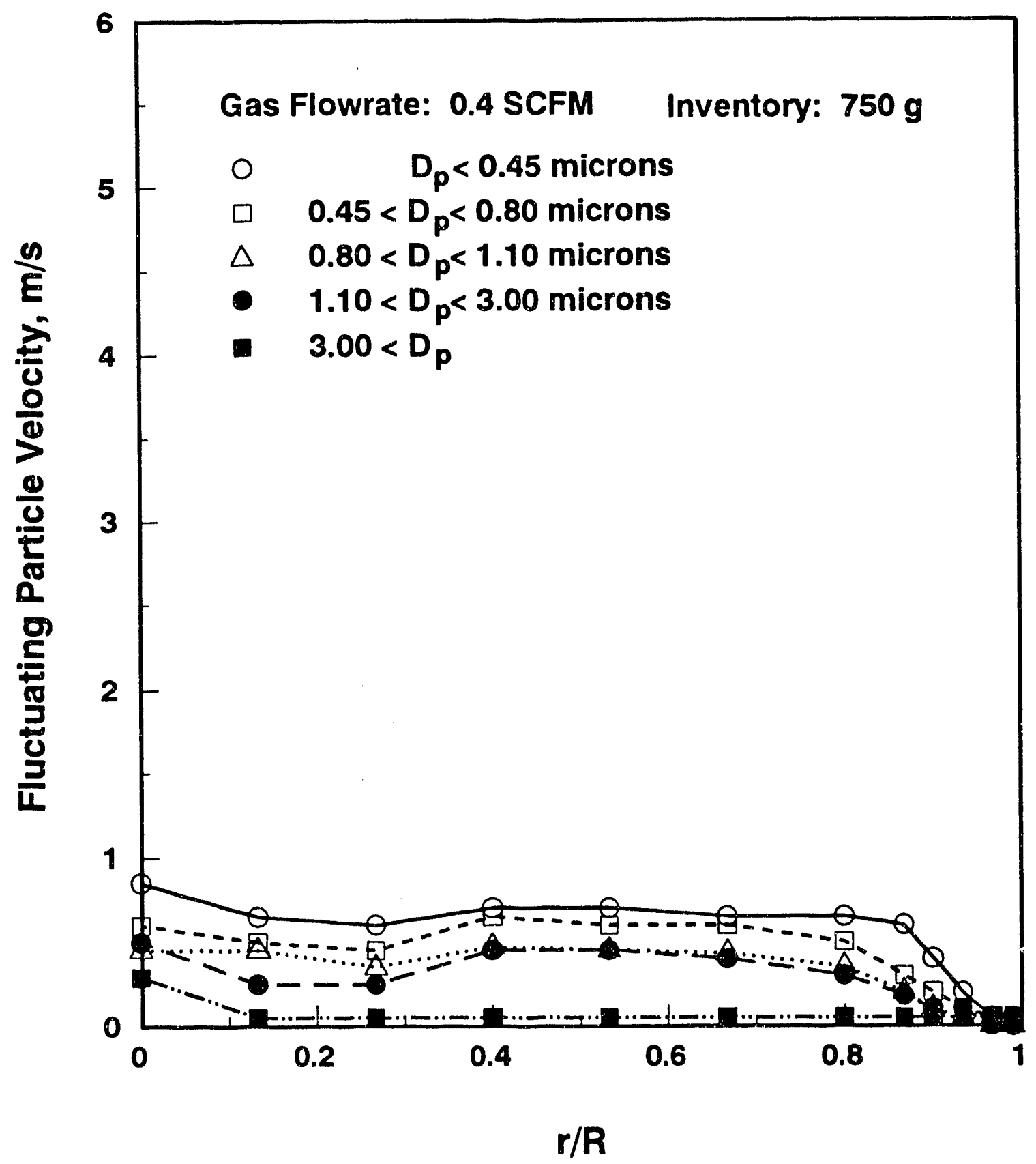

FVSR.4

Figure 52. RADIAL PROFILES OF FLUCTUATING PARTICLE VELOCITY AS A FUNCTION OF PARTICLE SIZE (GAS FLOW RATE: 0.4 SCFM) 


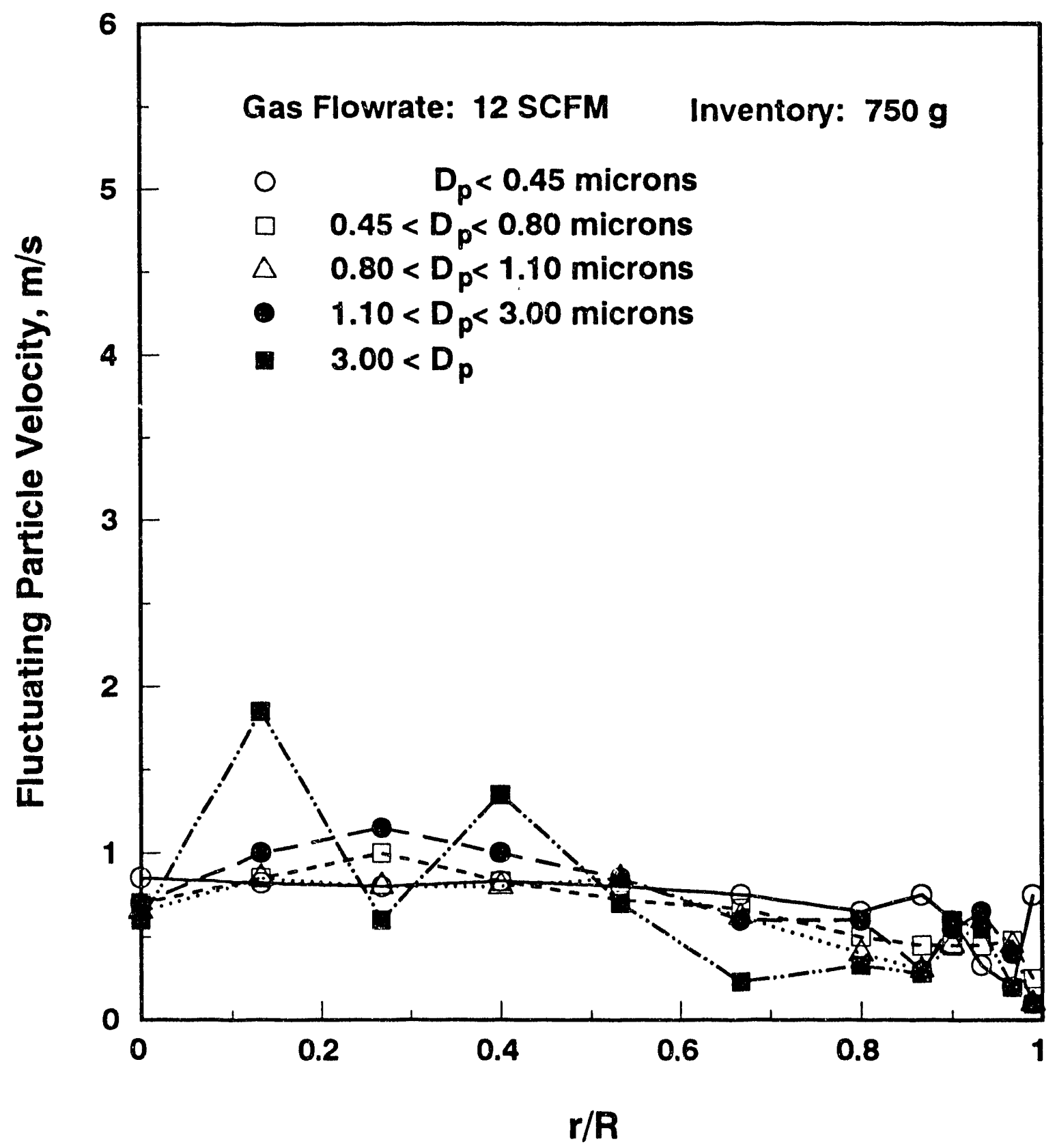

FWSR12

Figure 53. RADIAL PROFILES OF FLUCTUATING PARTICLE VELOCITY AS A FUNCTION OF PARTICLE SIZE (GAS FLOW RATE: 12 SCFM) 


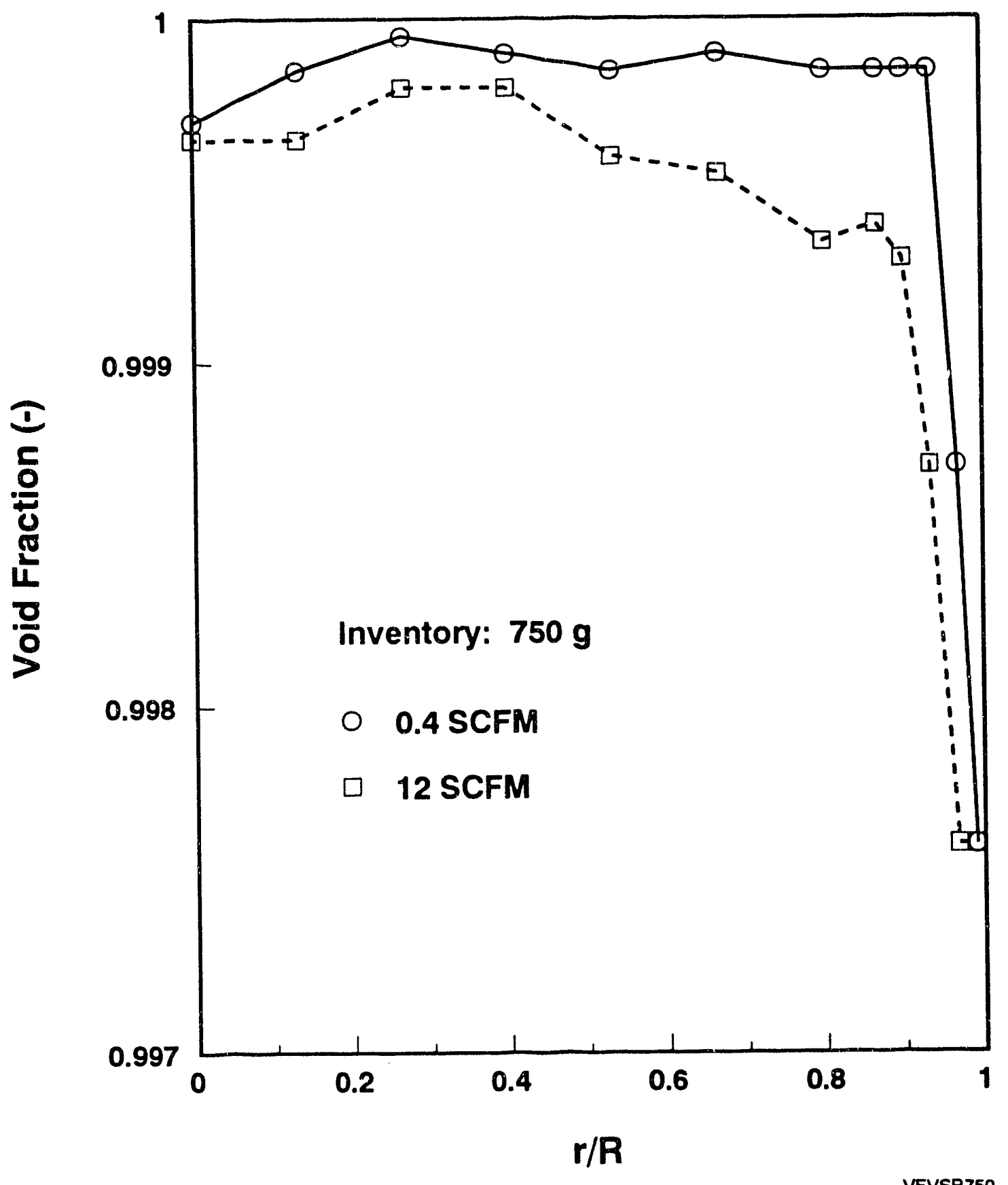

Figure 54. RADIAL VOID FRACTION PROFILES AS A FUNCTION OF GAS FLOW RATE (750 g INVENTORY)

103
I N S T I T U T E
O F
G A 5
T E C H N O L O G Y 
where $U_{\text {mean }}$ is the mean particle velocity. $T_{\text {granular }}$ is the so-called granular temperature, proportional to the random fluctuation of the particles. In Equation (82),

$$
\begin{gathered}
U_{\text {mean }}-\int_{-\infty}^{+\infty} u f_{\exp }(u) d u \\
T_{\text {granular }}-\int_{-\infty}^{+\infty}\left(u-U_{\text {mean }}\right)^{2} f_{\exp }(u) d u
\end{gathered}
$$

where $f_{\text {exp }}(u)$ is the velocity probability density obtained from the experiments.

In order to determine the deviation of the Maxwellian distribution from the experimental date, the following dimensionless quantities are defined:

$$
\begin{aligned}
x_{v} & =\frac{u-U_{\text {mean }}}{\sqrt{2 T_{\text {granular }}}} \\
Y_{\text {prob }} & -\sqrt{2 \pi T_{\text {granular }}} f(u)
\end{aligned}
$$

Thus the Maxwellian distribution may be written as:

$$
\mathrm{Y}_{\text {prob }}=\exp \left(-\mathrm{X}_{\mathrm{v}}^{2}\right)
$$

Figure 55 shows the comparison of the velocity probability predicted by the Maxwellian distribution with all of the experimental data. From Equation 82 , it is seen that the mean velocity is at the maximum probability in the Maxwellian distribution. However, the experimental results show (Figure 55) that the maximum probability position was shifted a small amount behind the mean velocity position in the actual granular flow. This indicates that there is an intrinsic deviation from the Maxwellian distribution for the actual probability distribution, although the Maxwellian distribution is a very good approximation. 


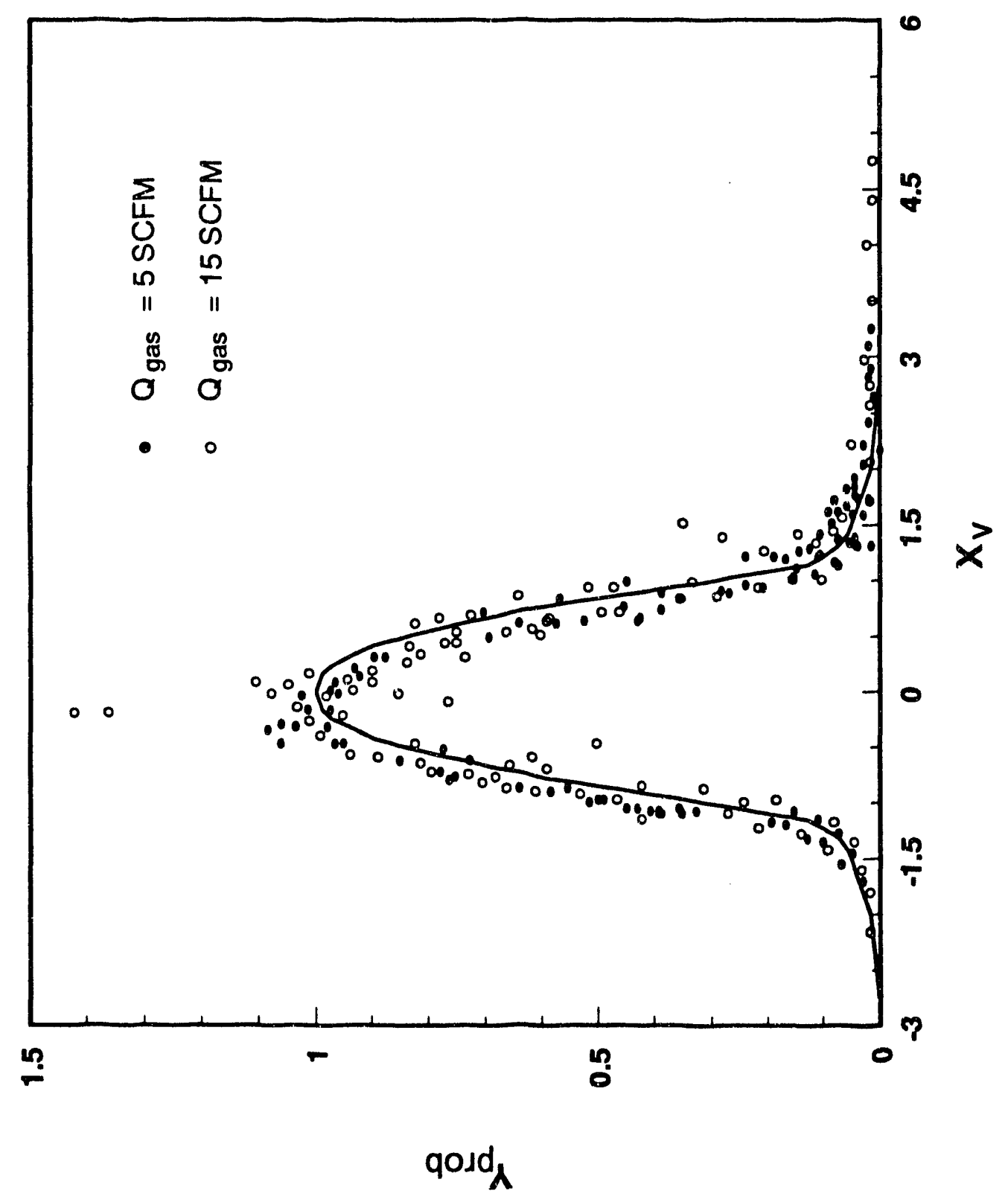

点

105

I NST T TUTE $T$ T O F G A S T E C H N O L O G Y 


\section{Task 5. Large-Scale Flow Tests}

A cold-flow model of the downcomer section of the large-scale test unit was constructed to determine the best method of controlling the flow rate of cohesive solids through the standpipe and slide valve. The cohesive solids were fluidized in a 12 -inch-diameter Plexiglas column, and were allowed to flow by gravity through a 3-inch-diameter clear PVC pipe approximately 14 feet long. A slide valve at the bottom of the standpipe controlled the flow rate of solids through the pipe. Four aeration ports were drilled into the stardpipe immediately above the slide valve. Gas was pulsed into the standpipe at this point to see if it would influence the solids flow rate. A schematic drawing of the large-scale, cold-flow model is given in Figure 56.

It was found that the cohesive ofl shale particles would not flow well unless aeration was pulsed into the standpipe. When aeration was pulsed into the standpipe, the flow was steady and controllable. The pulsing sequence which appeared to give the best results was approximately 0.2 seconds on, and 1 to 2 seconds off. The 12 -inch-dlameter standpipe in the large-scale test unit was then modified to add pulse-aeration ports above the controlling slide valve.

After installation of the pulsing aeration in the standpipe, the cohesive oil shale fines were added to the large-scale test unit. Tests were then conducted to determine 1) how the solids density in the riser varied with gas velocity, and 2) how the density varied with radial position across the riser as a function of solids mass flux. A description of the large-scale test unit and the experimental results are given below.

\section{Large-Scale Test Unit}

Solids were added to the large-scale test unit by pneumatically conveying them from a load hopper into a 5-foot-diameter fluidized bed located at the top of the unit. During operation, solids flowed out of the fluidized bed through a 12 -inch-diameter downcomer, through a 12 -inch-diameter slide valve, and into a 12-inch-diameter, 42-foot-long riser. Gas was pulsed into the bottom of the downcomer in order to initiate solids flow and to assist flow once it was started. The solids flowed up the riser, around the 135degree return bend, and back into the fluidized bed. 


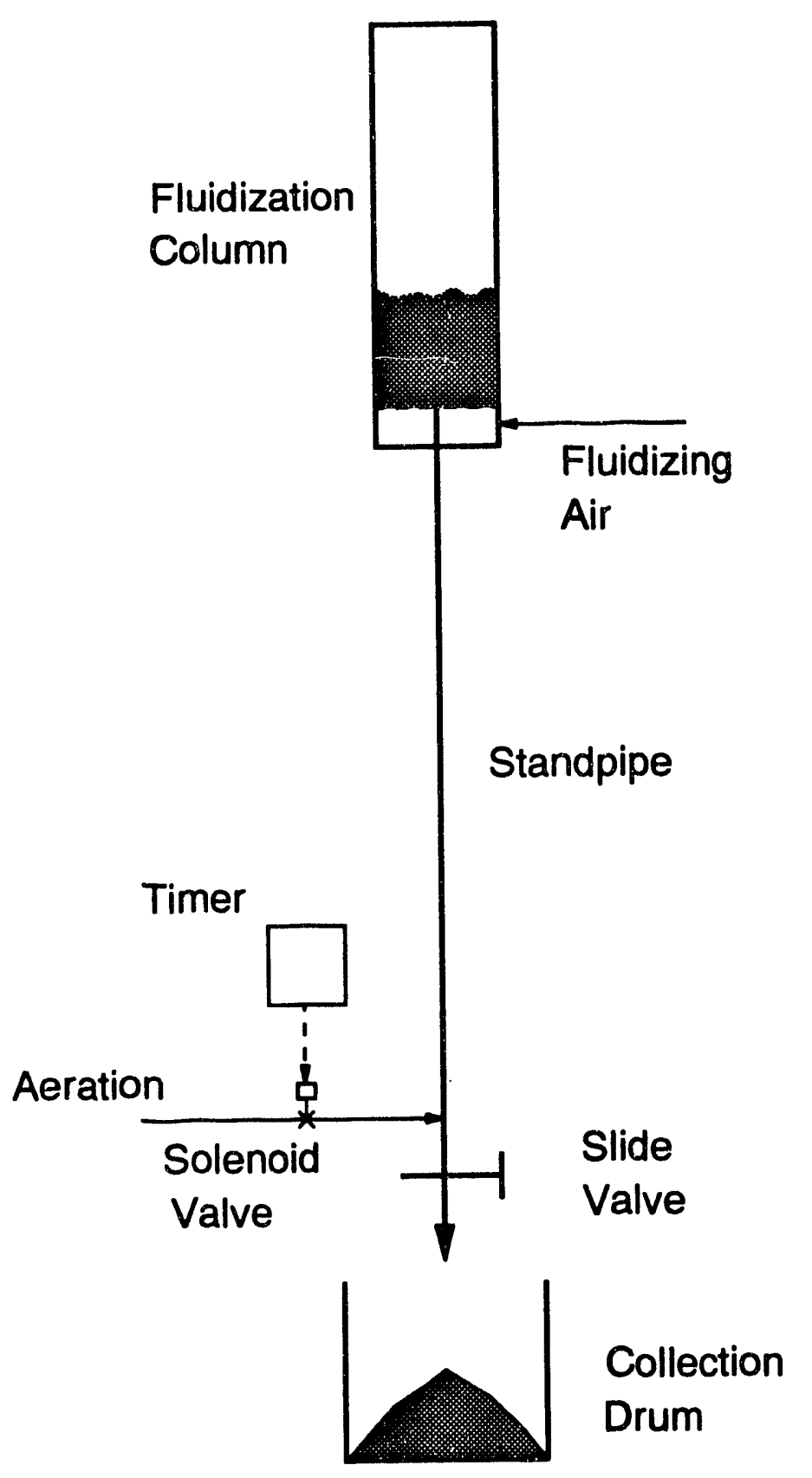

PULSCFM

Figure 56. SCHEMATIC DRAWING OF COLD-FLOW MODEL - 
Air from a 2000-hp, oil-free rotary screw compressor was used to convey the solids up the riser and to fluidize the solids in the 5-foot-diameter fluidized bed. The air from the fluidized bed and the riser passed through two stages of cyclones before being exhausted to atmosphere.

A large number of differential transmitters were located around the test unit in order to measure the pressure drops at various points in the system. The values of these pressure drops were used to analyze the operation of the test unit. All pressure drops in the test unit were recorded to facilitate analysis of the results. A schematic drawing of the large-scale test unit is shown in Figure 57.

\section{Experimental Results}

The first tests in the large-scale test unit were conducted to determine the phase diagram for the cohesive oil shale in air in the 12-inch-diameter riser. To conduct these tests, the gas flow rate was first set at a relatively high value. Then the solids flow rate was set at the desired value. The solids flow rate was determined by injecting a pulse of coal char into the downcomer, and then timing the flow of char between marks on a glass sight port in the downcomer.

After the solids flow rate was set at the desired value, the system was allowed to come to steady state, and the pressure profile in the riser and all other system variables were recorded. The gas velocity in the riser was then reduced while maintaining the solids flow rate constant and the system values again recorded. This procedure was continued until a gas velocity was reached which would not convey the solids at the desired flow rate.

Using this technique, the phase diagram for cohesive oil shale at three different mass fluxes $\left(12,20\right.$, and $\left.30 \mathrm{lb} / \mathrm{s}-\mathrm{ft} \mathrm{t}^{2}\right)$ was obtained, and is shown in Figure 58. In this figure, the riser pressure drop per unit length $(\Delta \mathrm{P} / \mathrm{L})$ is plotted as a function of superficial gas velocity in the riser (measured at the riser outlet) for each mass flux tested. As the gas velocity was decreased, the $\Delta P / L$ (which is proportional to the solids density in the riser) increased slowly, and then more rapidly at the lower gas velocities. This behavior is typical for such a system.

The lowest gas velocity at which solids could be transferred was approximately $4 \mathrm{ft} / \mathrm{s}$ for mass fluxes of 12 and $20 \mathrm{lb} / \mathrm{s}-\mathrm{ft}^{2}$, and $5.8 \mathrm{ft} / \mathrm{s}$ for 


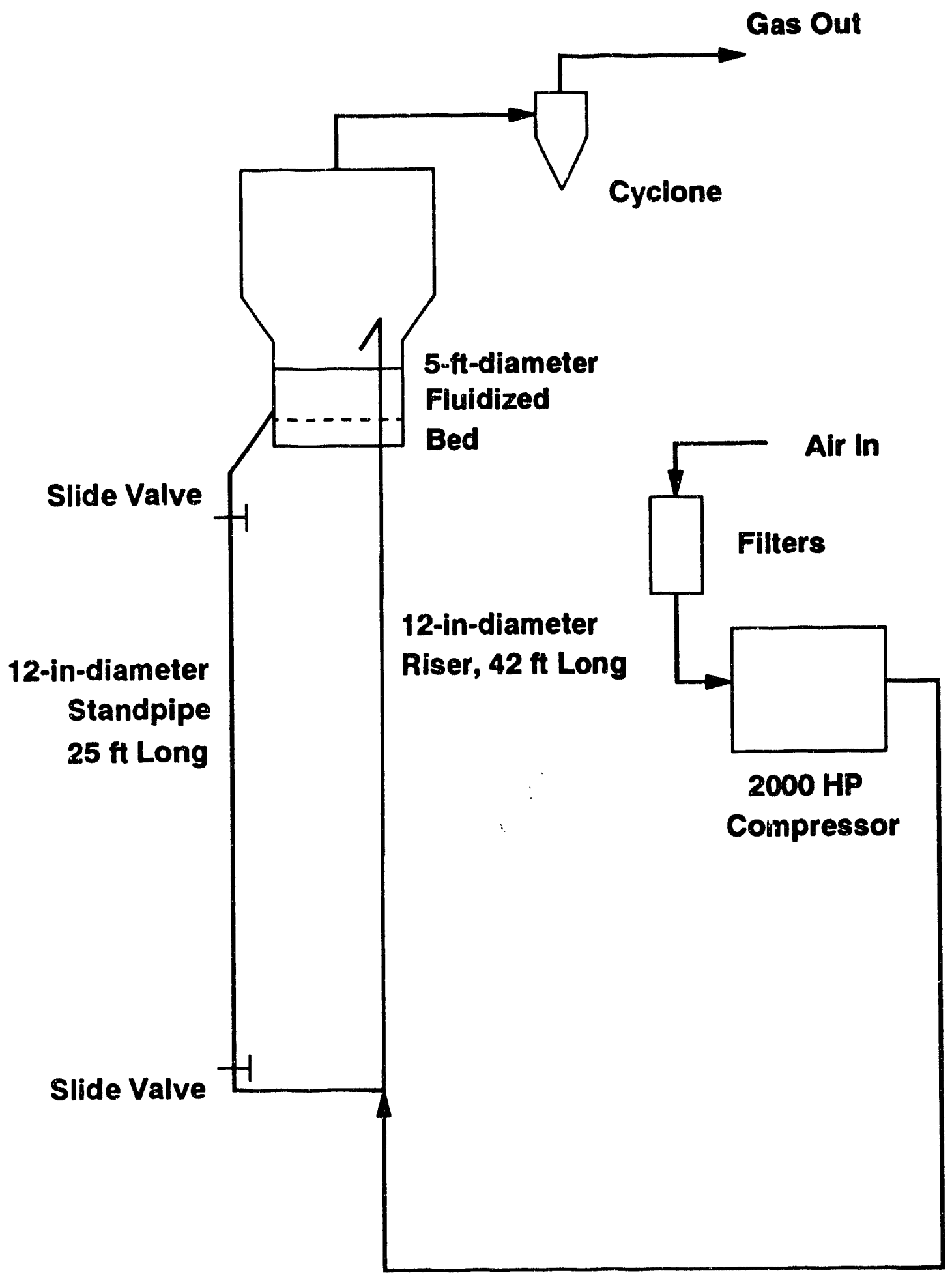

FLOSHT

Figure 57. SCHEMATIC DRAWING OF LARGE-SCALE, COLD-FLOW MEDEL
I N S T I T U T E
O F
G A S
TEC H NOL 


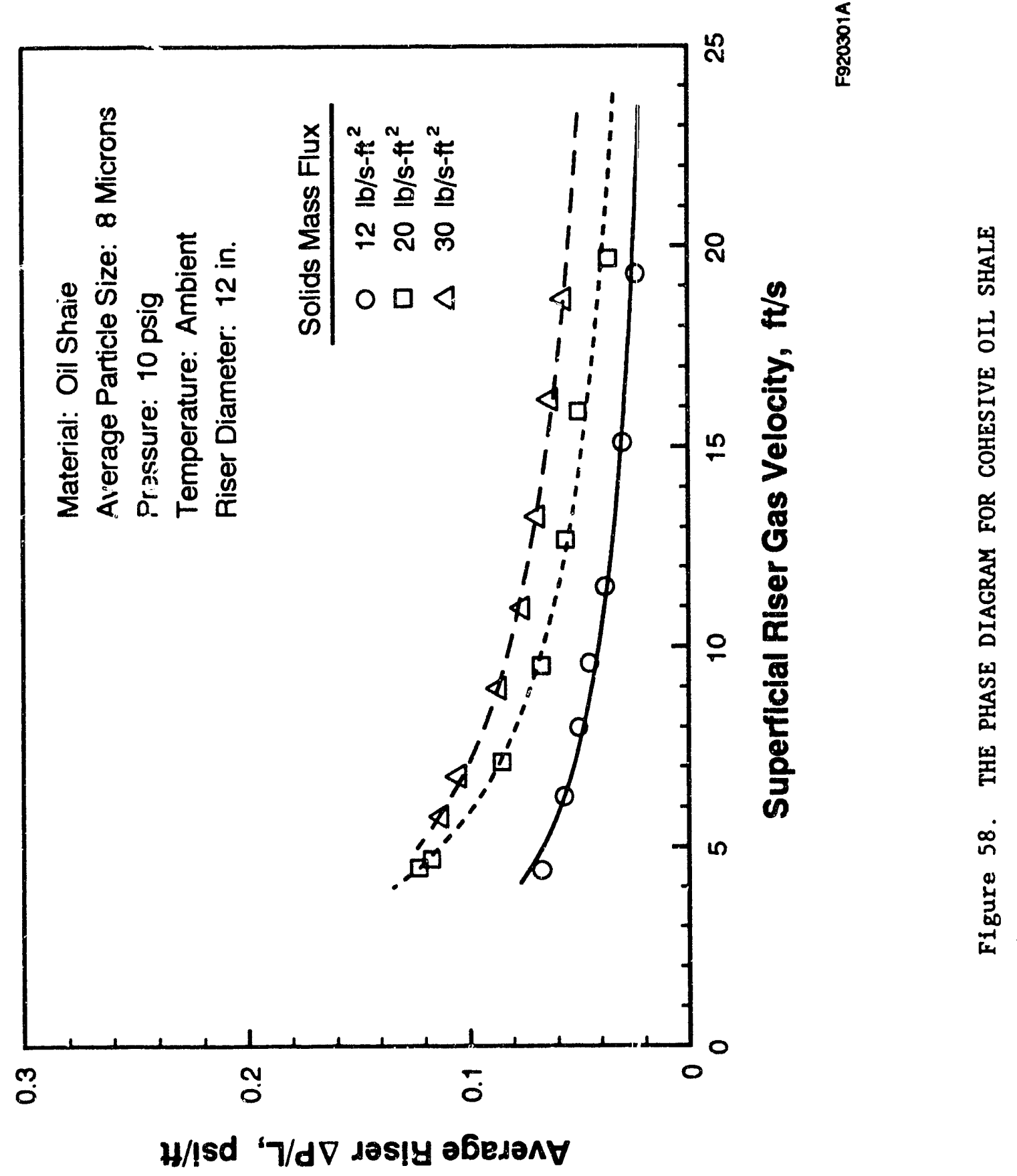


a mass flux of $30 \mathrm{lb} / \mathrm{s}-\mathrm{ft}^{2}$.

The phase diagram for cohesive oil shale was compared to the phase diagram for FCC catalyst obtained in the same unit. This comparison is shown in Figure 59 for a solids mass flux of $20 \mathrm{lb} / \mathrm{s}-\mathrm{ft}^{2}$.

The cohesive oil shale could be transported at a much lower gas velocity than the FCC catalyst (approximately $4.5 \mathrm{ft} / \mathrm{s}$ versus $9 \mathrm{ft} / \mathrm{s}$, respectively). The difference in behavior of these two materials appears to be due to the difference in particle size ( 8 microns for the oil shale, and 76 microns for the FCC catalyst). The difference cannot be attributed to particle density, because the particle density of the ofl shale $\left(1301 \mathrm{~b} / \mathrm{ft}^{3}\right)$ is greater than the particle density of the FCC catalyst $\left(107 \mathrm{lb} / \mathrm{ft}^{3}\right)$.

The maximum density in the riser attained with the oil shale was approximately $0.13 \mathrm{psi} / \mathrm{ft}\left(19 \mathrm{lb} / \mathrm{ft}^{3}\right)$, while the maximum density achieved with FCC catalyst was approximately $0.16 \mathrm{psi} / \mathrm{ft}\left(23 \mathrm{lb} / \mathrm{ft}^{3}\right)$.

Radial density profiles were also measured in the riser. These profiles were measured using a gamma-ray densitometer, similar to the one utilized in the small-scale urit tests. The densitometer consisted of a $25 \mathrm{mCu}$ Cesium-137 source and the same detection system used in the small-scale testing which is described in Task 4.

Curves of the riser suspension density versus radial position in the 12-inch-diameter riser, which were obtained with the gamma-ray densitometer are shown in Figure 60 for solid mass fluxes of 10, 20, and $30 \mathrm{lb} / \mathrm{s}-\mathrm{ft}^{2}$. The suspension density in the center of the riser was found to be lower than the density near the wall. Thus, the cohesive oil shale also appears to be in core-annulus flow in the riser as has been found to occur with FCC catalyst in the small-scale test unit.

The curves for each mass flux were approximately parallel, with the suspension density increasing with solids mass flux. The suspension density in the center of the riser was of the order of $6 \mathrm{lb} / \mathrm{ft}^{3}$. This corresponds to a solids mass fraction of approximately 0.04 . At the wall, the suspension densities ranged from about $18 \mathrm{lb} / \mathrm{ft}^{3}$ for a solids mass flux of $10 \mathrm{lb} / \mathrm{s}-\mathrm{ft}^{2}$, to about 24 for a solids mass flux of $30 \mathrm{lb} / \mathrm{s}-\mathrm{ft}^{2}$. These density values correspond to solids mass fractions of 0.14 to 0.18 , respectively. 


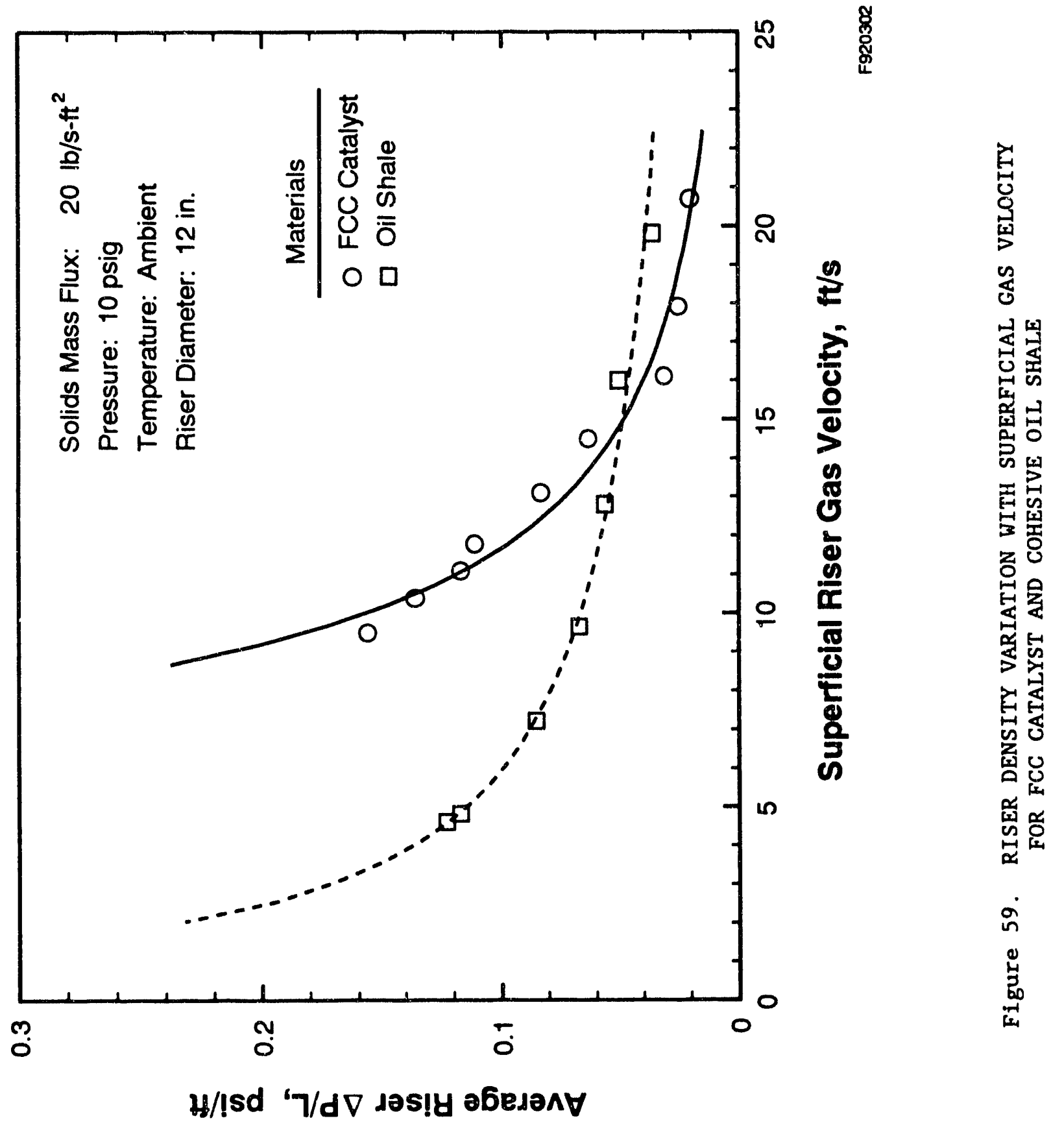




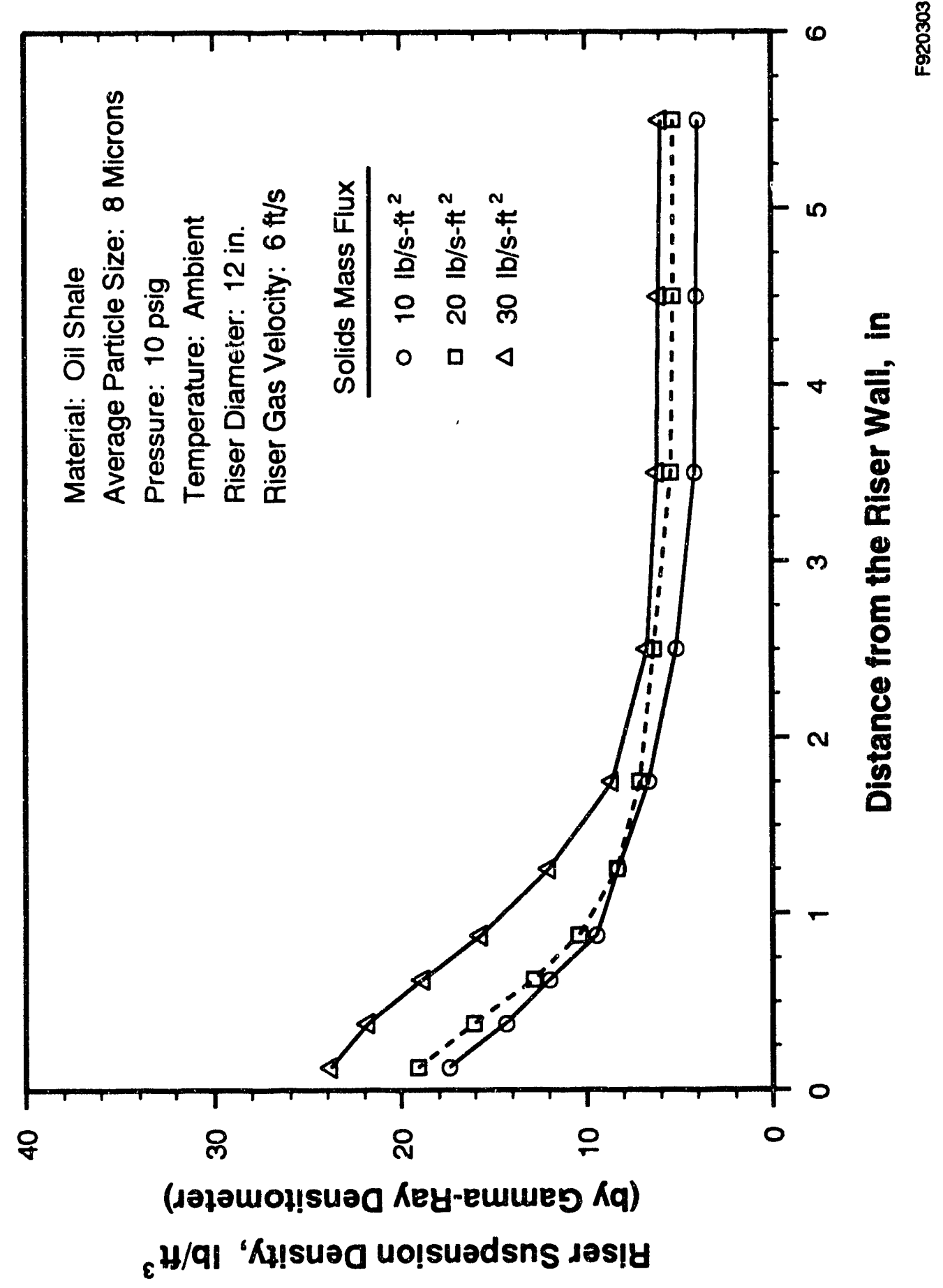

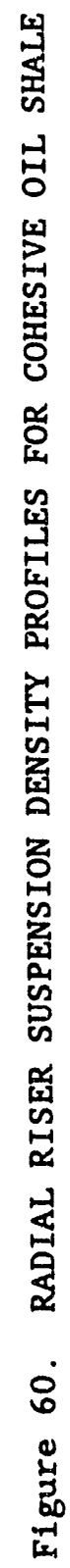


In Figure 61, typical curves illustrating the effect of riser gas velocity on riser suspension density at different radial positions in the riser are shown. As the gas velocity was decreased, from $18 \mathrm{ft} / \mathrm{s}$ to $6 \mathrm{ft} / \mathrm{s}$, the riser suspension density increased significantly, primarily in the wall region. At the wall, the density increased from approximately $8 \mathrm{lb} / \mathrm{ft}^{3}$ at a riser gas velocity of $18 \mathrm{ft} / \mathrm{s}$ to about $20 \mathrm{lb} / \mathrm{ft}^{3}$ at a riser gas velocity of $6 \mathrm{ft} / \mathrm{s}$. Thus, as the superficial gas velocity is decreased, the radial solids density profile becomes more parabolic indicating that there is a greater difference in density between the core and the annulus.

A comparison of the radial density profiles obtained for cohesive oil shale and FCC catalyst is also shown in Figure 61. The radial density profiles for FCC catalyst are more parabolic than those for cohesive oil shale. Thus there is a greater change in density between the wall and center regions of the riser for FCC catalyst. This also means that the density for FCC is generally greater than that for oil shale in the riser. This is consistent with the results shown in the comparative phase diagram shown in Figure 59. Task 6. Comparison of Model with Data and Preparation of Final Report

The objective of this task was to compare the predictions of one of the models developed for use with cohesive solids with the data for cohesive oil shale obtained in the large-scale test unit. The contacting-bond energy model was selected to compare its predictions with the data. This model was selected because it does not require a huge mainframe computer, but can be used with a workstation (although it takes substantial time to produce the results from the calculations).

The potential use of using the developed equations for designing a dilute-phase, pneumatic conveying systems lies in calculating the gas-velocity which bounds the dilute-phase conveying regime and the dense-phase conveying regime. The boundary between these two regimes can be defined by a velocity called the choking velocity. This velocity is the lowest gas velocity which will convey the solids in dilute-phase flow. The riser diameters used by the researchers who first measured this velocity were generally small. Therefore, when conditions in the riser approached this dense/dilute boundary, the solids would slug or "choke" the 1ine. When this occurred, the pressure drops in the 


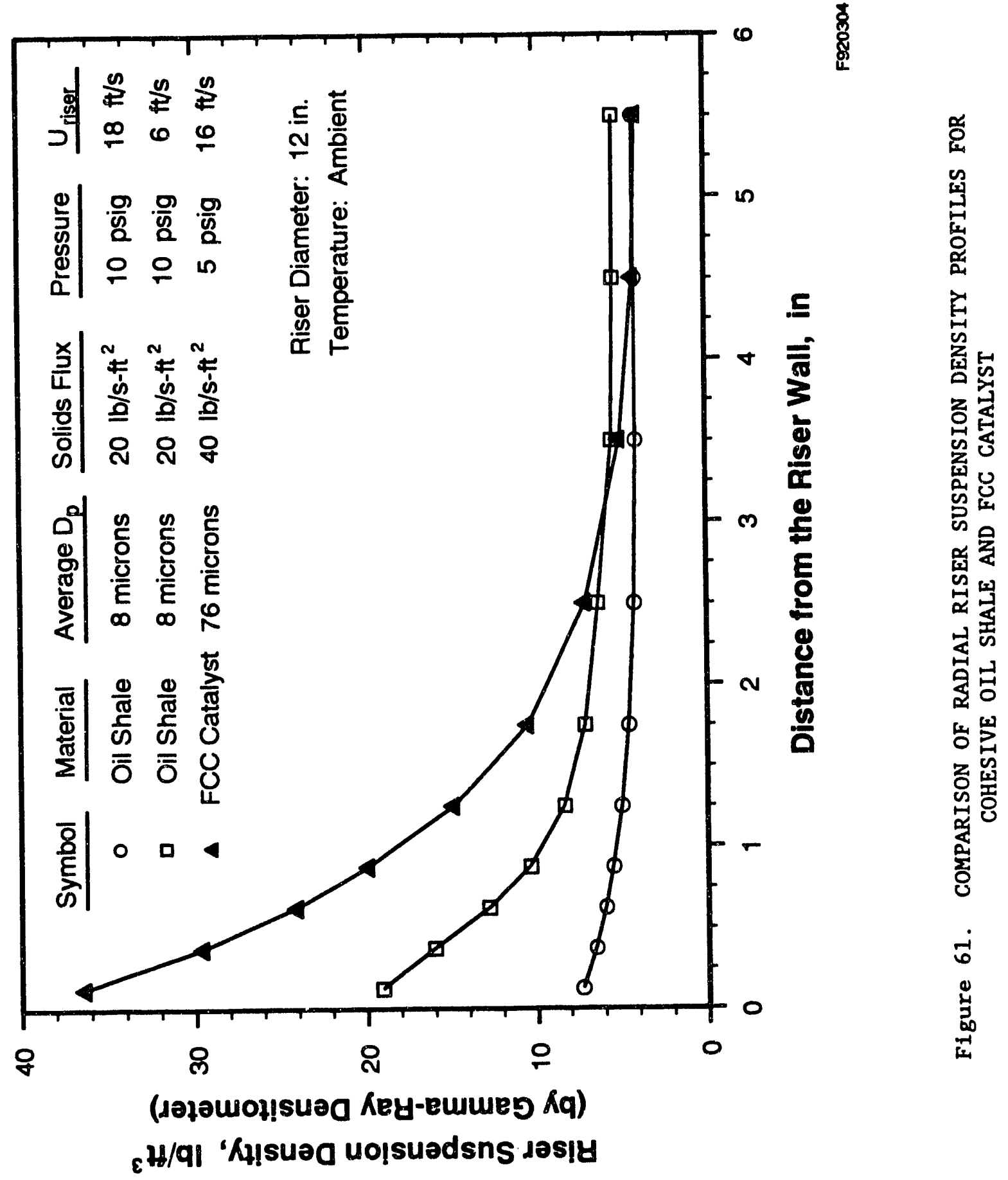


line would oscillate wildly, and riser operation was unstable. As a result, designers of dilute-phase, pneumatic conveying systems viewed the choking velocity as the lower gas-velocity operating limit for their system, and much money and effort was expended to determine this gas-velocity limit for different system conditions. Eventually, correlations were developed to predict the choking velocity, but none apply to cohesive solids.

During the middle $1970^{\prime} s$, it was found that certain solids would not slug when the riser was at choking conditions. When the solids were very small (usually less than 100 microns) or when the riser diameter was large, there would be a gradual transition from dilute-phase, gas-solids flow into dense-phase, gas-solids flow as the gas velocity was gradually lowered at a constant solids flow rate in the riser. For these conditions, slugging would not occur.

Yang (1976) developed a criterion to predict when slugging would occur in a riser. The Yang criterion states that if:

$$
\begin{array}{ll}
\text { Fr }>0.35 & \text { slugging occurs } \\
\text { Fr }<0.35 & \text { slugging does not occur }
\end{array}
$$

where $\mathrm{Fr}=\mathrm{U}_{\mathrm{t}}{ }^{2} /(\mathrm{gD})$.

Because slugging does not occur under all conditions, the name "choking velocity" is often thought of as being misleading by many people. This is because choking is strongly identified with slugging. Therefore, some researchers prefer to use the term "saturation carrying velocity" in place of the choking velocity. However, both the choking velocity and the saturation carrying velocity refer to the gas velocity which bounds the dilute-phase and dense-phase pneumatic conveying regimes.

Geldart Group C (cohesive) solids do not generally flow well in densephase. This is because the interparticle forces cause the solids to clump together and prevent them from being free-flowing. Therefore, when designing a dilute-phase, pneumatic conveying system for cohesive solids, it is critical to be able to predict the boundary between dilute- and dense-phase conveying.

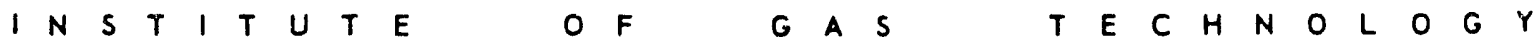


The choking velocity for a particular gas-solid system is determined by plotting the $\triangle \mathrm{P} / \mathrm{L}$ in the riser versus superficial gas velocity in the riser at a constant solids flow rate through the riser. This is generally accomplished by setting a solids flow rate in the riser at a relatively high gas velocity, and then measuring the pressure drop across the riser (excluding the acceleration region at the entrance and the decceleration region at the exit) at successively lower gas velocities while maintaining the solids flow rate at a constant value. A plot of $\Delta P / L$ versus gas velocity for several different solids flow rates is known as the phase diagram. A phase diagram for the cohesive oil shale material obtained in the large-scale test unit was presented in Figure 58. The choking velocities for this material range from approximately $3.9 \mathrm{ft} / \mathrm{s}(1.1 \mathrm{~m} / \mathrm{s})$ for a solids mass flux of $12 \mathrm{lb} / \mathrm{s}-\mathrm{ft}^{2}$ (58.7 $\left.\mathrm{kg} / \mathrm{s}-\mathrm{m}^{2}\right)$, to approximately $5.8 \mathrm{ft} / \mathrm{s}(1.77 \mathrm{~m} / \mathrm{s})$ for a solids mass flux of 30 $1 \mathrm{~b} / \mathrm{s}-\mathrm{ft}^{2}\left(146.7 \mathrm{~kg} / \mathrm{s}-\mathrm{m}^{2}\right)$.

A typical comparison plot of the model predictions versus the experimental data from the large-scale test unit is shown in Figure 62 in a phase diagram type of plot (i. e., $\Delta \mathrm{P} /$ L-vs.-superficial gas velocity). The model predicted the trend of the data extremely well, but the riser $\Delta P / L$ predictions were lower than the riser experimental data at each superficial gas velocity. The predicted riser $\Delta \mathrm{P} / \mathrm{L}$ from the model differed from the experimental riser $\Delta \mathrm{P} / \mathrm{L}$ by about 208 at the choking velocity. The predicted curve was essentially parallel to the experimental curve - but gave lower values of riser $\Delta P / L$.

The choking velocity (or the saturation carrying velocity) was predicted fairly well, also. If the predicted curve from the model is extended to the the same riser $\Delta \mathrm{P} / \mathrm{L}$ as the data, the predicted choking velocity is lower than the experimental choking velocity. The approximate values for the two choking velocities are $1.15 \mathrm{~m} / \mathrm{s}$ (experimental) and $0.9 \mathrm{~m} / \mathrm{s}$ (model prediction).

Thus, the model appears that it can be used to determine flow-regime boundaries (choking velocities) for cohesive solids. It appears that the data can be predicted within approximately 25 to 308 over the ranges studied.

In order to calculate the phase diagram curve shown in Figure 62 from the model, it was necessary to determine the cohesivity of the solids so that the parameter $E_{c}$ (the Contacting Bond Energy) could be determined. The

I NST T TUTE




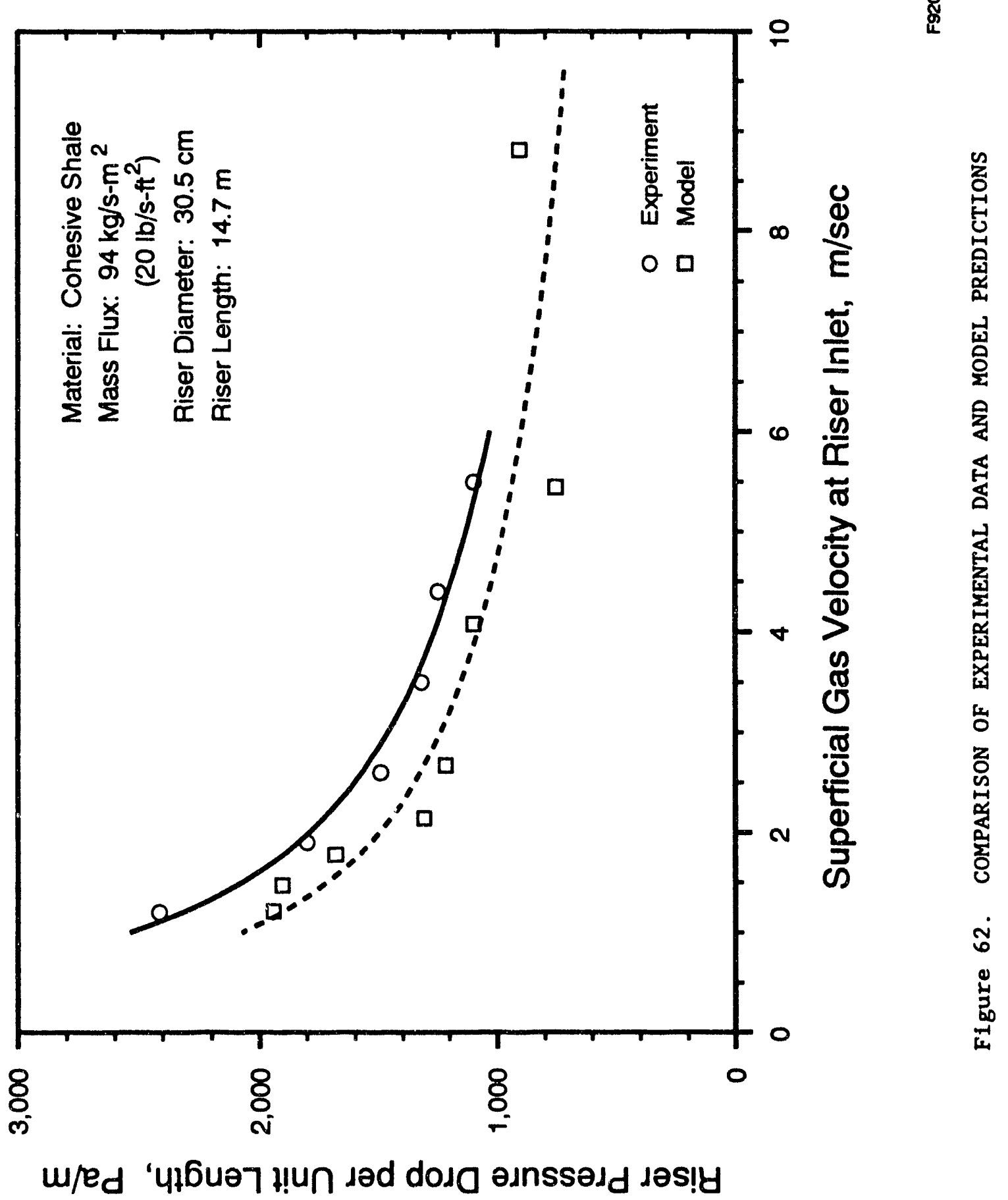


relative cohesivity of the solids was determined using the cohetester as described in Task 2 .

To apply the Contacting Bond Energy model to predict the pressure drop in a riser for a particular system, the following steps were required.

1. The Contacting Bond Energy for the test material was first determined using the cohetester (as described above).

2. A velocity profile was assumed at the inlet of the riser. For this work, the velocity profile was parabolic.

3. A solids velocity profile was also assumed at the inlet of the riser. This profile was also parabolic for the calculations shown.

4. Using the boundary conditions and the equations described in Task 2, calculations were made over a fine grid (proceeding from the inlet to the outlet) until the values of successive iterations were less than the desired difference. 


\section{NOMENCLATURE}

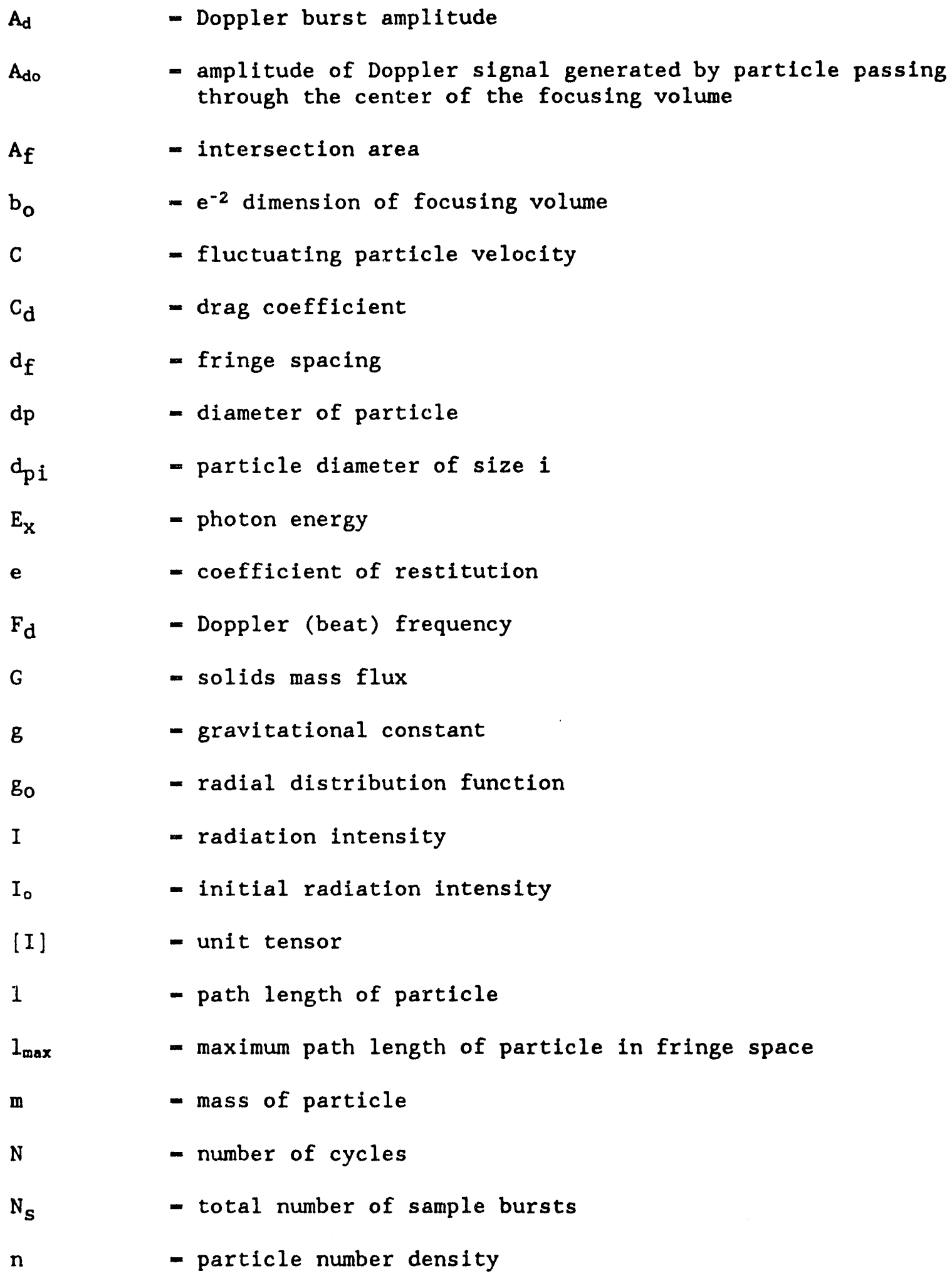




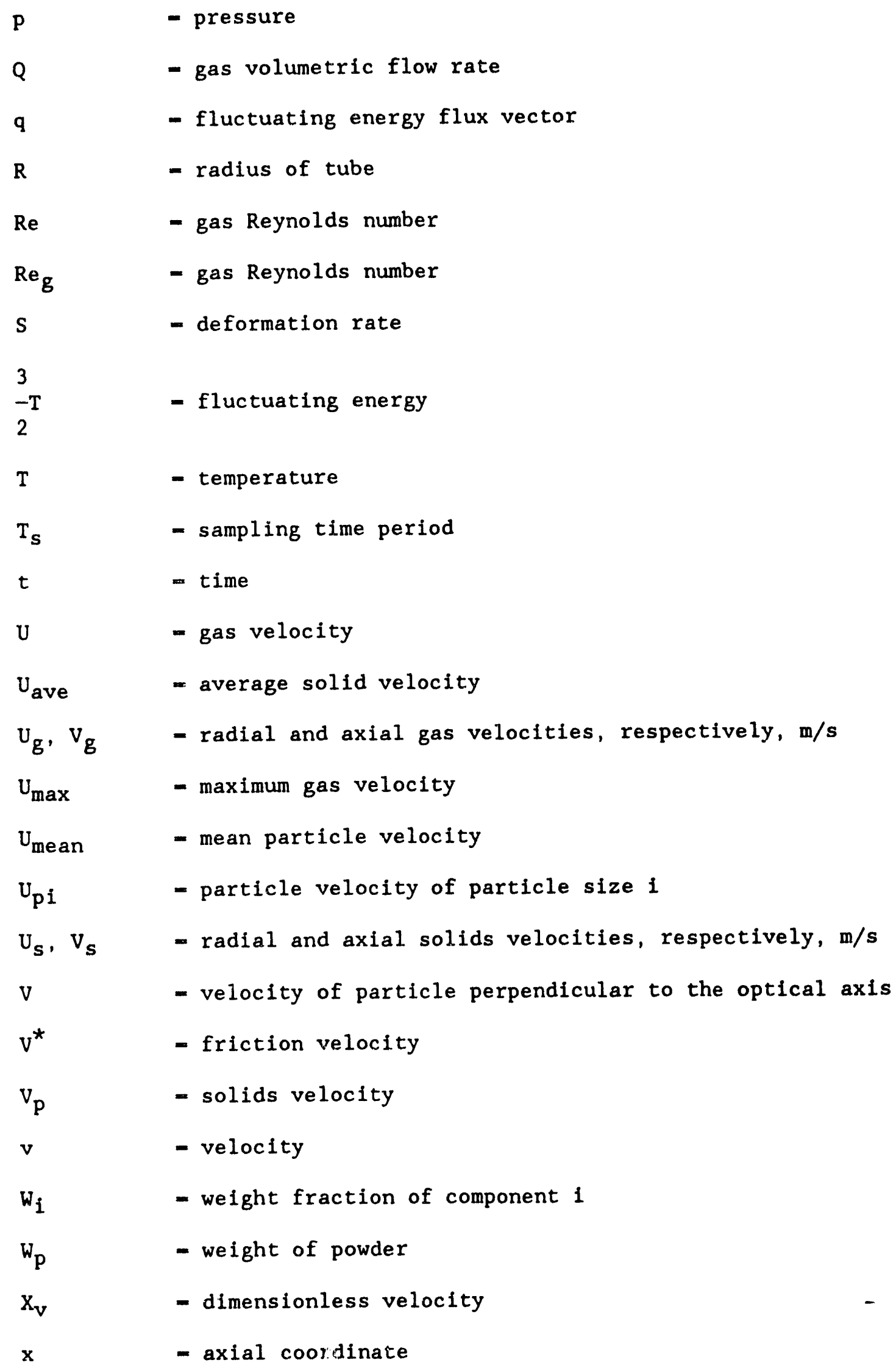




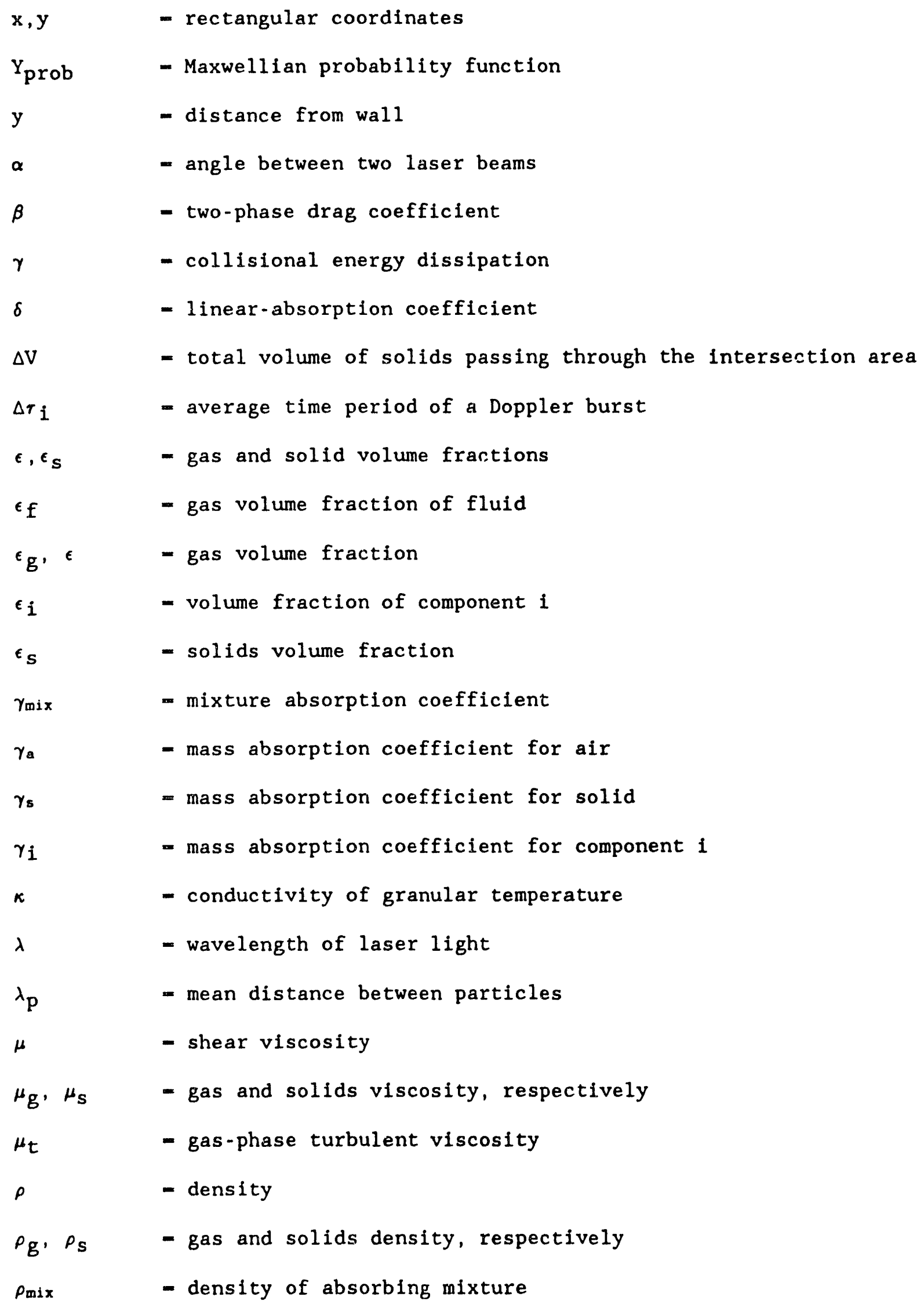




\begin{tabular}{|c|c|}
\hline Ps & - solid absorber density \\
\hline$\tau$ & - solids stress, particle-particle \\
\hline${ }^{\top} \mathrm{c}$ & = cohesive stress in the solid phase \\
\hline${ }^{\top} \mathrm{g},{ }^{\top} \mathrm{S}$ & - gas and solids microscopic viscous stress, respectively \\
\hline $\boldsymbol{\xi}$ & - bulk viscosity \\
\hline 9 & - kinematic velocity \\
\hline
\end{tabular}

\section{Subscripts}

$$
\begin{aligned}
& \text { g - gas phase } \\
& \text { s } \quad \text { solid phase }
\end{aligned}
$$

\section{Superscripts}

- denotes a vector quantity

[ ] - denotes a tensor quantity

\section{Operators}

$\begin{array}{ll}\nabla \cdot & =\text { divergence } \\ \nabla & =\text { gradient }\end{array}$

\section{LITERATURE CITED}

1. Bader, R., Findlay, J., and Knowlton, T. M., "Gas/Solid Flow Patterns in a 30.5-Cm-Diameter Circulating Fluidized Bed". Paper Presented at the 2nd International Circulating Fluidized Bed Conference, March 14-18, Compiegne, France, 1988.

2. Deardorff, J. W. "On the Magnitude of the Subgrid Scale Eddy Coefficient, J. Comput. Phy., 7, 120-133, 1971.

3. Ding, J. and Gidaspow, D., "A Bubbling Fluidization Model Using Kinetic Theory of Granular Flow". Submitted to: AIChE Journal (1989).

4. Farmer, W. M., Measurement of Particle Size, Number Density and Velocity Using a Laser Interferometer, Applied Optics, 11, No. 11, p. 2603, 1972.

5. Farmer. W. M., Measurement of Particle Size and Concentration Using LDV Techniques, Proceedings of the Dynamic Flow Conference, 1978.

6. Gidaspow, D., "Hydrodynamics of Fluidization and Heat Transfer:

Supercomputer Modeling", App1. Mech. Rev. 39, No. 1, 1-23, 1986. 
7. Lee, S. L, and Srinivasan, J., Measurement of Local Size and Velocity Prob bility Density Distribution in Two-Phase Suspension Flows by LaserDoppler Techniques, Int. J. Multiphase flow, 4, p. 141, 1978.

8. Chapman, S. and Cowling, T. G., The Mathematical Theory of Non-Uniform Gases, 3rd edition, Cambridge University Press. 

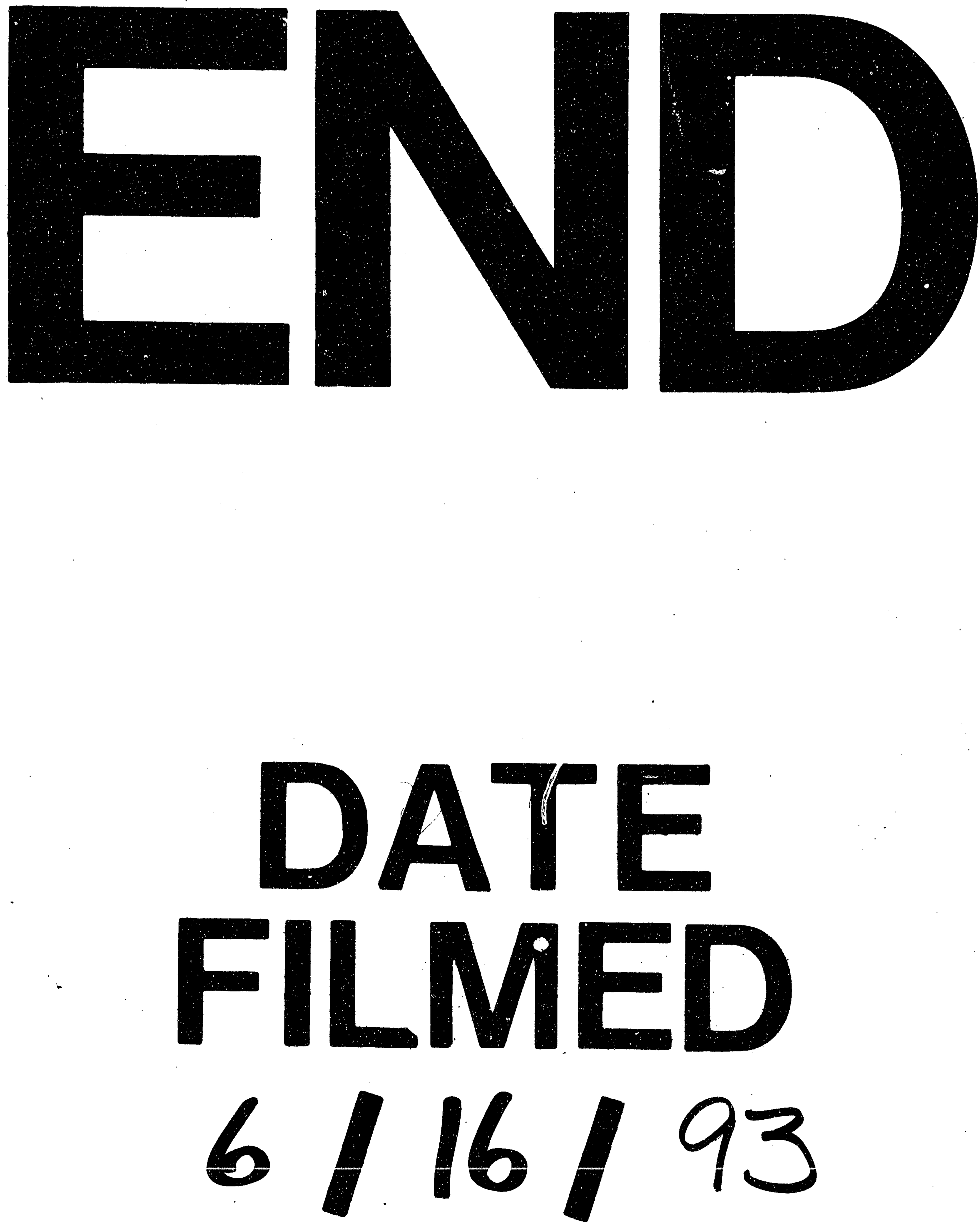
